The Free Internet Journal

for Organic Chemistry
Review

Arkivoc 2017, part i, 202-256

\title{
Copper-catalyzed steroid reactions
}

\author{
Malika Ibrahim-Ouali*a and Frédéric Dumur ${ }^{\mathrm{b}}$ \\ a Aix-Marseille Univ, CNRS, Centrale Marseille, iSm2, Marseille, France \\ ${ }^{b}$ Aix-Marseille Univ, CNRS, Institut de Chimie Radicalaire, ICR, Marseille, France \\ Email address: malika.ibrahim@univ-amu.fr
}

\section{Abstract}

We review the most important achievements of the last decade in the field of steroid synthesis in the presence of copper catalysts. This method shows great promise to allow the development of novel molecules with different functions using copper as catalyst.
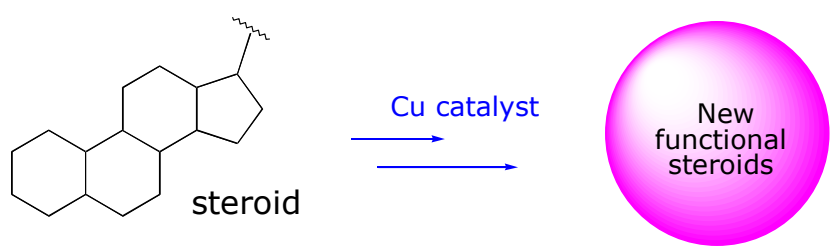

Keywords: Copper catalysed reactions; cycloaddition; triazoles; azidosteroids; alkynylsteroids 


\section{Table of Contents}

1. Introduction

2. Synthesis of Steroid Conjugates using $\mathrm{Cu}$ as Catalyst

3. Conclusions

4. Acknowledgements

References

\section{Introduction}

Steroids constitute an extensive and important class of biologically active polycyclic compounds that are widely used for therapeutic purposes. ${ }^{1}$ After decades of research, still, the synthesis of steroid nuclei by improved strategies continues to receive considerable attention. Numerous methods have been exploited for the synthesis of steroids which are widely distributed in Nature and which possess practical medical importance.

This article provide an overview of the various syntheses using copper as catalyst from the years 2011 to 2016. Although a previous review by Ju et al. has appeared in $2011,{ }^{2}$ some reports were missing from their compilation, moreover no details of the syntheses were given (only the number of steps). Thus, we have chosen to cover the literature under one section up to December 2016, omitting those works which have already been reported in the previous review. ${ }^{2}$

\section{Synthesis of steroid conjugates using $\mathrm{Cu}$ as catalyst}

In 2011, Wölfling et al. ${ }^{3}$ reported the efficient syntheses of several D-ring-substituted steroidal triazoles and tetrazoles by means of 1,3-dipolar cycloadditions. The simple and fast reactions were carried out under mild conditions that furnished the desired compounds in good yields. The novel synthesized compounds were screened for their activities against a panel of three human gynecological cancer cell lines (HeLa, MCF7 and A2780).

The reaction of $3 \beta$-hydroxy-16-hydroxymethylideneandrost-5-en-17-one $\mathbf{1}^{4}$ with acetic anhydride in pyridine medium afforded the diacetate $\mathbf{2}$ in excellent yield. The reduction of $3 \beta$-acetoxy-16-acetoxymethylideneandrost-5-en-17-one 2 with $\mathrm{KBH}_{4}$ under $\mathrm{pH}$-controlled conditions leads to three diol isomers. ${ }^{5}$ Two of them (compounds 3a, 3b), containing 17 3 -hydroxy groups with opposite configurations at C-16, were isolated in nearly identical amounts, while the third one, the $16 \beta, 17 \alpha$ isomer 3c, was obtained in a significantly smaller quantity ( $5 \%)$. After separation of the $16 \beta, 17 \beta$-hydroxymethyl isomer 3a by flash chromatography, the primary hydroxy group in $\mathbf{3 a}$ was converted into a good leaving group with $p$-toluenesulfonyl chloride. Finally, the crude product 4 was used without purification for further nucleophilic substitution with $\mathrm{NaN}_{3}$ in DMF to provide the desired $3 \beta$-acetoxy-16 $\beta$-azidomethylandrost-5-en-17 $\beta$-ol 5 in good yield. (Scheme 1)

Several D-ring-substituted androst-5-ene derivatives containing a 1,2,3-triazole ring 6 were synthesized by the reaction of $\mathbf{5}$ with various terminal alkynes through use of the "click" chemistry approach. (Scheme 2). Although there are a number of methods for generation of the active catalyst, ${ }^{6}$ one of the most common 

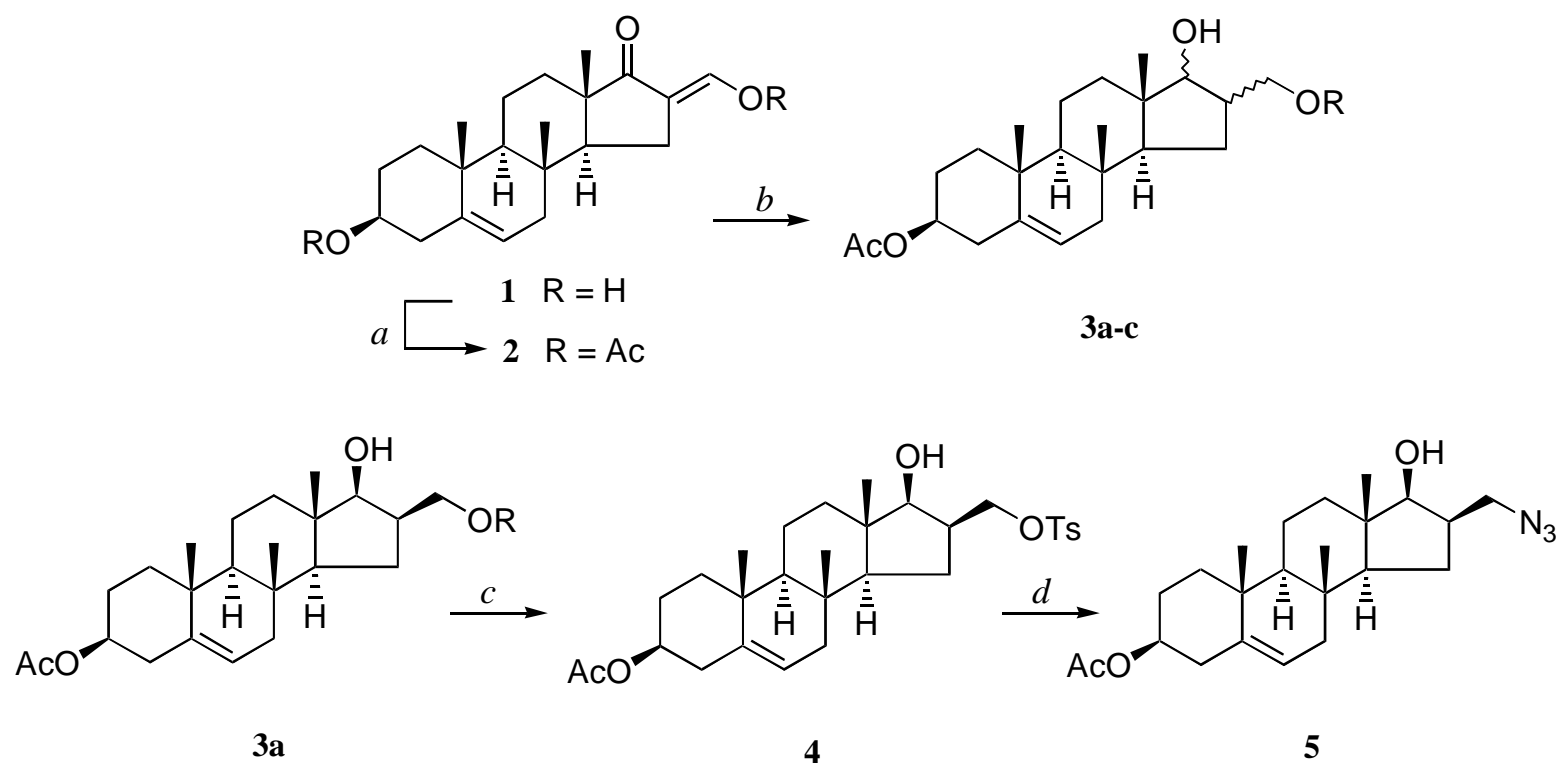

Reaction conditions : $a, \mathrm{Ac}_{2} \mathrm{O}$, pyridine; $b, \mathrm{KBH}_{4}, \mathrm{MeOH} / \mathrm{EtOH}(1 / 1)$;

$c, p-\mathrm{TsCl}$, pyridine; $d, \mathrm{NaN}_{3} / \mathrm{DMF}, 70^{\circ} \mathrm{C}, 6 \mathrm{~h}$.

Scheme 1. Formation of azidomethyl androstenol derivative 5.

techniques was chosen. Thus, the $\mathrm{Cu}(\mathrm{I})$ species was generated in situ by the reduction of $\mathrm{CuSO}_{4} \cdot 5 \mathrm{H}_{2} \mathrm{O}$ with sodium ascorbate to minimize the formation of by-products. Furthermore, a mixture of $\mathrm{CH}_{2} \mathrm{Cl}_{2}$ as solvent and water as co-solvent was employed to eliminate the need for ligands and to simplify the reaction protocol. In all cases, total consumption of the starting compound was observed within 1-4 $\mathrm{h}$ at room temperature. The reactions were very selective, and triazole products could be isolated in $78-93 \%$ yields. The trace quantities of copper and reagents remaining in the reaction mixtures were removed by flash chromatography.

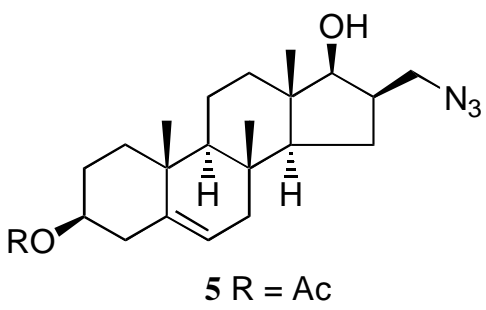

$5 R=A c$

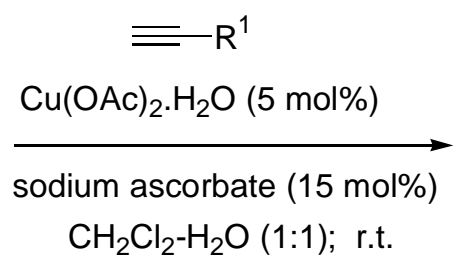

$\mathrm{R}^{1}=$

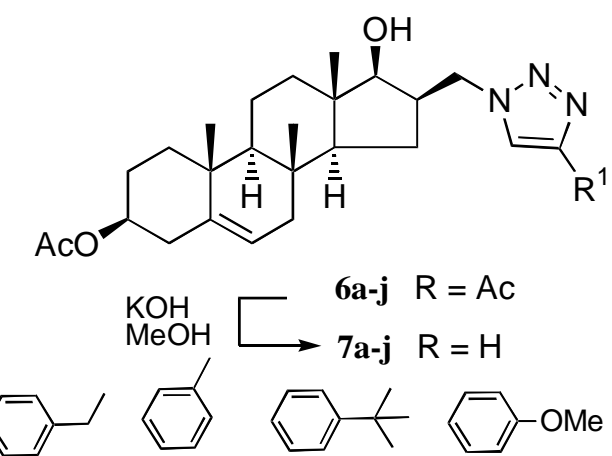

Scheme 2. Synthesis of 1,4-disubstituted steroidal triazoles.

The intermolecular [3+2] cycloadditions between the steroid azides $\mathbf{5}$ and several nitriles containing an electron-withdrawing group (EWG) afforded the desired 1,5-disubstituted steroidal tetrazoles 7. (Scheme 3) Highly electrophilic nitrile carbon atoms are required for successful addition; some commercially available acyl cyanides and cyanoformates were therefore chosen as reagents. In all cases, the reactions were carried out at room temperature, with stirring for 2 days, 10 mol \% copper(I) complex $\mathrm{Cu}_{2}(\mathrm{OTf})_{2} \cdot \mathrm{C}_{6} \mathrm{H}_{6}\left(\mathrm{OTf}=\mathrm{O}_{3} \mathrm{SCF}_{3}\right)$ being 
used as catalyst. The newly-synthesized tetrazolyl compounds could be isolated in $45-72 \%$ yields after purification by column chromatography.
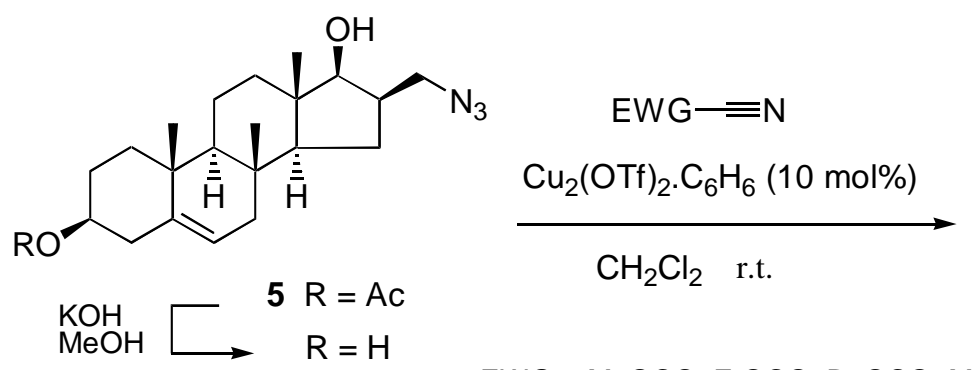

$E W G=M e O C O, E t O C O$, BnOCO, MeCO, PhCO

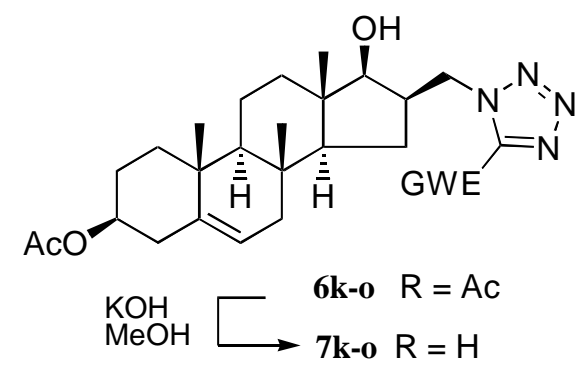

Scheme 3. Synthesis of 1,5-disubstituted steroidal tetrazoles.

Pospieszny et al. ${ }^{7}$ in 2012 developed a novel method for the synthesis of cholic acid derivatives using 'click chemistry' (Scheme 4). Intermolecular 1,3-dipolar cycloaddition of the propargyl ester and azide groups of $3 \alpha$-azidoacetoxy-7 $\alpha, 12 \alpha$-diformyloxy-5 $\beta$-cholan-24-oate gave a new dimer and oligomer linked by a 1,2,3-triazole ring. The biological activity spectra were predicted with PASS for four compounds synthesized. They also selected the types of activity that were predicted for a potential compound with the highest probability (focal activities). According to these data the most frequently predicted types of biological activity are inhibition of: 1-acylglycerol-3-phosphate O-acyltransferase, squalenehopene cyclase, peptidoglycan glycosyltransferase, acylglycerol lipase, hypercholesterolemic, $\mathrm{N}$-(long-chain-acyl)ethanolamine deacylase, alkenylglycero-phosphoethanolamine hydrolase, and cholesterol synthesis.

The synthesis of the cholic acid dimer 14 linked by a 1,2,3-triazole ring is shown in Scheme 11, as is the structure of the oligomeric compound 15. Compound 9 was prepared from cholic acid 8 according to the literature procedure. ${ }^{8}$ Alcohol $\mathbf{1 0}$ was obtained by a selective hydrolysis of the $3 \alpha-\mathrm{OCHO}$ group of compound 9. Their attempts to carry out the reaction according to the literature procedure failed. ${ }^{9}$ Carrying out the hydrolysis in acetone in the presence of 0.2 or $0.1 \mathrm{M} \mathrm{NaOH}$ aqueous solutions led to mixtures containing small amounts of product, but containing mostly unreacted substrate. Changing the solvent to methanol and using $0.1 \mathrm{M}$ aqueous $\mathrm{NaOH}$ gave compound $\mathbf{1 0}$ in high yield. The synthesis of compound $\mathbf{1 1}$ presented difficulties as well. Esterification in the presence of propargyl alcohol and a catalytic amount of $p$-toluenesulfonic acid caused hydrolysis of the -OCHO groups. ${ }^{10}$ Compound 11 was synthesized in the presence of DCC, DMAP, and propargyl alcohol in good yield. Chloroacetylation of $\mathbf{1 1}$ formed 12.

Compound 12 was transformed into azide 13 via a substitution reaction carried out in DMF in the presence of $\mathrm{NaN}_{3}$. Freshly obtained compound $\mathbf{1 3}$ was used as a substrate in the 'click' reaction in the presence of $\mathrm{CuSO}_{4} .5 \mathrm{H}_{2} \mathrm{O}$ and sodium ascorbate. Application of two different mixtures of solvents: $t-\mathrm{BuOH} / \mathrm{H}_{2} \mathrm{O}$ (9:1) and $\mathrm{DMF} / \mathrm{H}_{2} \mathrm{O}(4: 1)$ gave the same results. The mixture of unreacted substrate 13, acyclic dimer 14 and oligomeric compound $\mathbf{1 5}$ was obtained and separated by column chromatography. The oligomeric compound 15 is formed preferentially because it has a lower final heat of formation $(1287.0911 \mathrm{kcal} / \mathrm{mol})$ than cyclic compound $(664.5813 \mathrm{kcal} / \mathrm{mol})$. Furthermore, the presence of additional groups -OCHO in positions $7 \alpha$ and $12 \alpha$ of the steroid ring causes steric hindrance and increases the repulsive interaction between two steroid units. Thus, five new compounds linked by 1,2,3-triazole rings, propargyl $7 \alpha, 12 \alpha$-diformyloxy-3 $\alpha$-hydroxy-5 $\beta$ -

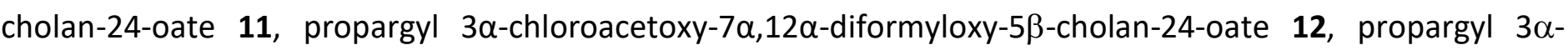


azidoacetoxy-7 $\alpha, 12 \alpha$-diformyloxy-5 $\beta$-cholan-24-oate 13 , dimer 14 , and oligomer 15 , of which the tetramer (n $=2$ ) is the major constituent, were prepared from cholic acid.
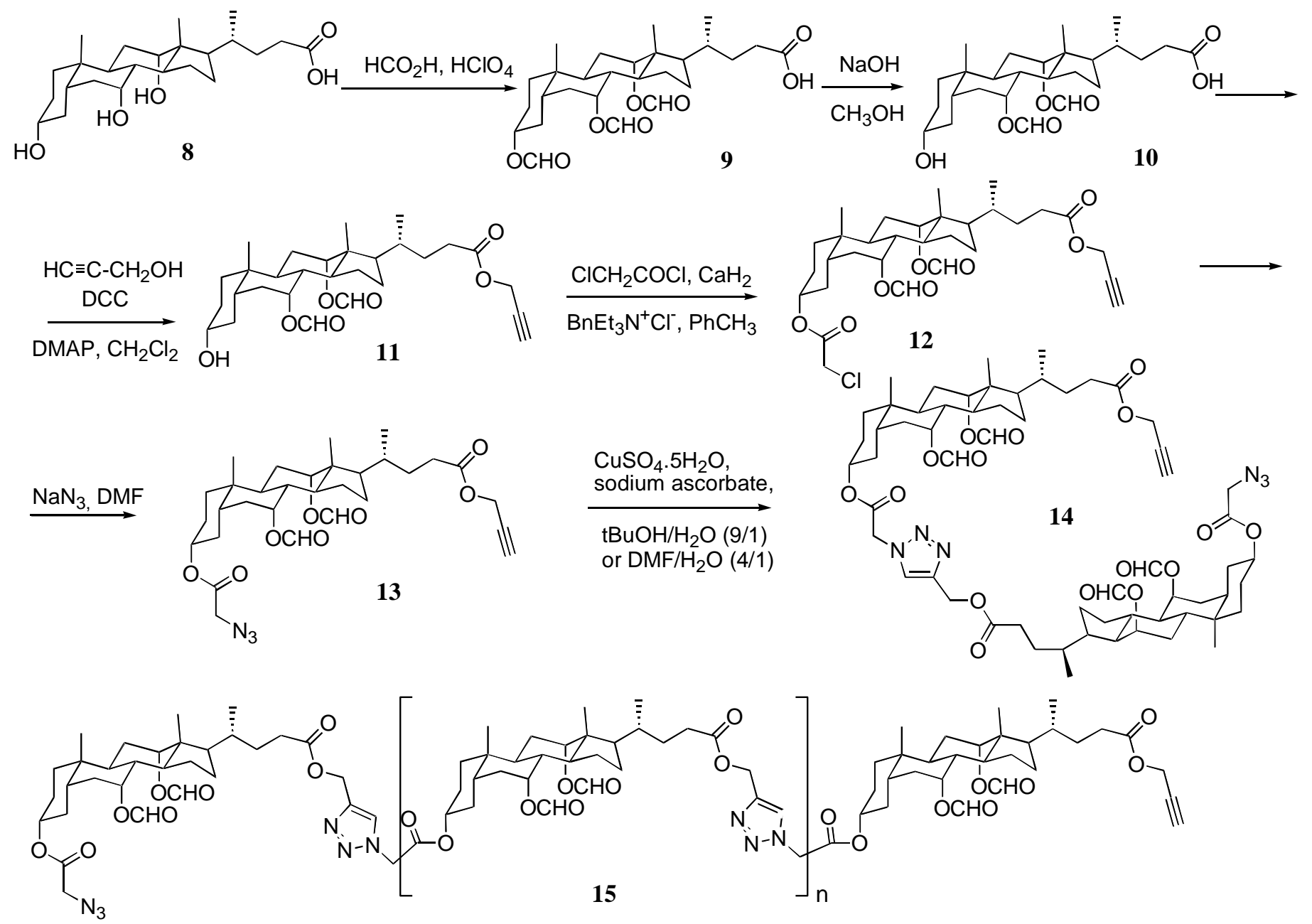

Scheme 4. Cholic acid-derived dimer and oligomer linked through a triazole ring.

In 2011, Skoda-Földes et al. ${ }^{11}$ reported an efficient methodology for the synthesis of ferrocene-labeled steroids. Three steroids 19-21, bearing the azido group in different positions of the steroidal skeleton, were synthesised as model compounds, starting from epoxides 16-18 (Scheme 5). The ring-opening was completely selective in each case, leading to the $16 \beta-19,2 \beta-20$ and $6 \beta$-azidoandrostanes 21 in moderate to excellent yields. No formation of other epimers could be detected.

Then, two alkynyl-ferrocene derivatives, ethynylferrocene 22a and a ferrocenyl-methylidenemalonic acid derivative $\mathbf{2 2} \mathbf{b}$ were prepared for use as reaction partners. (Scheme 5) Compound 22b was obtained by the cobalt-catalyzed domino reaction developed in their group. ${ }^{12}$ (Scheme 6) The cobalt-catalyzed carbonylation of ethyl diazoacetate $\mathbf{2 6}$ leads to ethoxycarbonyl ketene that reacts rapidly with ferrocenylimine $\mathbf{2 7}$ to yield the $\beta$-lactam 28. An immediate $\mathrm{N}(1)-\mathrm{C}(4)$ cleavage of the latter compound results in the formation of $\mathbf{2 2 \mathbf { b }}$. $17 \alpha$-Ferrocenyl-17 $\beta$-estradiol and $17 \alpha$-ferrocenylethynyl-17 $\beta$-estradiol were found to have a relative binding affinity of $8 \%$ and $28 \%$ to the estrogen $\alpha$-receptor, respectively. ${ }^{13}$ This shows a favorable effect of the introduction of a linker between the steroidal skeleton and the ferrocenyl moiety. 


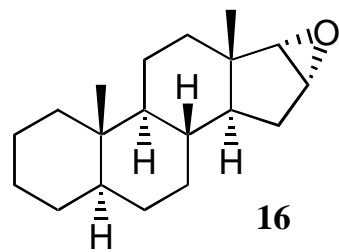

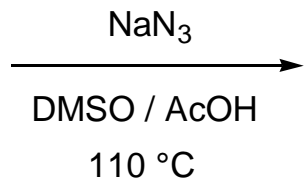<smiles>C[C@]12CCCC[C@H]1CC[C@@H]1[C@@H]2CC[C@]2(C)[C@H](O)C(N)C[C@@H]12</smiles><smiles>CC12[C@H]3CC[C@]4(C)C(=O)CC[C@H]4[C@@H]3CC[C@@H]1C[C@@H]1O[C@@H]12</smiles>

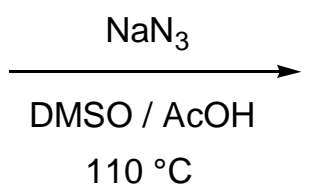<smiles>C[C@]12CC[C@H]3[C@@H](CC[C@@H]4C[C@@H](O)[C@@H](N)C[C@]34C)[C@@H]1CCC2=O</smiles>

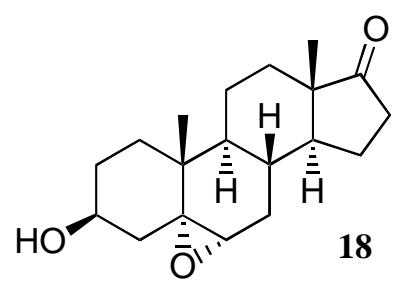

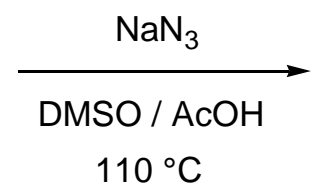

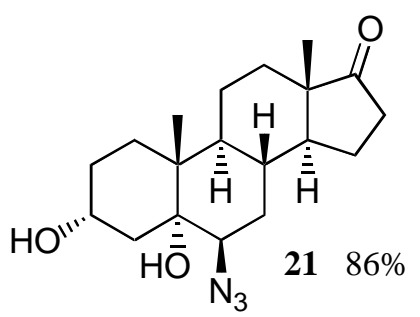
19, 20, 21 $+\mathrm{R} \underset{\text { 22a-f }}{\bar{\equiv}} \frac{\mathrm{Na} \text { ascorbate }}{\mathrm{CH}_{2} \mathrm{Cl}_{2} / \mathrm{H}_{2} \mathrm{O} \text {; r.t. }}$<smiles>[R]c1cn([C@@H]2C[C@H]3[C@H]4CC[C@H]5CCCC[C@]5(C)[C@H]4CC[C@]3(C)[C@H]2O)nn1</smiles>

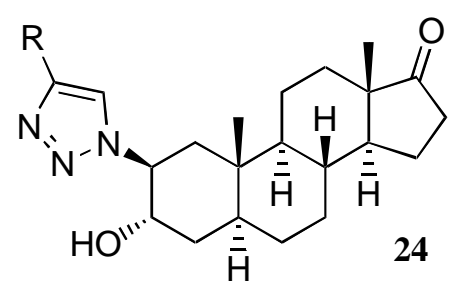<smiles>[R]c1cn([C@@H]2C[C@@H]3[C@@H]4CCC(=O)[C@@]4(C)CC[C@@H]3[C@@]3(C)CC[C@@H](O)C[C@@]23C)nn1</smiles>

$\mathrm{R}=\mathbf{a}:-\mathrm{Fc} ; \mathbf{c}:-\mathrm{Ph} ; \mathbf{d}:-\mathrm{C}_{6} \mathrm{H}_{13} ; \mathbf{e}:-\mathrm{CH}_{2} \mathrm{OC}(\mathrm{O}) \mathrm{CH}_{3} ; \mathbf{f}:-\mathrm{C}(\mathrm{O}) \mathrm{OCH}_{3}$<smiles></smiles>

Scheme 5. Synthesis of azido-androstanes 19-21 and their azido-alkyne coupling reaction products.

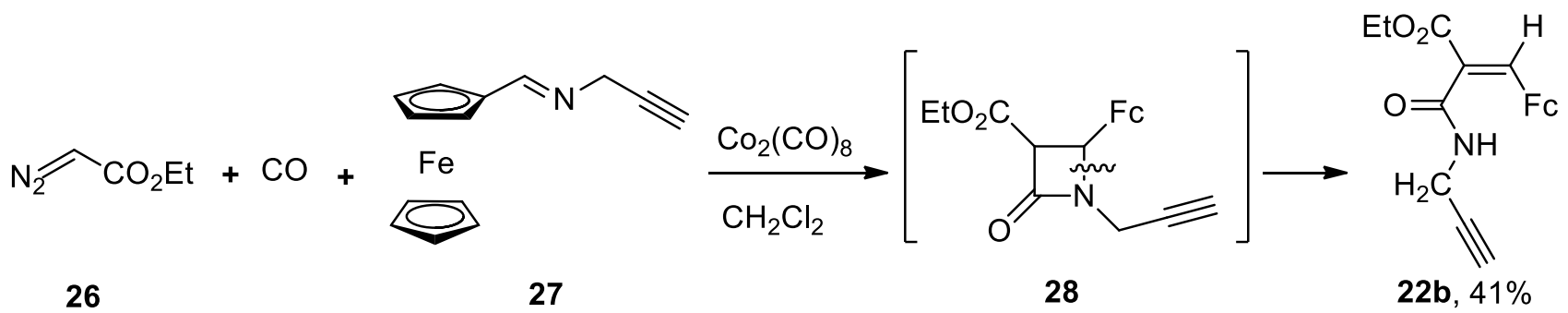

Scheme $\mathbf{6}$. Synthesis of $\mathbf{2 2 b}$ by the domino reaction of ethyl diazoacetate $\mathbf{2 6}$, ferrocenyl-imine $\mathbf{2 7}$ and CO. 
In the CUAAC reaction the key intermediate is a $\mathrm{Cu}(\mathrm{I})$ acetylide that is obtained in the reaction of the precursor $\mathrm{Cu}(\mathrm{I})$ salt and the terminal acetylene. ${ }^{14}$ The $\mathrm{Cu}(\mathrm{I})$ catalyst can also be obtained in situ, starting from a $\mathrm{Cu}$ (II) salt and sodium ascorbate. Cycloaddition of 22a and 19 (Scheme 5) was used as a model reaction to determine the optimal conditions. The activities of $\mathrm{Cul}+$ base and $\mathrm{CuSO}_{4}+\mathrm{Na}$-ascorbate catalyst systems, commonly used for similar reactions, were compared. The application of the $\mathrm{Cu}(\mathrm{II})$ precursor was found to be more efficient. Similar yields were obtained in the CuAAC reaction of $\mathbf{1 9}$ and $\mathbf{2 2} \mathbf{b}$ as well as in the cycloaddition of $\mathbf{2 0}$ and alkynes 22a,b. At the same time, a different behavior of the $6 \beta$-azido derivative $\mathbf{2 1}$ was observed. The target compound was detected only in traces by TLC in the CUAAC reaction of $\mathbf{2 1}$ with ethynylferrocene 22a. The application of other conditions, corresponding to those used for the cycloaddition of 19 and 22a did not improve the course of the cycloaddition, either. On the other hand, cycloaddition of $\mathbf{2 1}$ with $\mathbf{2 2} \mathbf{b}$, where the alkyne and the bulky ferrocene moieties are separated by a spacer, led to product 25b with acceptable yield.

In order to explore if this difference in the reactivity of the steroids $\mathbf{1 9 - 2 1}$ is restricted to the click reactions of the bulky ferrocenyl alkynes, cycloadditions of the azides 19-21 with simple alkynes (22c-f) were also investigated. The reactions of azides 19 and $\mathbf{2 0}$ gave the corresponding triazoles 23c-f and 24c-f in good yields. (Scheme 5) The results obtained with $\mathbf{1 9}$ were slightly better. Azide $\mathbf{2 1}$ was proved to be considerably less reactive again. No reaction was observed with $\mathbf{2 2 c}$ and $\mathbf{2 2 e}$ and the substrate was recovered unchanged in both cases. Triazole $\mathbf{2 5 f}$ was obtained in moderate yield using the activated alkyne $\mathbf{2 2} \mathbf{f}$. According to these experiments, the reactivity of steroidal azides decreased in the order $\mathbf{1 9}>\mathbf{2 0}>\mathbf{2 1}$.

In 2012, Lee et al. ${ }^{15}$ presented a new strategy to link AZT with betulin/betulinic acid (BA) by click chemistry. Click chemistry provides an easy and productive way for linking two molecules, even when one of them is a large natural product.

The synthetic route to compounds joined at the C-3 position of betulin is outlined in Scheme 7. The C-28 hydroxyl of betulin $\mathbf{2 9}$ was first protected by the reaction with tert-butyldimethylsilyl chloride (TBSCl) to yield the silyl ether 30. Prop-2-ynyl groups were then introduced at the C-3 position as either an ether 31 or carbonate ester 32. Compounds $\mathbf{3 1}$ and $\mathbf{3 2}$ were then reacted with the azido group of AZT in the presence of $\mathrm{Cu}$ and $\mathrm{CuSO}_{4} .5 \mathrm{H}_{2} \mathrm{O}$ to furnish final compounds $\mathbf{3 3}$ and $\mathbf{3 4}$ in quantitative yields. Analogous final compounds $\mathbf{3 7}$ and 38 were obtained by the same click reaction of AZT with the C-28 deprotected betulin derivatives 35 and 36. Oxidation of the C-28 hydroxyl of $\mathbf{3 5}$ with Jones reagent yielded 39, which was also reacted with AZT to yield 40, an AZT-BA conjugate. Finally, a 3,3-dimethylsuccinyl ester was introduced at the C-28 position of $\mathbf{3 5}$ to yield compound $\mathbf{4 1}$, which by click chemistry formed the conjugate $\mathbf{4 2}$.

Scheme 8 depicts the synthesis of AZT-bevirimat conjugates. A prop-2-ynyl ester moiety was added to the C-28 position of bevirimat 43 to furnish $\mathbf{4 4}$, followed by the click reaction of $\mathbf{4 4}$ with AZT to yield the final compound 45. Compared with the previous yields (43-87\%) for conjugating AZT with betulin derivatives via an ester bond the click reactions of AZT with betulin/BA derivatives were achieved quantitatively, which is a significant advantage in the last step of synthesizing the target compounds. In addition, the reaction time was shortened significantly to $30 \mathrm{~min}$ by using microwave conditions at $120{ }^{\circ} \mathrm{C}$ rather than the prior overnight esterification reaction. Therefore, the click reaction provides a much more productive and rapid approach to obtain the final products of AZT-betulin/BA conjugates. Compounds $\mathbf{4 4}$ and $\mathbf{4 5}$ showed potent anti-HIV activity with EC50 values of 0.067 and $0.10 \mathrm{IM}$, respectively, which are comparable to that of AZT (EC50: 0.10 IM) in the same assay. 


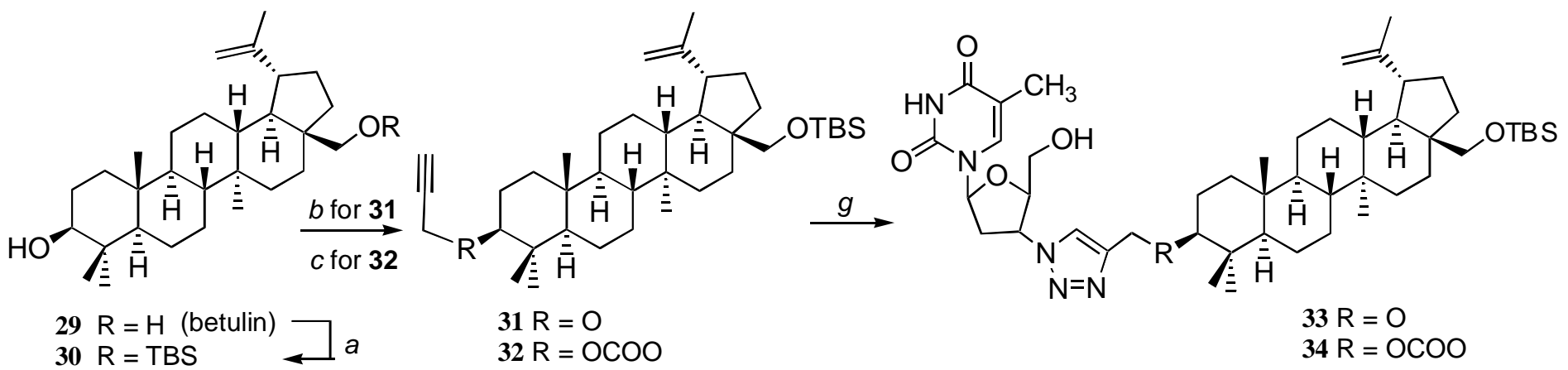

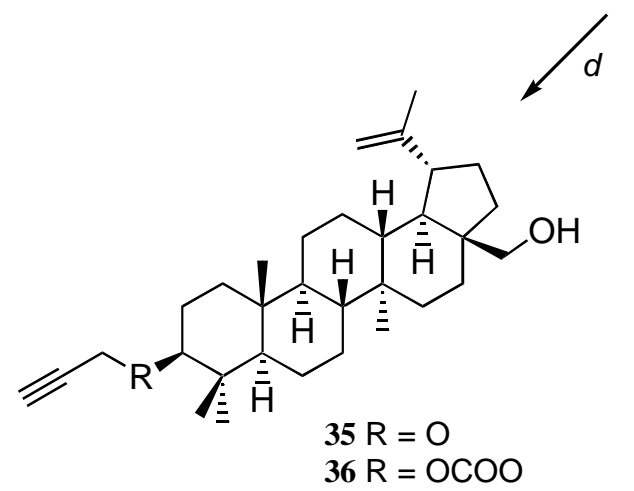

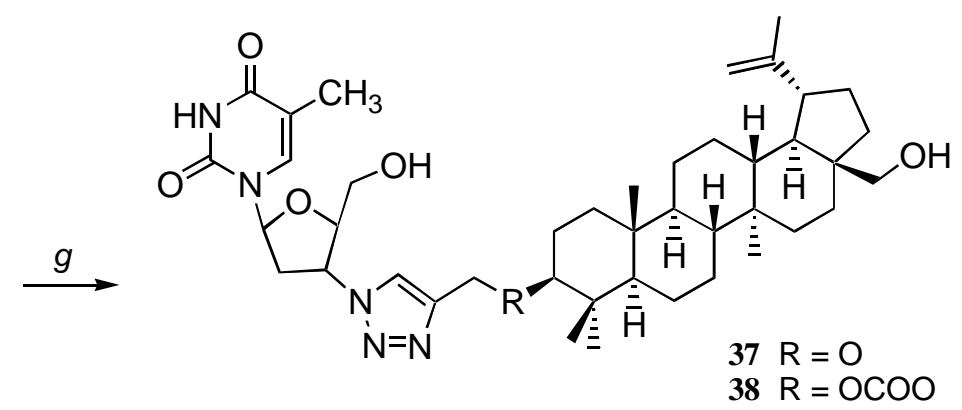

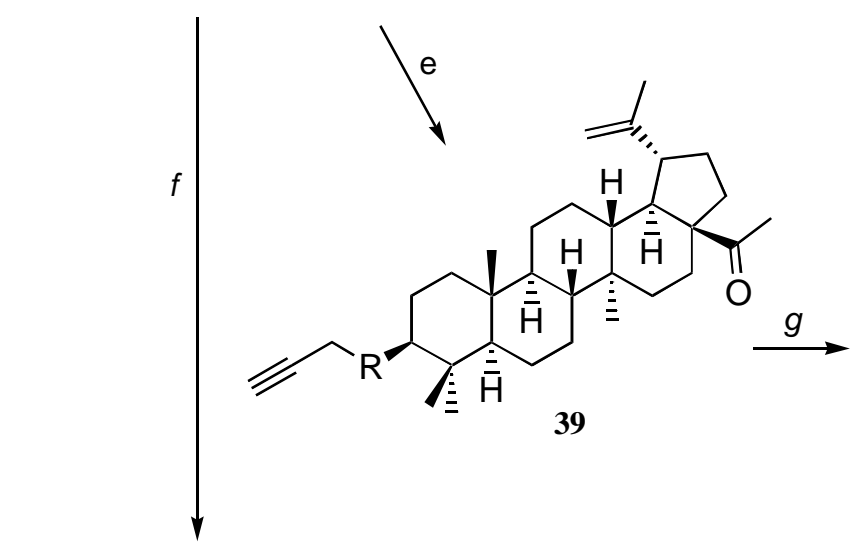

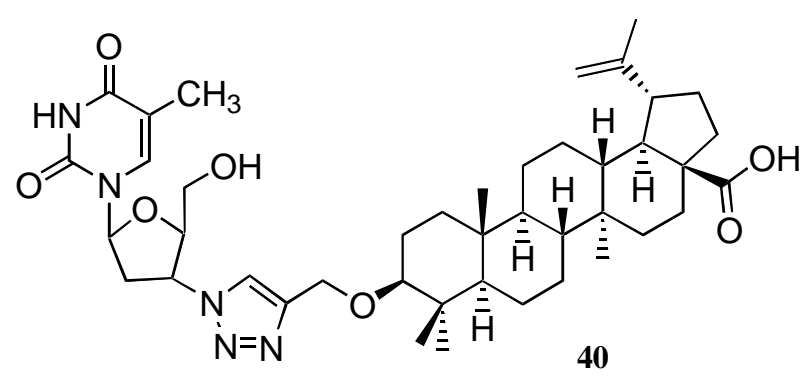

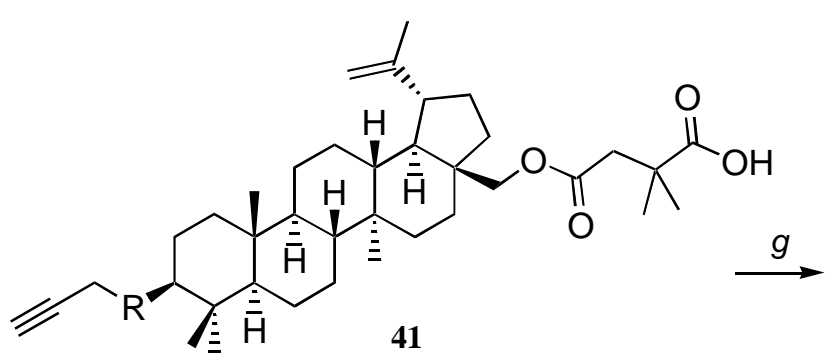

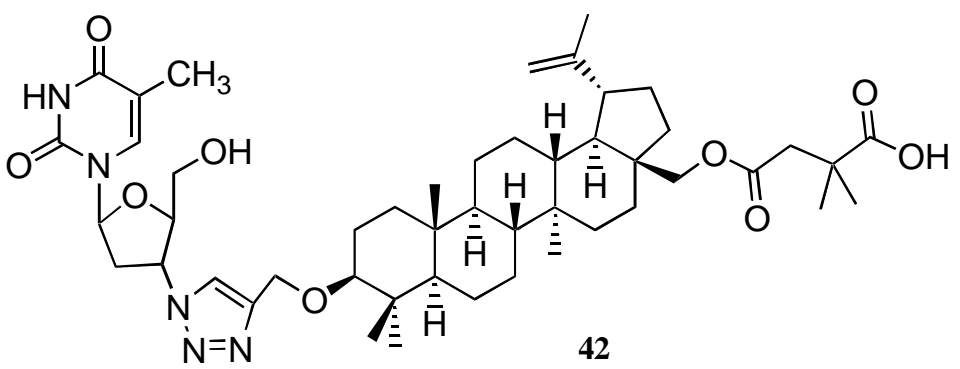

Reaction conditions: $a$, TBSCI, DMF/THF (1:1), DMAP, DIPEA, $0^{\circ} \mathrm{C} ; b$, propargyl bromide, NaH, THF; $c$, triphosgene, pyridine, THF, then propargyl alcohol, pyridine, THF; $d$, TBAF/THF; $e$, Jones reagent, acetone; $f$, 2,2-dimethylsuccinic anhydride, DMAP, DMF, $70^{\circ} \mathrm{C} ; g, \mathrm{AZT}, \mathrm{Cu} / \mathrm{CuSO}_{4} .5 \mathrm{H}_{2} \mathrm{O}, \mathrm{H}_{2} \mathrm{O}, t-\mathrm{BuOH}$, under $\mathrm{N}_{2}$

Scheme 7. AZT conjugation at the C-3 position of betulin derivatives. 


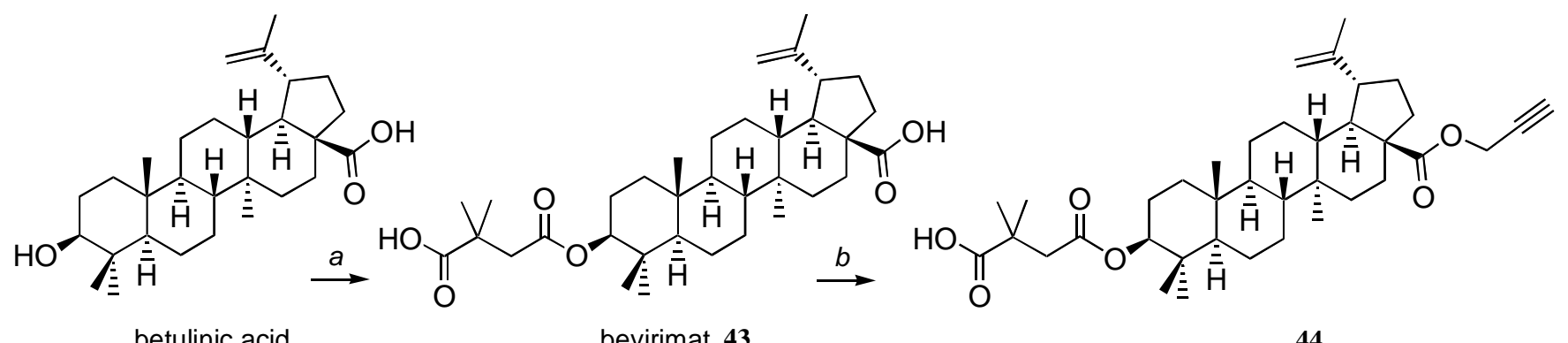

betulinic acid

bevirimat $\mathbf{4 3}$

44

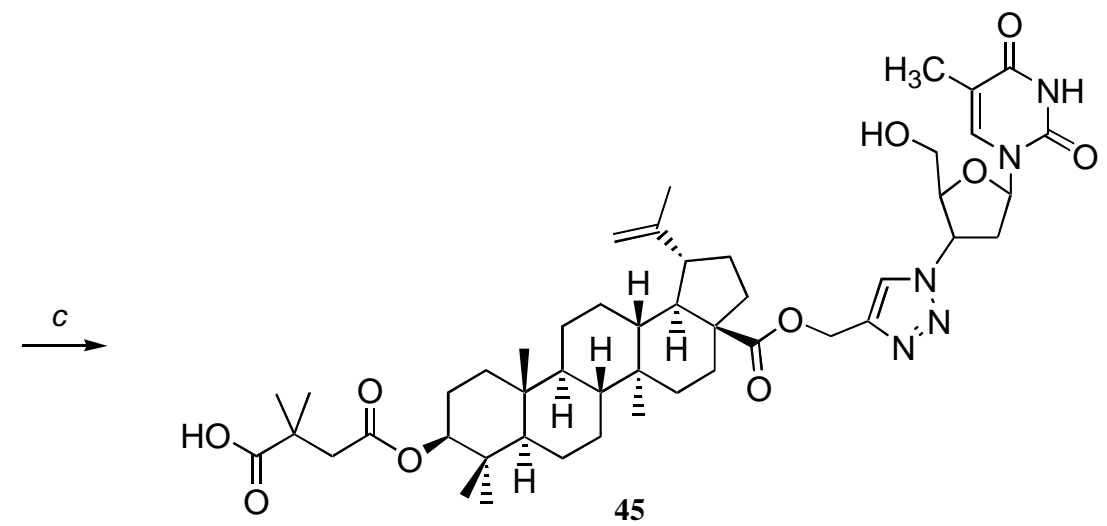

Reaction conditions : a, 2,2-dimethylsuccinic anhydride, DMAP, DMF, $70^{\circ} \mathrm{C}$;

b, propargyl bromide, $\mathrm{Cs}_{2} \mathrm{CO}_{3}$, DMF/THF (1:1), r.t.; $c, \mathrm{AZT}, \mathrm{CuSO}_{4} \cdot 5 \mathrm{H}_{2} \mathrm{O}, \mathrm{H}_{2} \mathrm{O}, \mathrm{tBuOH}, \mathrm{N}_{2}$

Scheme 8. Synthesis of AZT-betulin/BA 45 conjugated at C-28.

In 2012 Wölfling and co-workers reported a simple and convenient synthetic route for the formation of novel $2 \alpha$-triazolylcholestane derivatives. ${ }^{16}$ For the preparation of novel steroid derivatives via copper(I)catalysed azide-alkyne cycloaddition (CuAAC), 2 2 -azido-5 $\alpha$-cholestan-3-one 48 was chosen as starting compound. The synthetic strategy for the preparation of the starting azide is illustrated in Scheme 9. $2 \alpha$-Bromo-5 $\alpha$-cholestan-3-one 47 was obtained by bromination of the readily available cholestanone (46). ${ }^{17}$ After purification of the $\alpha$-bromo ketone, the compound was stirred for $8 \mathrm{~h}$ in the presence of sodium azide to provide the desired $2 \alpha$-azido ketone $\mathbf{4 8}$ in good yield.

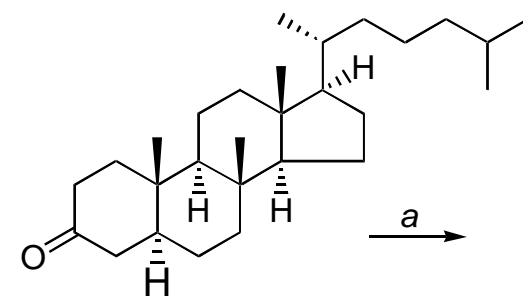

46

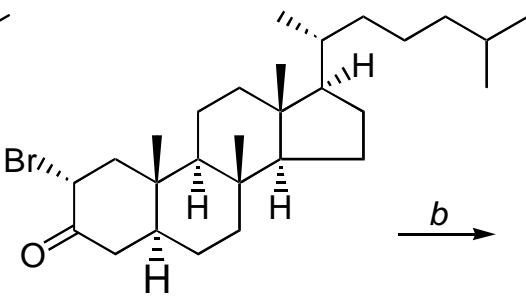

47

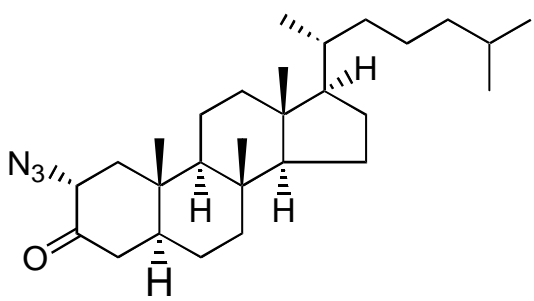

48

Reagents and conditions: $a, \mathrm{Br}_{2}, \mathrm{HBr}, \mathrm{AcOH} ; b, \mathrm{NaN}_{3}, \mathrm{DMF}, 8 \mathrm{~h}$.

Scheme 9. Synthesis of $2 \alpha$-azido-5 $\alpha$-cholestan-3-one.

Several A-ring-substituted 1,2,3-triazolylcholestan-3-ones $\mathbf{5 0}$ were synthesized in very good yields by the reactions of $\mathbf{4 9}$ with various terminal alkynes (Scheme 10). In all cases, total consumption of the starting compound was observed within $1.5-8 \mathrm{~h}$ at ambient temperature. The reactions were very selective, and the 
triazolyl ketones could generally be isolated in $84-92 \%$ yields. Treatment of 50 with $\mathrm{KBH}_{4}$ in $\mathrm{MeOH} / \mathrm{CH}_{2} \mathrm{Cl}_{2}$ $(4: 1)$ resulted in two diastereomeric 3-hydroxy-2-triazolylcholestanes in an overall yield of $\sim 95 \%$. The mixture of epimers could be separated by flash chromatography to yield $\mathbf{5 1}(3 \alpha-\mathrm{OH})$ and $\mathbf{5 2}(3 \beta-\mathrm{OH})$ in a ratio of 1:2. A similar diastereomeric ratio was reported by Schönecker et $a /$ in the reduction of $2 \alpha$-azidocholestan-3-one 49 with $\mathrm{LiBH}_{4}{ }^{18}$
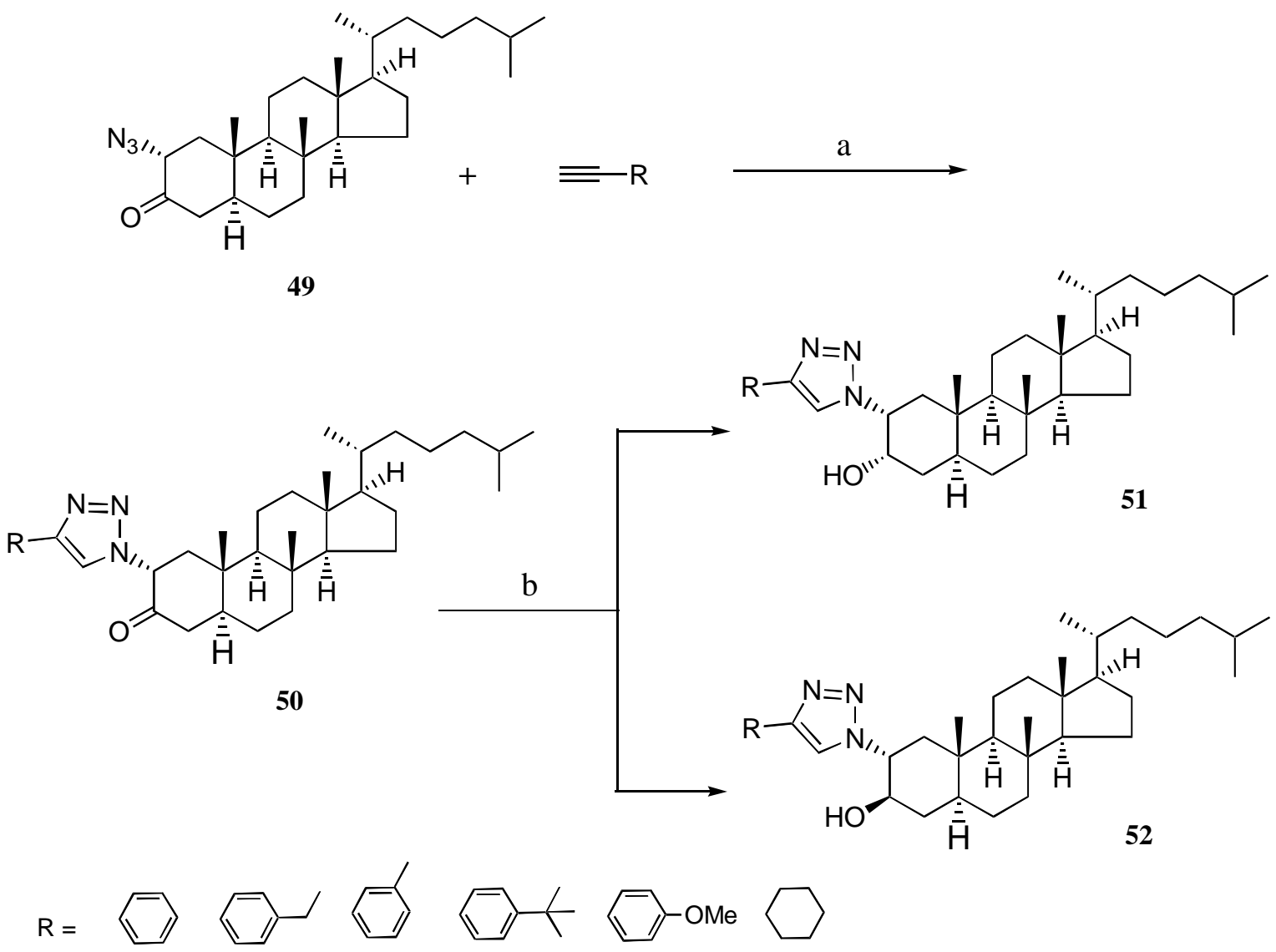

Reaction conditions : (a) $\mathrm{CuSO}_{4} \cdot 5 \mathrm{H}_{2} \mathrm{O}(5 \mathrm{~mol} \%), \mathrm{NaAsc}(15 \mathrm{~mol} \%), \mathrm{CH}_{2} \mathrm{Cl}_{2} / \mathrm{H}_{2} \mathrm{O}$ (1:1), r.t.

(b) $\mathrm{KBH}_{4}, \mathrm{MeOH} / \mathrm{CH}_{2} \mathrm{Cl}_{2}(4: 1), 20$ min, r.t.

Scheme 10. Formation of 3-hydroxy-2-triazolylcholestanes.

The cycloadducts were tested in vitro for their antiproliferative activities; however only a few derivatives displayed limited cell growth inhibition. According to their observations different structural elements on the hetero-ring might have an impact on the cytostatic effects. Cycloalkyl group or a heteroaromatic substituent on the triazole moiety is generally favoured over substitution with aryl rings.

In 2012 new ferrocene labelled steroid derivatives were obtained by Skoda-Földes et al. ${ }^{19}$ via a palladiumcatalyzed carbonylative Sonogashira coupling and a copper-catalyzed azide alkyne cycloaddition. Three steroid derivatives with a $17 \alpha$-ethynyl substituent (Scheme 11, 53a-55a) were chosen as model compounds to obtain new ferrocene-steroid conjugates. The carbonylative coupling of ethynylsteroids and iodoferrocene (56) was carried out in the presence of the most widely used $\mathrm{PdCl}_{2}\left(\mathrm{PPh}_{3}\right)_{2} / \mathrm{Cul}$ catalytic system. Steroid $\mathbf{5 3 a}$ was reacted with iodoferrocene 56 using different 53a/56 ratios, catalyst system and CO pressure. When iodoferrocene and $\mathbf{5 3 a}$ were reacted in equimolar amounts, the product $\mathbf{5 3 b}$ could be isolated in $45 \%$ yield. It should be 
mentioned that 53a was used as a non separable mixture of $D^{5}$ and $D^{4}$ isomers $53 a b$ in a ratio of $8 / 2$. The use of a slight excess of steroid $\mathbf{5 3}$ a led to an increase in the yield of 53b. The absence of the Cul cocatalyst, as well as the use of a higher CO pressure resulted in lower yields. The products $\mathbf{5 4 b}$ and $\mathbf{5 5 b}$ were obtained in $50 \%$ and $51 \%$ yields, respectively. The estradiol derivative $\mathbf{5 5 b}$ had been synthesized previously by a four-step procedure via the lithiation of MOM-protected ethynylestradiol, followed by coupling with the Weinreb-amide derivative of ferrocene, and deprotection of the $\mathrm{OH}$ groups. ${ }^{20}$ It is worth noting that the carbonylative Sonogashira reaction tolerates the tertiary alcohol functionality, and therefore protection of $17-\mathrm{OH}$ groups is not necessary. Slow decomposition of ferrocenyl alkynyl ketones $\mathbf{5 4 b}$ and $\mathbf{5 5 b}$ was observed in solution.

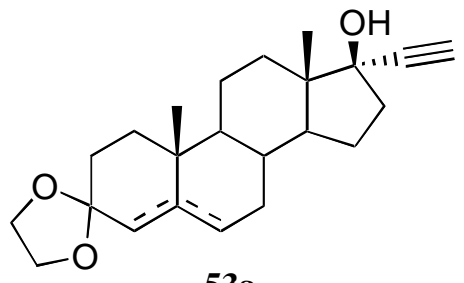

53a

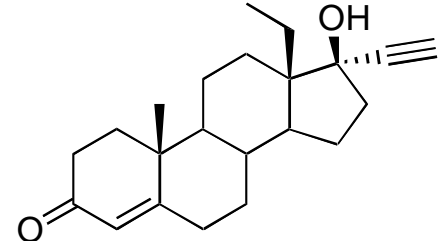

54a

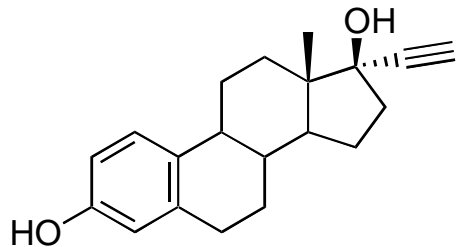

$55 \mathbf{a}$<smiles>[R][C@]12CCC[C@H](CC[C@@]1(O)C#C)[C@@H]2F</smiles>

53a $R=M e$

54a $R=E t$

55a $R=M e$

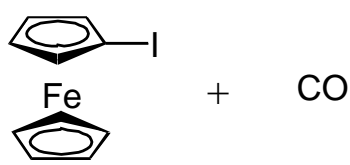

56

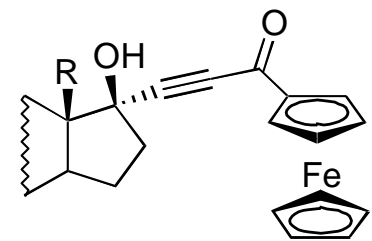

53b $\mathrm{R}=\mathrm{Me}$

54b $R=E t$

55b $\mathrm{R}=\mathrm{Me}$

Scheme 11. Ethynyl steroids 53a-55a, used as substrates, and their carbonylative coupling to iodoferrocene.

The $\mathrm{CuSO}_{4} /$ sodium ascorbate catalytic system was also applied in the synthesis of steroid-ferrocene derivatives 53c-55c, in a $\mathrm{CH}_{2} \mathrm{Cl}_{2} /$ water mixture in the presence of ferrocenyl azide $\mathbf{5 7}$ as the reaction partner (Scheme 12). The reactions were followed by thin-layer chromatography. Ethynyl-steroids 53a-55a could be converted to the triazoles 53c-55c selectively, no formation of side products was observed. Steroid-ferrocene conjugates 53c-57c were obtained in good yields and they showed good stability even in solution. As racemic ferrocenyl azide $\mathbf{5 7}$ was used as reaction partner and the products were obtained in nearly quantitative reactions, cycloadditions undoubtedly led to $1 / 1$ mixtures of two epimers of products 53c-55c.

Although ferrocenyl derivatives of 17-ethynyl-steroids can be obtained in one step without protection of $\mathrm{OH}$ groups of the steroids, the yields are moderate and some of the products show low stability in solution.

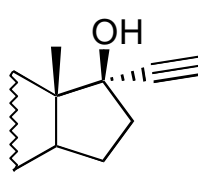

53a $R=M e$

54a $R=E t$

55a $R=M e$

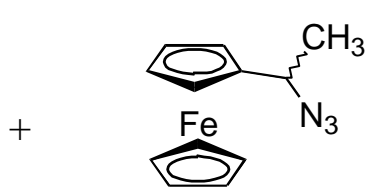

57

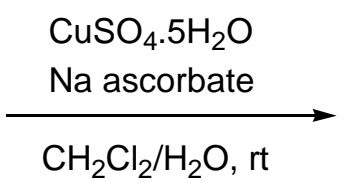

$\mathrm{CH}_{2} \mathrm{Cl}_{2} / \mathrm{H}_{2} \mathrm{O}, \mathrm{rt}$

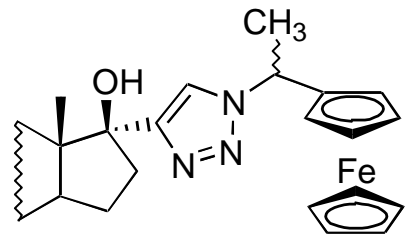

53c $\mathrm{R}=\mathrm{Me}$

$\mathbf{5 4 c} R=\mathrm{Et}$

55c $\mathrm{R}=\mathrm{Me}$

Scheme 12. Copper-catalyzed azide-alkyne cycloaddition of steroids 53a-55a with (1-azidoethyl)ferrocene 57. 
The copper-catalyzed azide-alkyne cycloaddition (CuAAC) has been used by Paixão et al. for the synthesis of 1,2,3-triazoles containing a steroidal moiety. ${ }^{21}$

In order to get the best reaction conditions for the 1,3-dipolar cycloaddition of phenylacetylene with the azidocholesterol $\mathbf{5 8}^{22}$ the reaction was carried out in a mixture of THF- $\mathrm{H}_{2} \mathrm{O}(1: 1)$ in the presence of $10 \mathrm{~mol} \%$ $\mathrm{Cu}(\mathrm{OAc})_{2} \cdot \mathrm{H}_{2} \mathrm{O}$ and sodium ascorbate $(20 \mathrm{~mol} \%$ ) (Scheme 13). The desired product 60a was obtained in quantitative yield. The experimental procedure involves the in situ generation of $\mathrm{Cu}(\mathrm{I})$ species by reducing $\mathrm{Cu}(\mathrm{OAc})_{2} \cdot \mathrm{H}_{2} \mathrm{O}$ with sodium ascorbate in aqueous solution. When the reaction time was decreased from 12 to 6 hours the chemical yield was dramatically dropped to 56\%. The use of different amounts of copper salt and sodium ascorbate were also studied. Decreasing the copper catalyst loading to $5 \mathrm{~mol} \%$ along with $10 \mathrm{~mol} \%$ of sodium ascorbate the 1,2,3-triazole 60a was obtained in $65 \%$ yield. Using 5 mol\% of $\mathrm{Cu}(\mathrm{OAc})_{2} \cdot \mathrm{H}_{2} \mathrm{O}$ with 20 mol\% of sodium ascorbate the triazole 60 a was obtained in a reasonable chemical yield of $82 \%$. By changing the copper acetate to $\mathrm{CuBr}_{2}$ (10 mol\%) the cholesterol containing the triazole ring was obtained in $45 \%$ yield. Additional parameters were analyzed including change of the solvent and temperature. A mixture of ethanolwater (1:1) gave the desired product in $25 \%$ yield. When the reaction was run in PEG $400-\mathrm{H}_{2} \mathrm{O}$ or [ $\left[\mathrm{BMIM}^{\mathrm{B}} \mathrm{BF}_{4}-\right.$ $\mathrm{H}_{2} \mathrm{O}$ at room temperature for 12 hours the triazole 60 a was obtained with $28 \%$ and $35 \%$ yield, respectively.

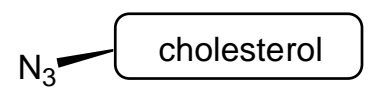

58

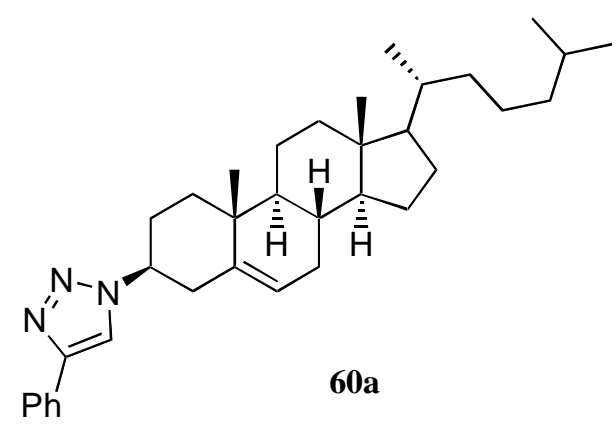

Scheme 13. Optimization studies of the copper-catalyzed 1,3-dipolar cycloaddition of 3 3 -azidocholesterol 58 with phenylacetylene.

Next, they examined the possibilities and limitation of this cycloaddition reaction by varying the nature of the terminal alkyne (Scheme 14). The results showed that several substituted terminal alkynes coupled efficiently with the $3 \beta$-azidocholesterol 58 to provide the corresponding 1,2,3-triazoles 60a-e in excellent isolated yields (>87\%). When the reaction was carried out using hex-1-yne as a reaction partner the click product was obtained in $96 \%$ yield. Alkylalkynes bearing hydroxy and amino groups were also successfully employed in the 1,3-dipolar cycloaddition reaction. Likewise, when a strong electron-withdrawing group was present in the terminal alkyne, the product was obtained in very good chemical yield.

Next, the reactivity of terminal alkynes derived from cholesterol towards different azides was evaluated. Benzylic azides 58f-j with electron-neutral and electron-deficient substituent react with 3- $\beta$-prop-2ynyloxycholesterol 59 to give the expected 1,2,3-triazoles in good to excellent yields. The hindered orthobiphenylyl azide was also used forming $60 \mathrm{f}-\mathbf{k}$ in $84 \%$ yield. The use of this methodology has proven that different groups attached to the aryl ring are compatible with this reaction ${ }^{23}$ thus, providing an opportunity for further functionalization of the product. In addition, the 2,3,4,6-tetra-O-acetyl- $\beta$-D-galactopyranosyl azide 60j also reacted smoothly with $3 \beta$-prop-2-ynyloxycholesterol 59 to give the product $\mathbf{6 0}$ in $\mathbf{7 5 \%}$ yield. With regard to stereochemistry on the anomeric carbon of the galactopyranosyl azide, they observed that the stereoconfiguration does not play an important role in determining the degree of chemical yield. For instance, 
2,3,4,6-tetra-O-acetyl- $\alpha$-D-glucopyranosyl azide underwent click coupling with similar level of yield as the $\beta$ analogue.
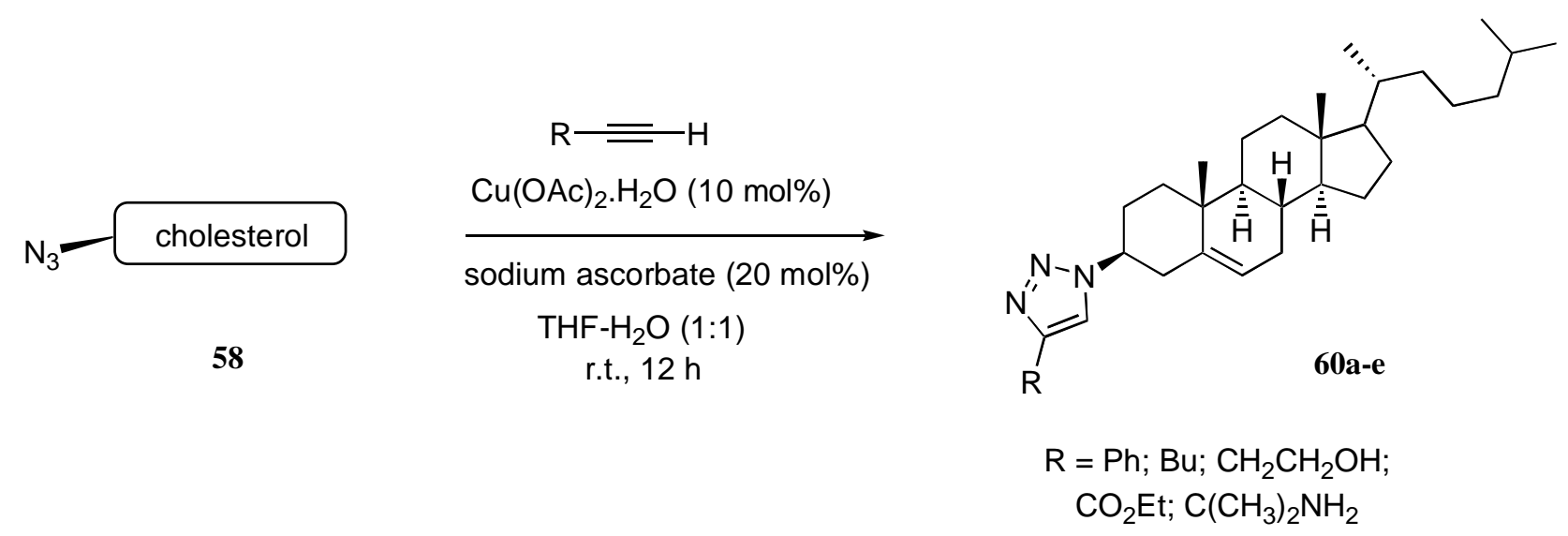

Scheme 14. Variation of the alkyne partner.
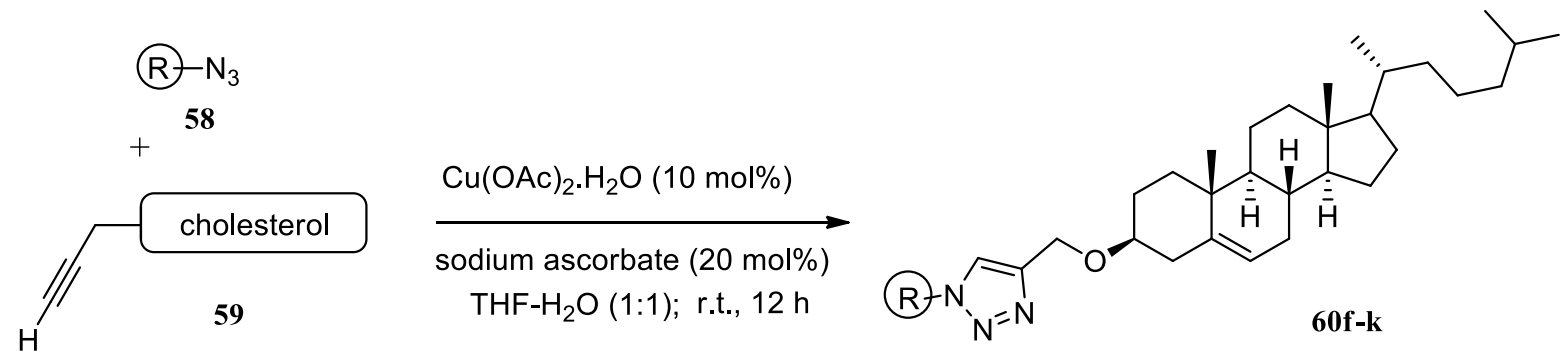

Scheme 15. Scope of the click reaction using alkynylcholesterol building block.

The CUAAC was then successfully applied to the reaction between propargylic glycosides and azidofunctionalized steroids. The authors were able to synthesize a library of saponins and digitalis derivatives containing the triazole moiety. The natural versions of these two classes of compounds are widely recognized for their antifungal, cardiovascular, and antitumor activity. ${ }^{24}$ Effectively, the click chemistry involving 2propynyl-2,3,4,6-tetra-O-acetyl- $\alpha$-D-glucopyranoside and azidosteroids were performed to give the steroidal glycosides. Different azidosteroids were evaluated and in all the cases the corresponding products were obtained in rather good levels of chemical yield. When the propargylic partner was changed from $\beta$-D-glucose pentaacetate to a disaccharide or trisaccharide, the analogues of this special class of natural product were also obtained in satisfactory yields.

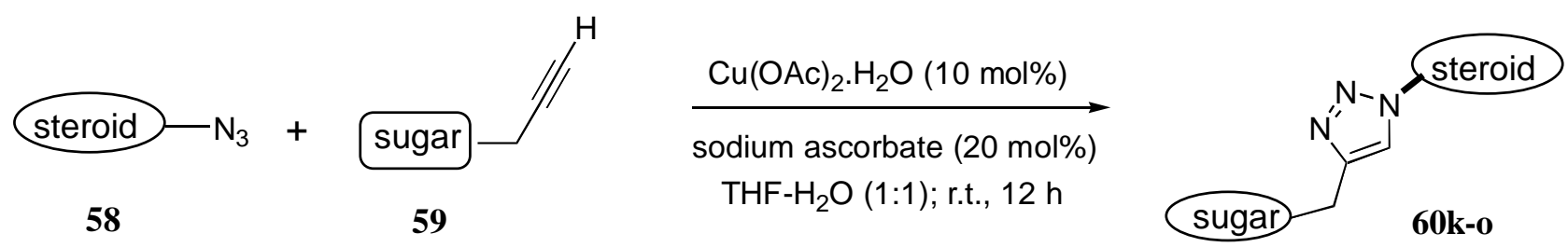

Scheme 16. Synthesis of saponins and digitalis derivatives. 
A convergent synthesis of a novel estrogen receptor-targeted drug hybrid was developed in 2012 by Hanson and co-workers ${ }^{25}$ based on structures of the potent anti-proliferative mitomycin $\mathrm{C}$ and the steroidal anti-estrogen RU 39411.

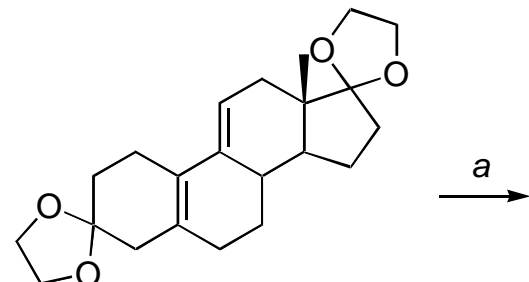

61

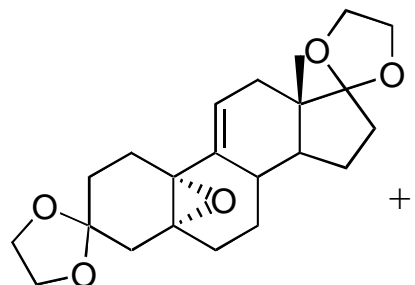

62

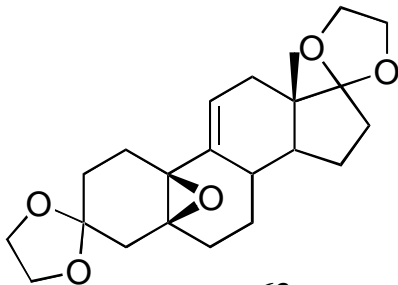

63

$\alpha: \beta=3: 1$

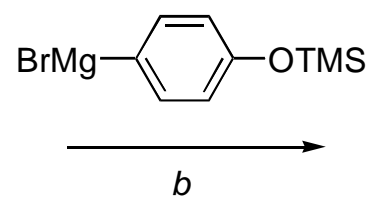<smiles>CCC1C2CCC3=CC(=O)CCC3=C2[C@@H](c2ccc(O)cc2)CC12OCCO2</smiles>

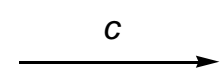

64a

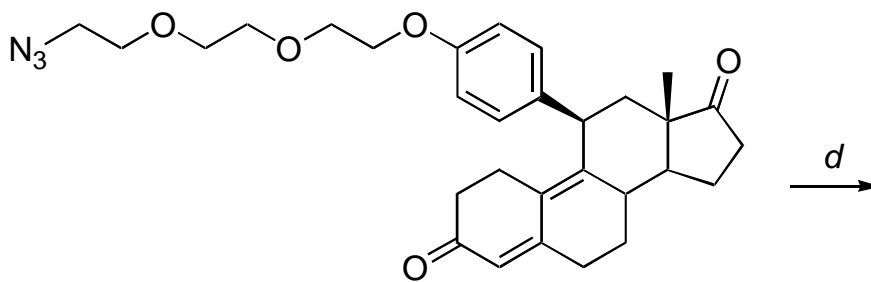

65

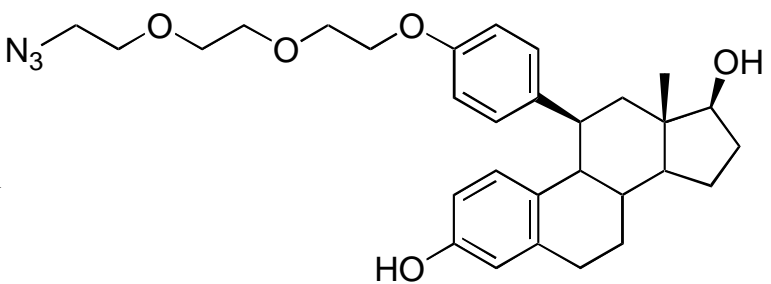

66

Reaction conditions : $a, \mathrm{CF}_{3} \mathrm{COCF}_{3}, \mathrm{H}_{2} \mathrm{O}_{2}$, pyridine, r.t.; $b, 1: \mathrm{Cu}(\mathrm{I}), 2-\mathrm{HCl}$;

c, 1 :triethylene glycol ditosylate, $\mathrm{K}_{2} \mathrm{CO}_{3}, \mathrm{CH}_{3} \mathrm{CN}$, reflux, 2: $\mathrm{NaN}_{3}$, ethanol, reflux;

d, 1: $\mathrm{AcBr}, \mathrm{Ac}_{2} \mathrm{O}, \mathrm{CH}_{2} \mathrm{Cl}_{2}$, rt, 2: $\mathrm{KOH}, \mathrm{MeOH}, 0-5^{\circ} \mathrm{C}, 3: \mathrm{NaBH}_{4}, \mathrm{KOH}$, methanol

Scheme 17. Preparation of the $11 \beta$-[4- $\omega$-azidotriethyleneglycoloxy)-phenyl]estradiol.

The synthesis of the estradiol component began with the estra-5-(10), 9(11)-diene 3,17 diethylene ketal 61, an intermediate that the authors had previously synthesized (Scheme 17). ${ }^{26}$ Epoxidation using hydrogen peroxide and hexafluoroacetone under basic conditions gave the 5,10- $\alpha$-epoxide 62 and the 5,10- $\beta$-isomer 63 in a $76 \%$ isolated yield (3:1 ratio). $\mathrm{Cu}(\mathrm{I})$-catalyzed 1,4- addition of 4-(trimethylsilyloxy) phenylmagnesium bromide followed by dehydration and deketalization provided the 11ß-(4-hydroxyphenyl)-estra-4,9-diene3,17-dione 65 in a $90 \%$ yield for the three steps. ${ }^{27}$ It should be noted that under these conditions, the $\alpha-4-$ hydroxyphenyl steroid generated from the $\beta$-isomer 63 undergoes isomerization to the more stable 11 product 64a. Tosylation of triethylene glycol proceeded in high yield to give the ditosylate derivative ${ }^{28}$ which underwent Williamson ether synthesis with the 4-hydroxyphenyl steroid 86. Subsequent displacement of the 
terminal tosylate group with sodium azide in ethanol gave the azido-triethylene glycoloxyphenyl derivative $\mathbf{6 5}$ in $10 \%$ isolated yield (two steps). ${ }^{29}$ Aromatization of the estradiene-dione with acetic anhydride-acetyl bromide, acetate saponification and stereoselective borohydride reduction of the 17-ketone gave the 11ß-(4azido-triethylene glycoloxyphenyl)estradiol intermediate 66 in 56\% isolated yield for the three steps.

Preparation of the mitomycin C component began with $\mathrm{N}$-methylation of mitomycin C 67 with methyl iodide to give porfiromycin 68 in $61 \%$ yield (Scheme 18). ${ }^{30}$ Subsequent hydrolysis of the quinone amine to the hydroxy derivative, followed by methylation with diazomethane gave the intermediate methyl ether. The intermediate underwent the displacement reaction with propargylamine to give the desired 7-( $N$-propargyl)porfiromycin 69 in 55\% yield for the three steps. Modifications of the amination step and combining the last three steps into a single pot method significantly improved the overall yield.

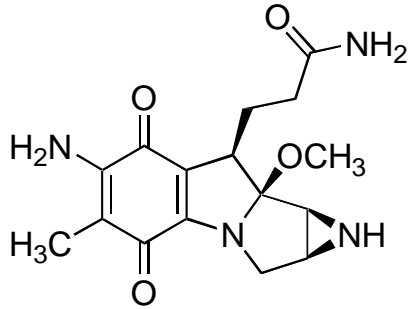

67

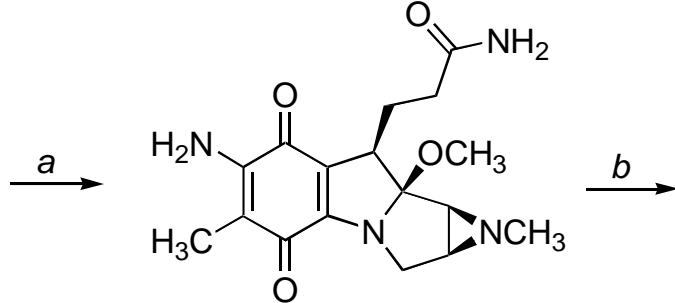

68

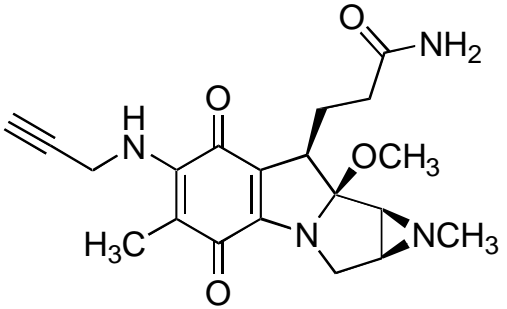

69

Reaction conditions: $a, \mathrm{CH}_{3} \mathrm{I}, \mathrm{K}_{2} \mathrm{CO}_{3}$, acetone, reflux; $b, 1: 0.1 \mathrm{~N} \mathrm{NaOH}$, rt, 2: $1 \mathrm{~N} \mathrm{H}_{2} \mathrm{SO}_{4}, 0{ }^{\circ} \mathrm{C}, 3: \mathrm{CH}_{2} \mathrm{~N}_{2}$, ether, 4: propargylamine, methanol, rt.

Scheme 18. Preparation of the mitomycin C component.

Ligation was accomplished using the Huisgen [3 + 2]-cycloaddition reaction between the terminal alkynyl and azido groups (Scheme 19). ${ }^{31}$ A slight modification of the conventional method was used, resulting in an isolated yield of $81 \%$ for the antiestrogen-mitomycin C hybrid $\mathbf{7 0}$. Analysis indicated a single cycloaddition product in which the two coupling moieties were 1,4- to one another. None of the 1,5-isomer was detected by NMR.

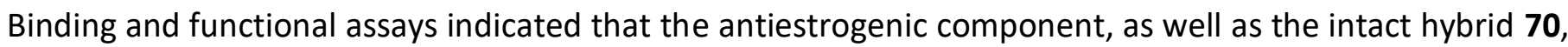
retained high affinity for ER $\alpha$-LBD and possessed potent antiestrogenic activity in ER-responsive cells. Cell proliferation assays with two breast cancer cell lines indicated that the mitomycin-C component, as well as the intact hybrid 70, retained potent cytotoxic effects. The results indicated that although hybrid 70 was not selective for ER(+)-MCF-7 cells as compared to ER(-)-MDA-MB-231 cells, the individual components within the intact hybrid retained their biological properties.

In 2013, Lukashev et al. described an efficient approach to azolyl-substituted steroids through coppercatalyzed Ullmann C-N coupling. ${ }^{32}$ The elaborated protocol has permitted iodosteroids with various substituted indoles, imidazoles, carbazole, indazole, and secamides (secondary amides) to be coupled, affording the corresponding azolylsubstituted steroids in good to excellent yields. Steroidal vinyl iodides needed for the modified Ullmann coupling were synthesized according to the standard procedures ${ }^{33}$ through the oxidation of hydrazones obtained from the corresponding ketosteroids by iodine. ${ }^{34}$ Thus, enol ether $\mathbf{7 1}$ was transformed into 17-hydrazone 72, which was then treated with iodine, yielding, after subsequent removal of the enol ether protecting group, 17-iodosteroid 73 in good yield (Scheme 20). A similar procedure was applied to the preparation of testosterone $\mathbf{7 4}$ and cholest-4-en-3-one 75 derivatives 78 and 79 . The 
iodination of 3-hydrazones $\mathbf{7 6}$ and $\mathbf{7 7}$ followed by equilibration of the forming iododiene mixture in the presence of triflic acid afforded 3-iodosteroids $\mathbf{7 8}$ and $\mathbf{7 9}$ in moderate yields.<smiles>C#CCNC1=C(C)C(=O)C2=C(C1=O)C(CCC(N)=O)C1(OC)CN2C1C</smiles>

69

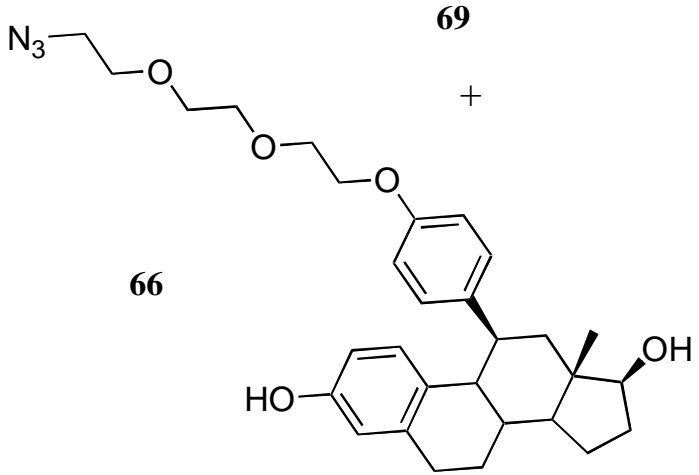<smiles>CC1=C(NCc2cn(CCCl)nn2)C(=O)C2=C(C1=O)[C@@H](CCC(N)=O)[C@@]1(O)C3[C@@H](CN21)N3C</smiles>

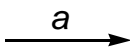

70

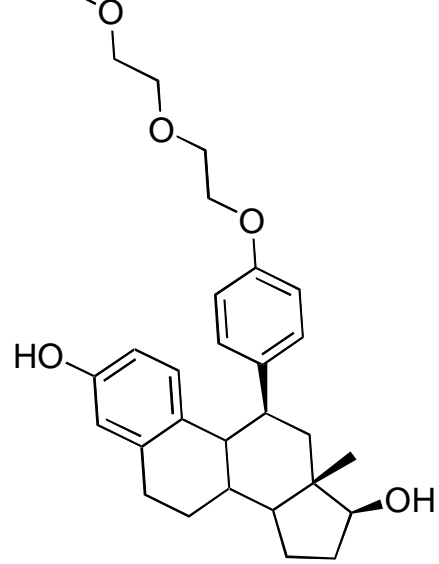

Reaction conditions: a, 0.02 eq $\mathrm{CuSO}_{4} \cdot 0.11$ eq sodium ascorbate, $\mathrm{H}_{2} \mathrm{O} / \mathrm{tBuOH}: 1 / 1$, rt, $20 \mathrm{~h}$.

Scheme 19. Ligation of mitomycin C and estradiol components to form target hybrid 70.

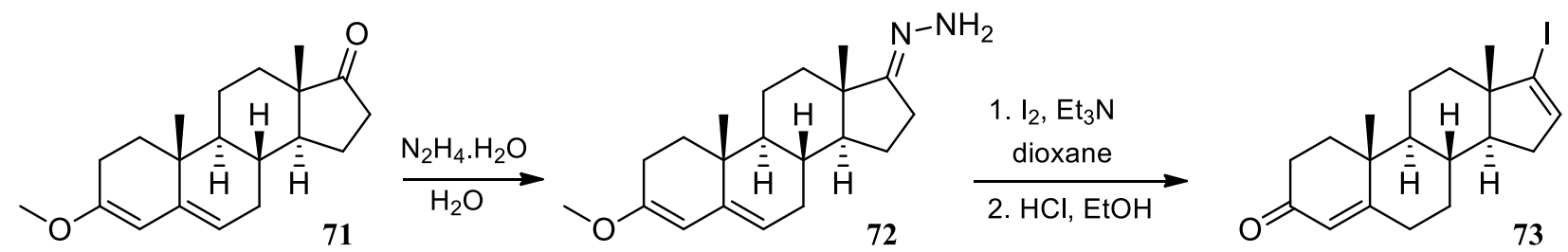

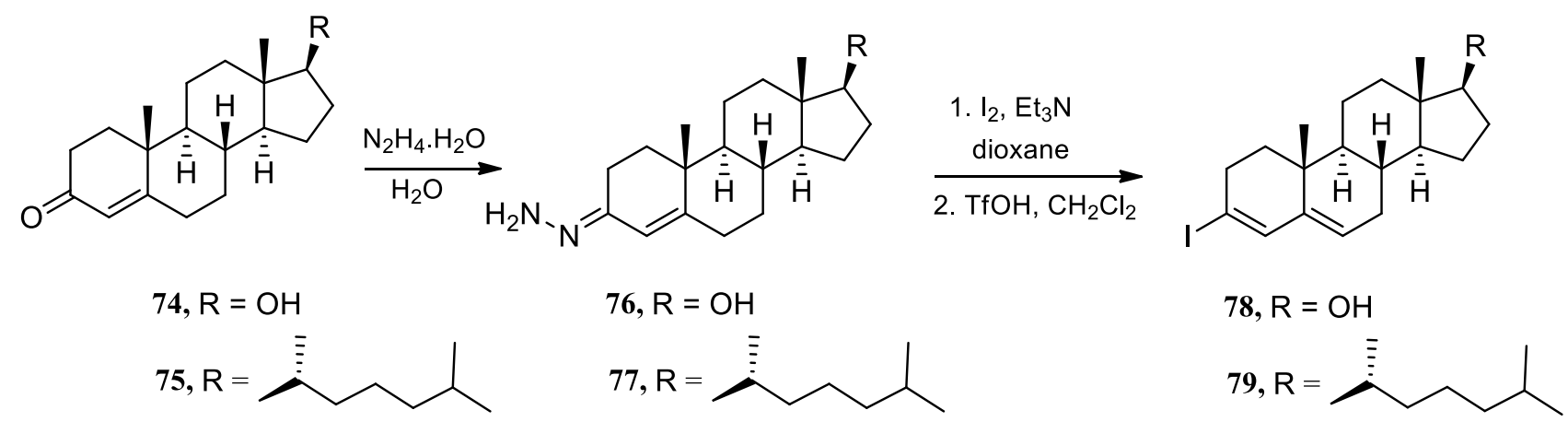

Scheme 20. Synthesis of 17 -iodosteroid 73 and 3-iodosteroids $\mathbf{7 8}$ and $\mathbf{7 9 .}$ 
Conditions for the reaction between vinyliodides and azoles were optimized by using the cross-coupling of iodosteroid $\mathbf{7 3}$ with indole as a model reaction (Scheme 21).

Use of a ligand-free protocol ${ }^{35}$ led to a mixture of $5 \%$ coupling product $80 \mathrm{a}$ and $30 \%$ by-product 81 . Reductive dehalogenation reaction of iodosteroid $\mathbf{7 3}$ giving $\mathbf{8 1}$ was also observed in the absence of indole. This side-reaction is known to accompany Cu-catalyzed amination when the substrates used are sterically hindered. ${ }^{36}$ Although the mechanism of reductive dehalogenation remains unclear, possible pathways can include either protonation or homolytic cleavage of copper(III) intermediates.

The poor performance of the ligand-free system prompted them to study a number of $\mathrm{N}, \mathrm{N}-, \mathrm{N}, \mathrm{O}-$ and $\mathrm{O}, \mathrm{O}$ donating ligands. The choice of ligand indeed had a dramatic influence on the catalytic activity, and the use of different ligands resulted in levels of iodosteroid 73 conversion that varied over a wide range (from 14 to $93 \%$ ) and resulted in different selectivity towards products $\mathbf{8 0 a}$ and $\mathbf{8 1 .}$

Interestingly, the introduction of additional substituents, which usually improves the performance of $\mathrm{Cu}$ catalyzed systems, in this case led to a decrease in the yields and loss of selectivity. The reaction did not occur in nonpolar solvents such as toluene or dioxane. The best conversion was observed in dimethyl sulfoxide (DMSO), and the addition of water had no significant effect.

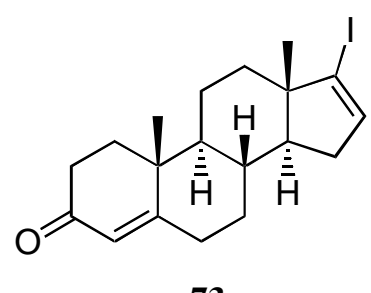

73

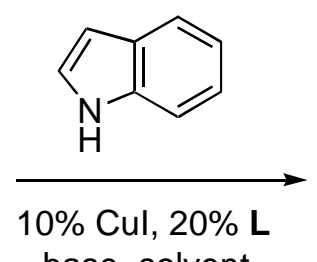

base, solvent

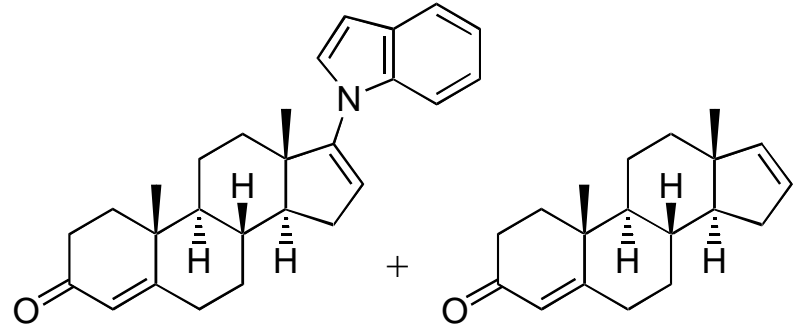

80a

81

Scheme 21. Amination of 17-iodosteroid 73 with indole.

The authors investigated the coupling of $\mathbf{7 3}$ with various azoles under the developed conditions as indicated in scheme 22. Despite the high conversion and rather good selectivity reached with dipivaloylmethane (DPM) as ligand, the formation of by-product $\mathbf{8 1}$ significantly complicated chromatographic isolation of the coupling product $80 \mathrm{a}$ and, as a result, the isolated yield was only 55\%. 5-Methoxyindole also gave a moderate yield of $\mathbf{8 0 b}$ (55\%), whereas the reaction of $\mathbf{7 3}$ with 5-bromoindole was complicated by competing amination of $\mathbf{8 0 c}$ with 5-bromoindole. Thus, the reactivity of the $\mathrm{C}-1$ bond in $\mathbf{7 3}$ towards Cu-catalyzed amination is roughly comparable to that of the $\mathrm{C}-\mathrm{Br}$ bond in 5-bromoindole. Coupling of $\mathbf{7 3}$ with indoles bearing electron-withdrawing substituents such as 3-formyl- and 4-cyano-indole gave very low yields together with the formation of significant amounts of reductive dehalogenation product $\mathbf{8 1}$. The amination of $\mathbf{7 3}$ proved to be very sensitive to steric effects exerted by the heterocycle.

The developed procedure proved to be very efficient in coupling of less sterically hindered 3-iodosteroids 78 and 79, with various $\mathrm{NH}$-heterocycles (pyrazole, imidazole, indazole, benzotriazole) giving azolylsubstituted steroids $\mathbf{8 2}$ and $\mathbf{8 3}$ in good to excellent yields (Scheme 23). The yields with cholestane derivative 79 were consistently lower than with $\mathbf{7 8}$, reflecting significantly diminished solubility of this substrate in DMSO. The formation of by-products by reductive dehalogenation was not observed at all, in contrast to the amination of substrate 73. 


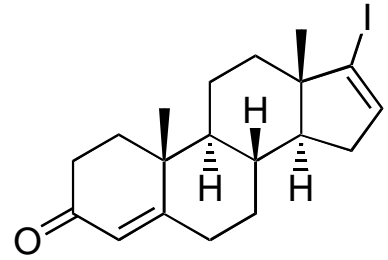

73

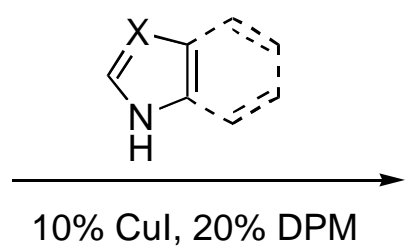

$\mathrm{K}_{2} \mathrm{CO}_{3}$, DMSO

$100^{\circ} \mathrm{C}, 24 \mathrm{~h}$

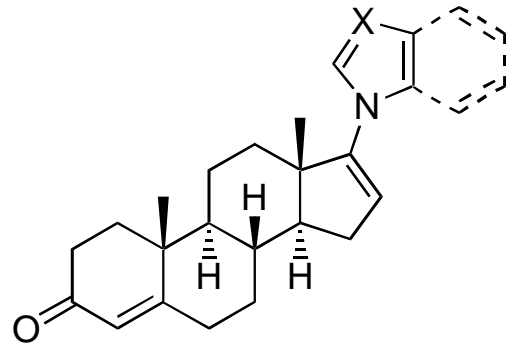

80a-d, $26-55 \%$<smiles>C[13C](C)C(=O)CC(=O)C(C)(C)C</smiles>

Azolyl substituent:<smiles>Cn1ccc2ccccc21</smiles>

80a<smiles>COc1ccc2c(ccn2C)c1</smiles>

80b<smiles>Cn1ccc2cc(Br)ccc21</smiles>

80c

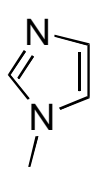

80d

Scheme 22. Reaction of $\mathbf{7 3}$ with azoles.<smiles>[R]C1CC[C@H]2[C@@H]3CC=C4C=C(I)CC[C@]4(C)[C@H]3CC[C@]12C</smiles>

78, $\mathrm{R}=\mathrm{OH}$

79, $\mathrm{R}=$<smiles>[Y][X]c1ccccc1</smiles>

benzotriazole pyrazole imidazole indazole

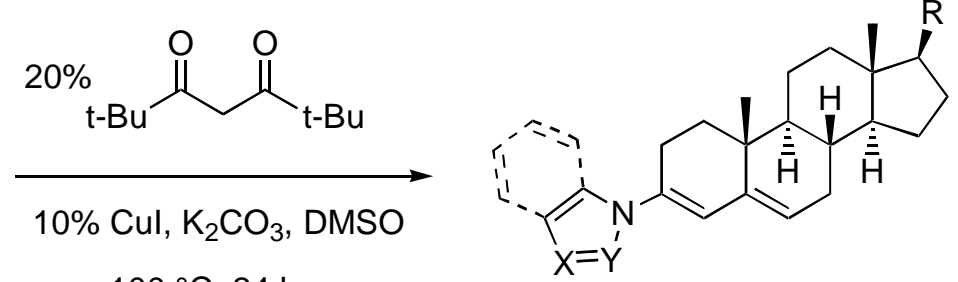

$100^{\circ} \mathrm{C}, 24 \mathrm{~h}$
82, $\mathrm{R}=\mathrm{OH}$

$83, \mathrm{R}=$

Scheme 23. Reaction of $\mathbf{7 8}$ and $\mathbf{7 9}$ with N-nucleophiles.

In 2013 Fletcher et al. ${ }^{37}$ examined a hydrometallation-addition sequence with unsaturated steroids and found that copper catalyzed conjugate addition reactions readily occur, and functional groups are tolerated (Scheme 24). 


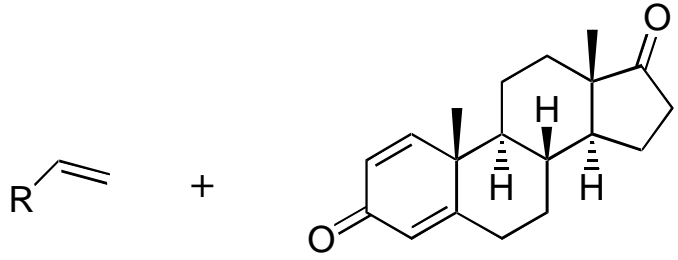

84

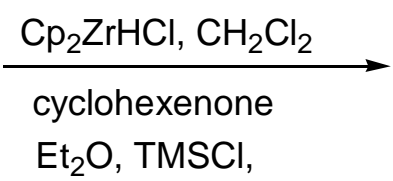

10 mol\% A, r.t.

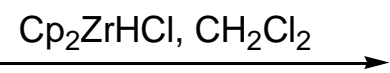

cyclohexenone

$\mathrm{Et}_{2} \mathrm{O}, \mathrm{TMSCl}$,

$10 \mathrm{~mol} \% \mathrm{~A}$, r.t.

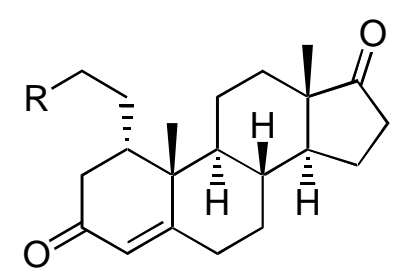

86
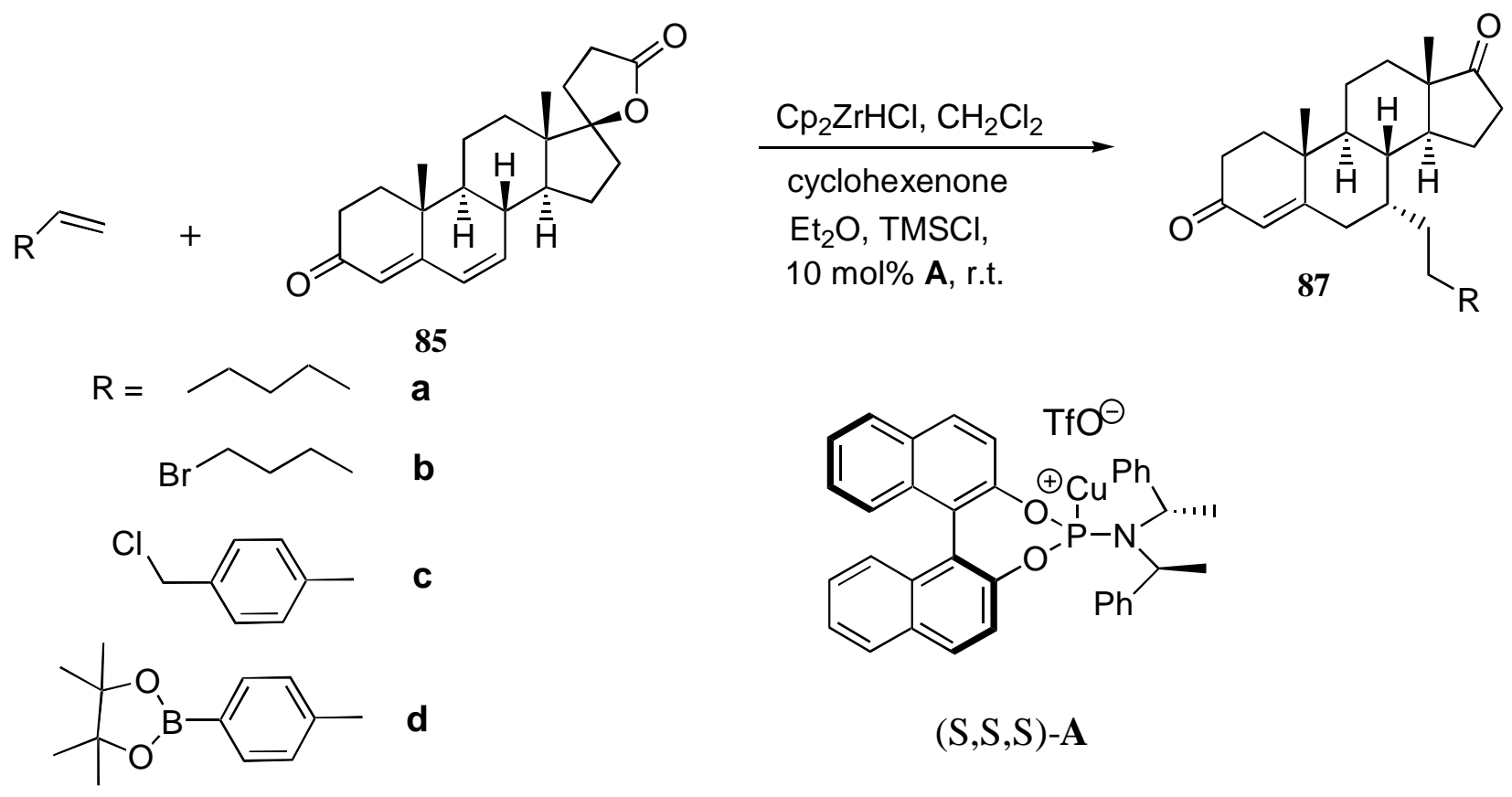

85

b

C<smiles>C[C@H](c1ccccc1)N([C@H](C)c1ccccc1)[PH]([Ge])(Oc1ccccc1)Oc1ccc2ccccc2c1-c1c(O)ccc2ccccc12</smiles>

$(\mathrm{S}, \mathrm{S}, \mathrm{S})-\mathbf{A}$

Scheme 24. 1,4- and 1,6-addition reactions to steroids.

1,4-Androstadiene-3,17-dione 84 is a cross-conjugated dienone capable of 1,4-addition reactions, 1,2additions to the dienone and ketone moieties, as well as other possibilities, such as rearrangement. Canrenone 85, contains a lactone, and is capable of 1,2-, 1,4-, and 1,6-addition reactions. The products of hydrometallation-addition to $\mathbf{8 4}$ and $\mathbf{8 5}$ would be functionalized steroids, which are valuable compounds, for example cholesteryl benzoate was the first compound found to form chiral nematic liquid crystals, and fulvestrant (Faslodex) ${ }^{38}$ is an established breast cancer drug. ${ }^{39}$

Hydrometallation-addition of 1-hexene to 84, catalyzed by copper complex $(S, S, S)$-A at room temperature, was found to proceed in a 1,4-fashion to give a crude B3.5: 1 ratio of diastereoisomers in favour of the 1- $\alpha$ isomer $\mathbf{8 6 a}$, which was isolated in $50 \%$ yield. The $1-\beta$-isomer could also be isolated in $16 \%$ yield. Hydrometallation-addition of functionalized alkenes to $\mathbf{8 4}$ shows that reactive functional groups such as bromides and benzyl chlorides are tolerated. In the case of canrenone 85, hydrozirconation of 1-hexene, followed by $(S, S, S)$-A catalyzed addition, favoured the $\alpha-1,6$-addition product 87 a, which was isolated in $59 \%$ yield. A minor, $\beta$-isomer, 1,6-addition product could also be isolated in $21 \%$ yield. They examined the possibility of adding functionalized alkenes to canrenone, and found that, while the yields are lower, alkenes and styrenes bearing reactive groups are surprisingly well tolerated. These reactions give steroids containing groups that should be useful handles for further derivatization - primary alkyl bromides $\mathbf{8 7 b}$, benzyl chlorides $\mathbf{8 7 c}$, and boronic esters $\mathbf{8 7 d}$. 
Drasar and co-workers ${ }^{40}$ have synthesized in 2013 new types of ribbon type steroidal dimers derived from three types of steroidal skeletons (cholic acid, etienic acid, estrone) using the Cul-catalyzed 1,3-dipolar cycloaddition reaction. (Schemes 27,28 ) Steroid parts of the molecular "ribbons" are linked by heterocyclic moiety, namely by 2,6-bis[(1H-1,2,3-triazol-1-yl)methyl]pyridine.

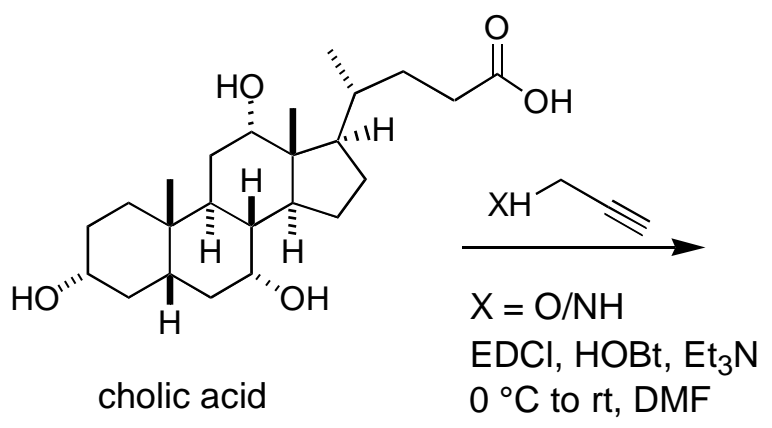

cholic acid

$$
0{ }^{\circ} \mathrm{C} \text { to rt, DMF }
$$

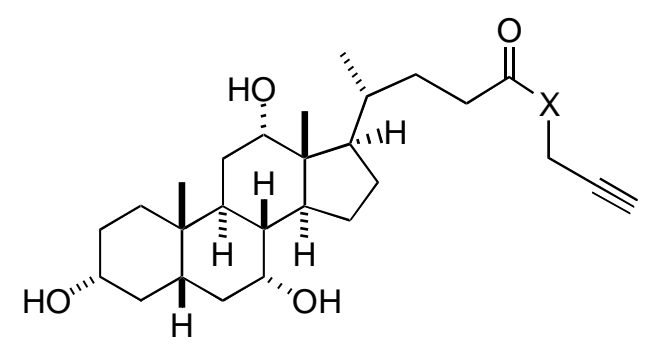

88a $X=0 ; 92 \%$

88b $\quad X=\mathrm{NH} ; 82 \%$

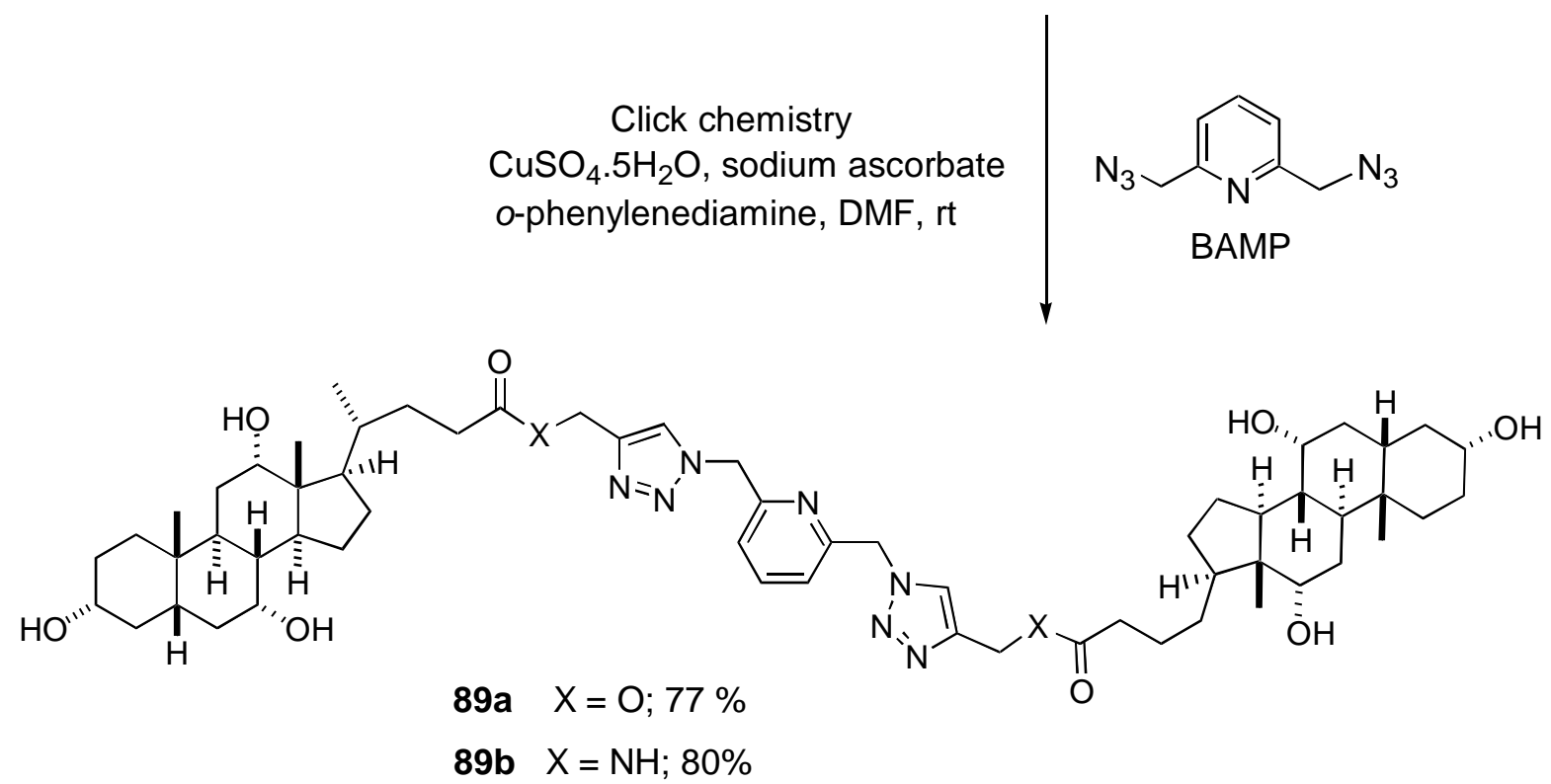

Scheme 25. Typical synthetic procedure demonstrated with cholic acid.

Propargyl ester and propargyl amide of cholic acid $\mathbf{8 8 a}$ and $\mathbf{8 8} \mathbf{b}^{\mathbf{4 1}}$ (Scheme 25 ) were prepared using ethyl$\left(N, N^{\prime}\right.$-dimethylamino)propylcarbodiimide hydrochloride (EDCl) and 1-hydroxybenzotriazole (HOBt). Rewarding nucleophilic acyl substitution reactions of etienic acid (compounds $\mathbf{8 8} \mathrm{c}$ and $\mathbf{8 8 d}$ ) were carried out using $N, N^{\prime}$ dicyclohexylcarbodiimide (DCC) and catalytic amount of 4-( $N, N^{\prime}$-dimethylamino)pyridine (DMAP). 3-OPropargylestrone ${ }^{42} \mathbf{8 8 e}$ was prepared using an excess of propargyl chloride in presence of potassium bicarbonate. 2,6-Bis(azidomethyl)pyridine ${ }^{43}$ was prepared from 2,6-bis(bromomethyl)pyridine according to known procedure. The Huisgen copper-catalyzed 1,3-dipolar cycloaddition reaction (CuAAC) between terminal alkynes and azides is well known for its simplicity and high selectivity to 1,4-disubstituted 1,2,3-triazoles. They used classical click chemistry conditions using copper (II) sulfate pentahydrate/sodium ascorbate and $o^{-}$ phenylenediamine. ${ }^{44}$ This way they synthesized five different bis-steroidal compounds of ribbon type, bridged with pyridine in good yields (Schemes 25, 26). Compounds synthesized possess different cytotoxic and hormone receptor modulating activities. 
<smiles>CC12CC[C@@H](O)CC1=CC[C@H]1[C@@H]2CC[C@]2(C)[C@H]1CC[C@H]2C(=O)O</smiles><smiles>CC12CC[C@]3(C)c4ccc(O)cc4CC[C@H]3[C@H]1CCC2=O</smiles><smiles>C1CCCCC1</smiles><smiles>[X]C(=O)[C@H]1CC[C@H]2[C@@H]3CC=C4C[C@@H](O)CC[C@]4(C)[C@H]3CC[C@]12C</smiles>

88c $X=0 ; 73 \%$
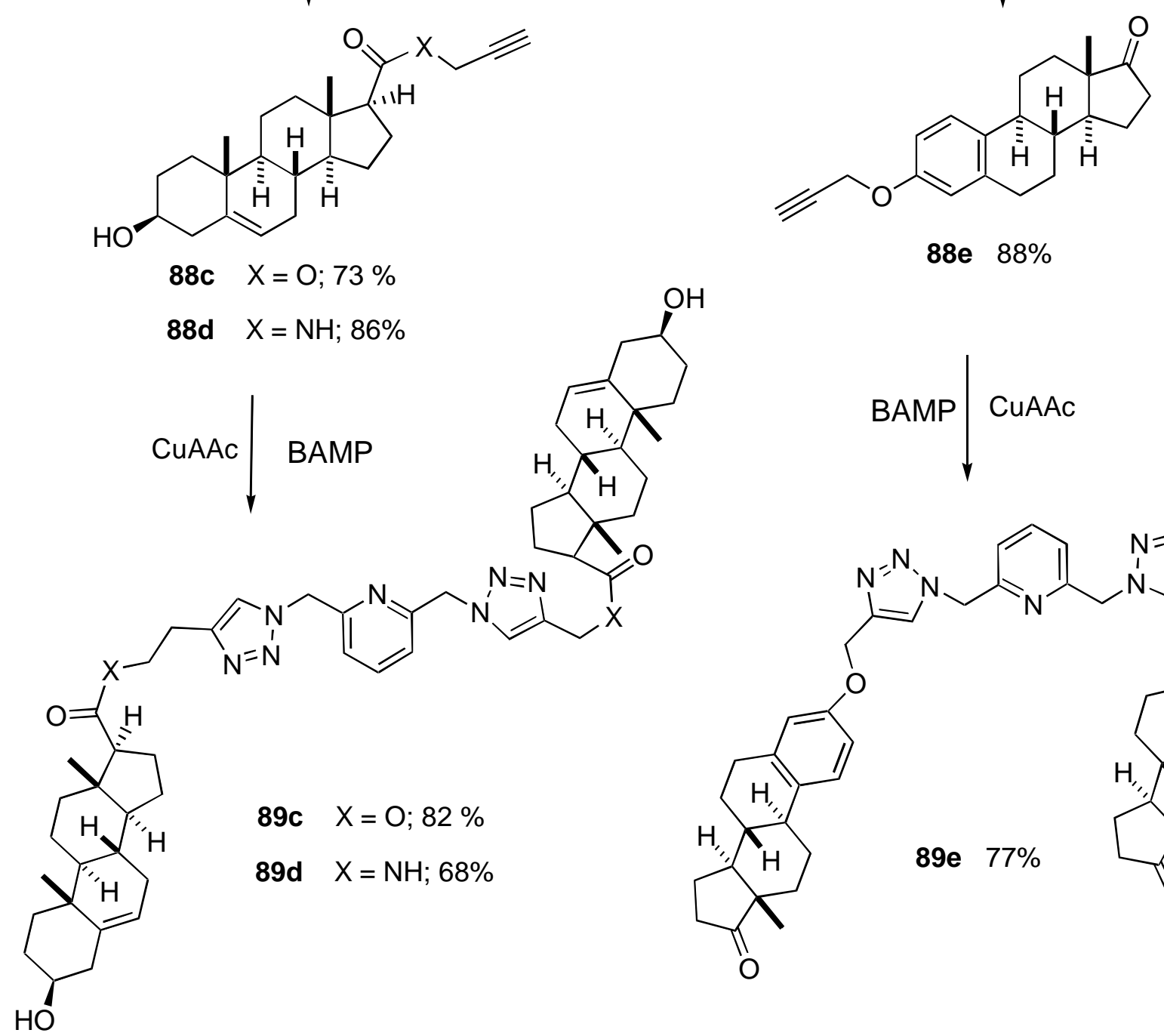

$$
\begin{array}{rl}
\mathbf{8 8 c} & X=0 ; 73 \% \\
\mathbf{8 8 d} & X=N H ; 86 \%
\end{array}
$$<smiles>CCC1C(C)CCC2=CC[C@H](O)CC21C</smiles>

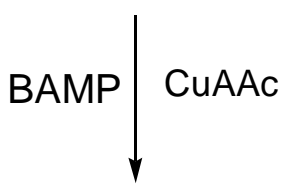

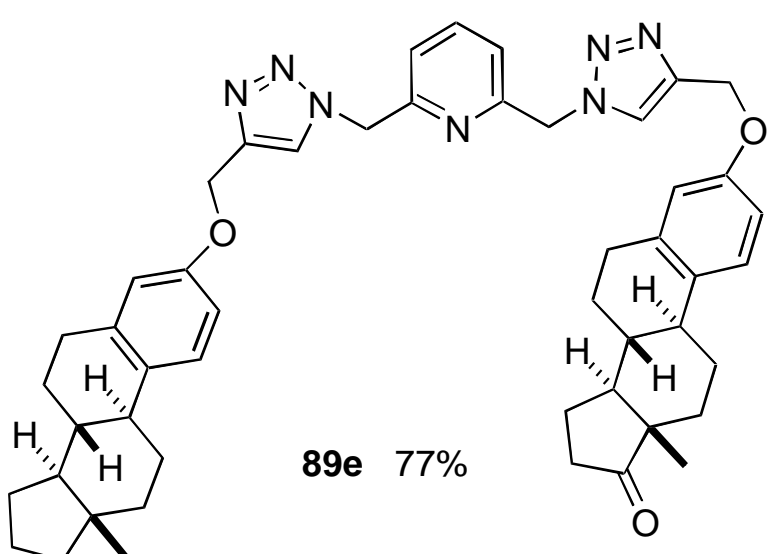

Reaction conditions : a, propargyl alcohol, propargylamine, $\mathrm{CH}_{2} \mathrm{Cl}_{2}-\mathrm{THF}$, DCC, DMAP, r.t. to $70{ }^{\circ} \mathrm{C}$; b, propargyl chloride, $\mathrm{K}_{2} \mathrm{CO}_{3}$, Toluene-DMF, $70{ }^{\circ} \mathrm{C}$, CuAAc: $\mathrm{CuSO}_{4} \cdot 5 \mathrm{H}_{2} \mathrm{O}$, sodium ascorbate, o-phenylenediamine, DMF, r.t.

Scheme 26. Etienic acid and estrone derivatives.

In 2014, the present authors developed a simple synthetic approach for the synthesis of a novel class of secosteroidal triazoles via intramolecular 1,3-dipolar cycloaddition. ${ }^{45}$ Two syntheses have been envisaged (Schemes 27 and 28) and in the two cases, cholic acid, a commercial bile acid, both inexpensive and readily 
available, was chosen as starting material. These syntheses of 7,8- and 12,13-secosteroidal macrocycles have been accomplished in eleven and nine steps respectively.

In the case of 12,13-secosteroidal macrocycles matching a cis A/B ring junction and a 1,2,3-triazole ring, the key reactions leading to these new secosteroids are depicted in Scheme 29. First, simple esterification of cholic acid led to propargyl cholate $90,{ }^{46}$ which was methylated affording propargyl $3 \alpha, 7 \alpha$-dimethoxycholate 91 in a yield of $86 \%$. Simultaneous protection of the secondary hydroxyl groups at C-3 and C-7 was needed prior to the reductive opening of the lactone ring. In the following step, they reduced the ester function of the lateral chain of 91. Thus, reduction according to the Pettit and Piatak procedure, ${ }^{47}$ afforded the expected ether derivative 92 in a satisfactory yield (56\%).

Microwave (MW) ${ }^{48}$ irradiation of $\mathbf{9 2}$ with pyridinium chlorochromate furnished ketone 93 very quickly and in $68 \%$ yield. Baeyer-Villiger oxidation of ketocholane $\mathbf{9 3}$ led to lactone 94 as the single regioisomer, as a result of a higher migration aptitude of the quaternary C-13 compared to the secondary C-11. Next, the reduction of the lactone moiety on ring $\mathrm{C}$ of $\mathbf{9 4}$ (LAH) afforded the diprotected tetrahydroxysecocholane $\mathbf{9 5}$ in $85 \%$ yield. Next, the azide moiety required for the intramolecular 1,3-dipolar cycloaddition was introduced. Two steps were necessary: chloro derivative $\mathbf{9 6}$ was easily obtained from ester $\mathbf{9 5}$ in high yield. This latter was transformed into the corresponding azide $\mathbf{9 7}$ via a substitution reaction carried out in DMF in the presence of $\mathrm{NaN}_{3}$.

The 'click reaction' of $\mathbf{9 7}$ was accomplished in the presence of $\mathrm{CuSO}_{4} .5 \mathrm{H}_{2} \mathrm{O}$ and sodium ascorbate, in a $t \mathrm{BuOH} / \mathrm{H}_{2} \mathrm{O}$ mixture. The desired macrocycle $\mathbf{9 8}$ was isolated as the sole product in a fair yield (18\%). The activities of $\mathrm{CuSO}_{4}+\mathrm{Na}$ ascorbate and Cul+base catalyst systems commonly used for similar reactions, were compared. The application of the $\mathrm{Cu}(\mathrm{l})$ precursor was found to be less efficient. The cycloaddition was found to be efficient in a solvent system of $\mathrm{DMF} / \mathrm{H}_{2} \mathrm{O}$ to produce the macrocycle 98 in $66 \%$ yield. The progress of the reaction was found to be slow and took $12 \mathrm{~h}$ to reach completion. Otherwise, the new triazole is formed in a completely regioselective manner.

Then, to obtain ether-linked macrocycle $\mathbf{9 9}$ (Scheme 27), the ester function of 98 was reduced, and the expected macrocycle derivative $\mathbf{9 9}$ was isolated in a satisfactory yield (44\%). Finally, removal of methoxy groups of macrocycle $\mathbf{9 9}$ was carried out with trimethylsilyl iodide ${ }^{49}$ to afford the desired compound $\mathbf{1 0 0}$ in $90 \%$ yield. 


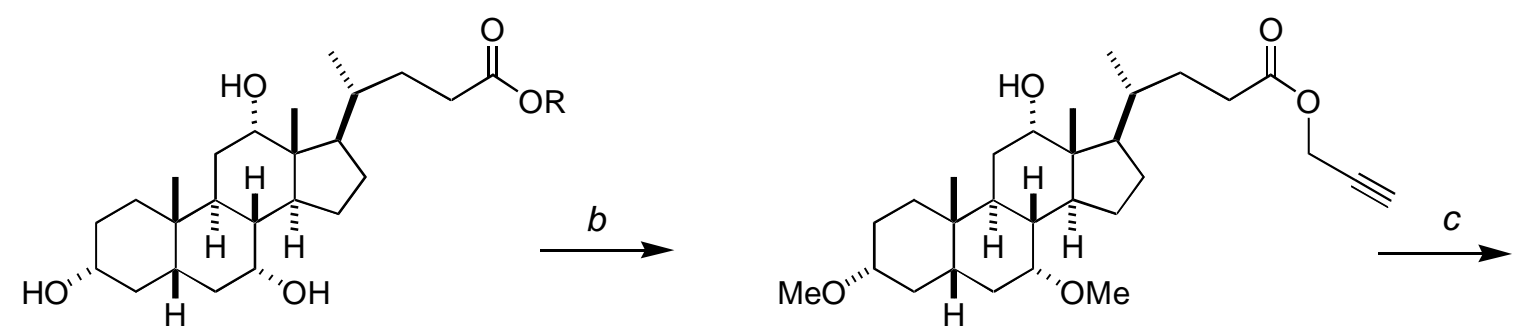

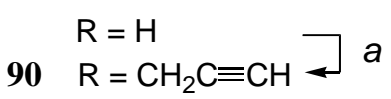

91

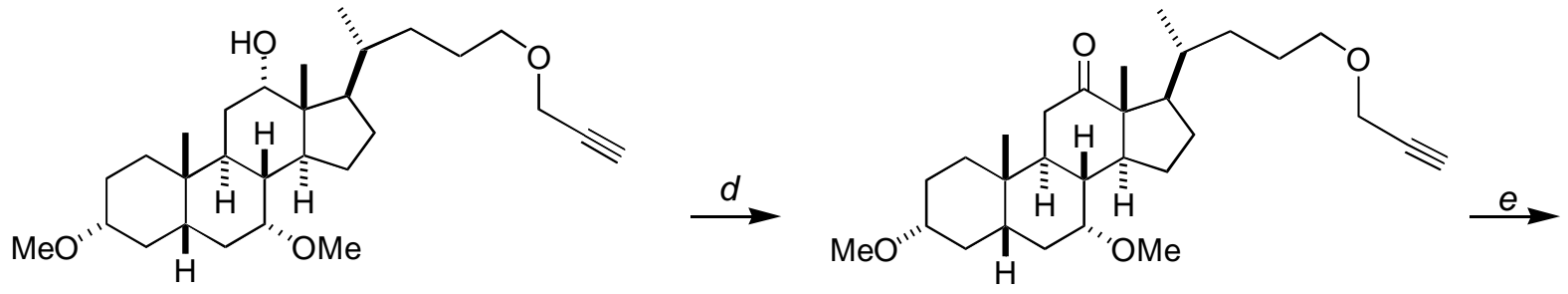

92

93

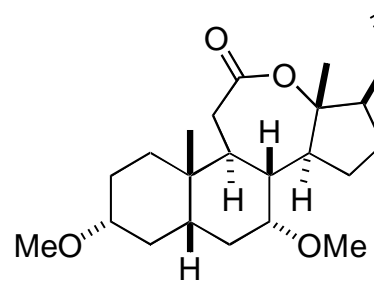

94

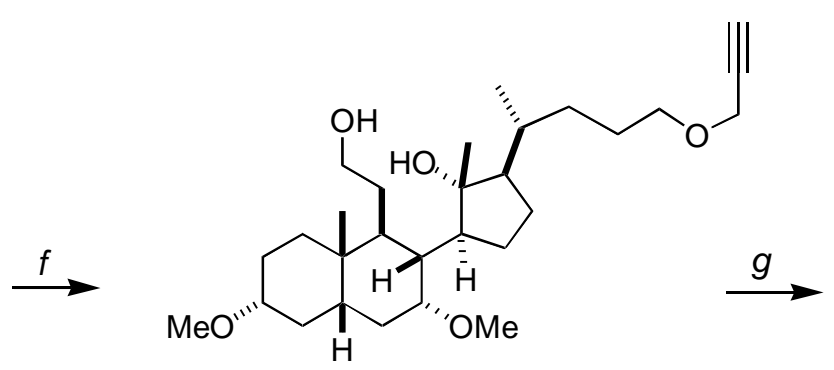

95

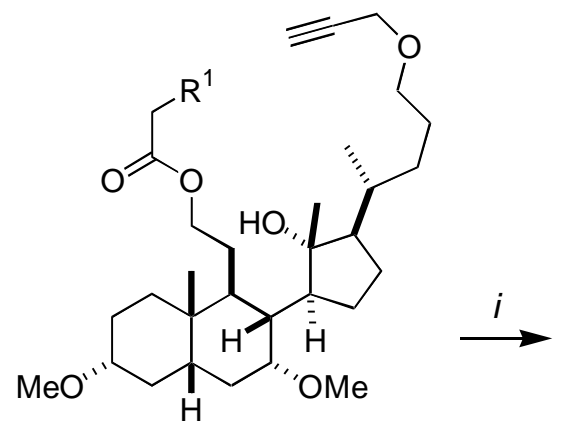

$96 \mathrm{R}^{1}=\mathrm{Cl}$
$97 \mathrm{R}^{1}=\mathrm{N}_{3}$$\longrightarrow h$

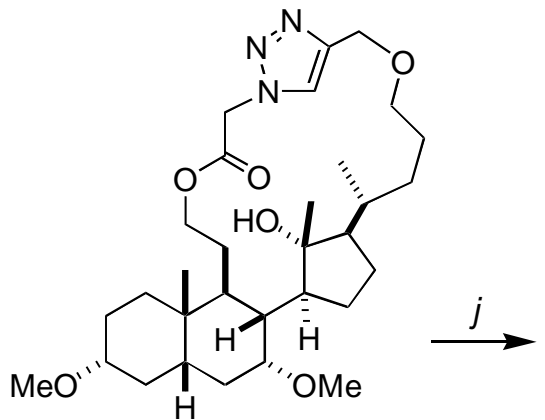

98

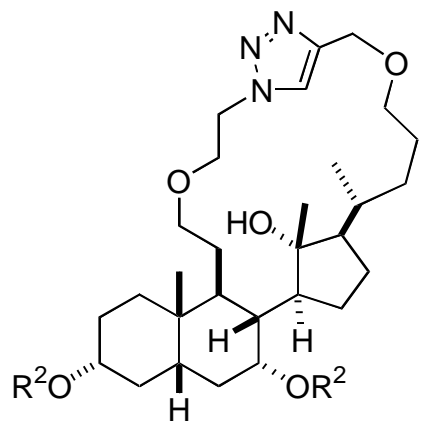

$\begin{array}{ll}99 & R^{2}=M e \\ 100 & R^{2}=H\end{array}$

Reaction conditions : a, propargyl bromide, $\mathrm{CH}_{2} \mathrm{Cl}_{2}$, DCC, DMAP, r.t., $12 \mathrm{~h}, 75 \% ; b, \mathrm{CH}_{3} \mathrm{I}$, $\mathrm{NaH}$, THF, r.t., $86 \% ; c, \mathrm{NaBH}_{4}, \mathrm{BF}_{3} . \mathrm{Et}_{2} \mathrm{O}$, THF-diglyme, $0^{\circ} \mathrm{C}, 4 \mathrm{~h}, 56 \% ; d, \mathrm{PCC}, \mathrm{MW}, 5 \mathrm{~min}, 68 \% ; e, m$-CPBA, PTSA, $\mathrm{CH}_{2} \mathrm{Cl}_{2}$, r.t., 24 h, $96 \% ; f$, $\mathrm{LiAlH}_{4}$, THF, $0{ }^{\circ} \mathrm{C}$ to r.t., $12 \mathrm{~h}, 85 \% ; g, \mathrm{ClCH}_{2} \mathrm{COCl}, \mathrm{CaH}_{2}, \mathrm{BnEt}_{3} \mathrm{~N}^{+} \mathrm{Cl}^{-}$, toluene, $\Delta$, $3 \mathrm{~h}, 70 \% ; h, \mathrm{NaN}_{3}$, DMF, $60{ }^{\circ} \mathrm{C}, 24 \mathrm{~h}, 62 \% ; i, \mathrm{CuSO}_{4} .5 \mathrm{H}_{2} \mathrm{O}$, sodium ascorbate, DMF/H $\mathrm{H}_{2} \mathrm{O}$, r.t., $12 \mathrm{~h}, 66 \%$ j, $\mathrm{NaBH}_{4}, \mathrm{BF}_{3} . \mathrm{Et}_{2} \mathrm{O}$, THF-diglyme, $0{ }^{\circ} \mathrm{C}, 4$ h, $44 \% ; k$, ISi $\left(\mathrm{CH}_{3}\right)_{3}, \mathrm{CHCl}_{3}$, r.t., 24 h, $90 \%$.

Scheme 27. Ring-C-secosteroidal macrocycle $\mathbf{1 0 0}$ derived from cholic acid in eleven-step sequence. 

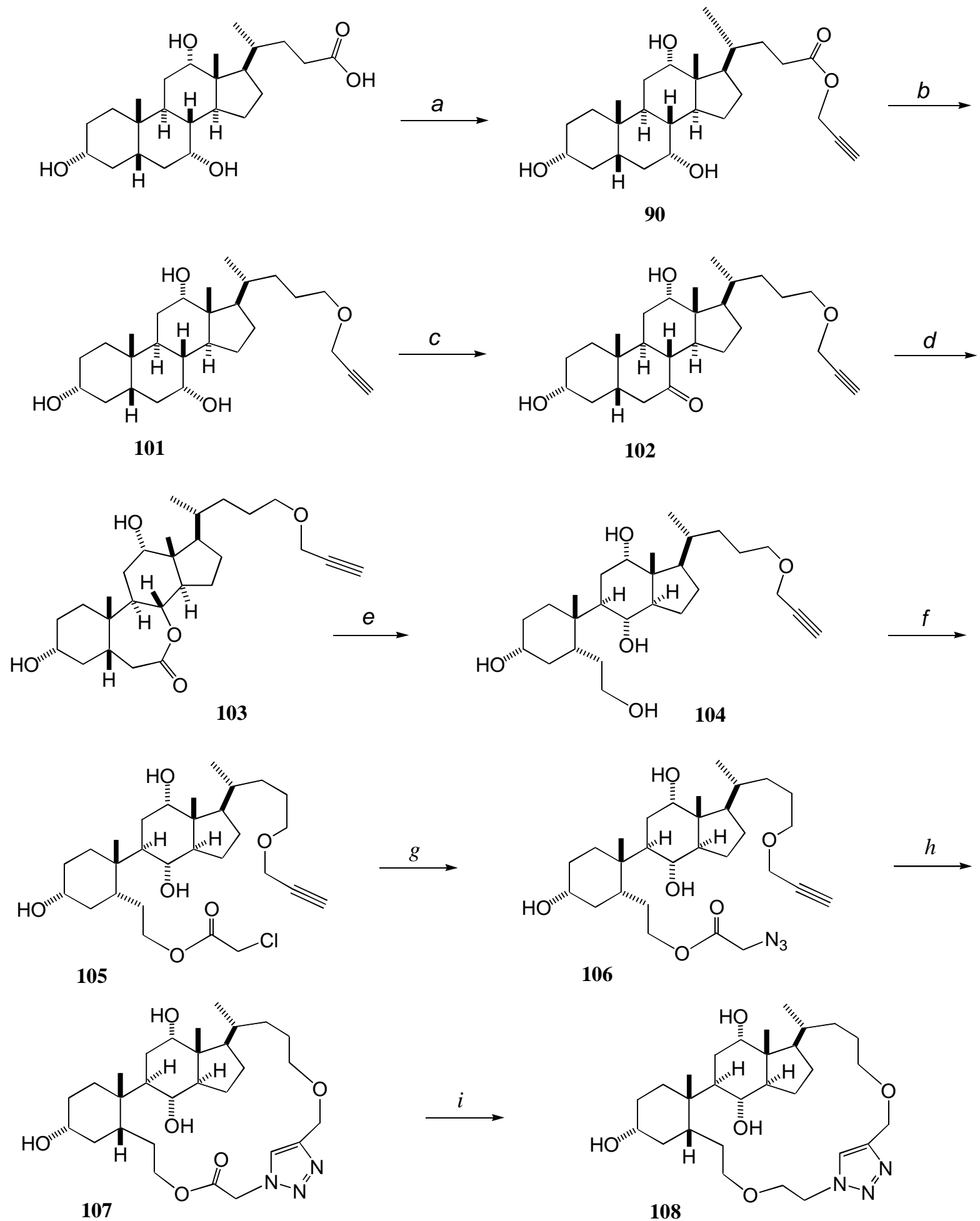

Reagents and conditions: $a$, propargyl bromide, $\mathrm{CH}_{2} \mathrm{Cl}_{2}$, DCC, DMAP, r.t., $12 \mathrm{~h}, 75 \% ; b, \mathrm{NaBH}_{4}$, $\mathrm{BF}_{3}$. Et ${ }_{2} \mathrm{O}$, THF-diglyme, $0{ }^{\circ} \mathrm{C}, 6 \mathrm{~h}, 48 \%$; $\mathrm{c}, \mathrm{NBS}, \mathrm{H}_{2} \mathrm{O}, \mathrm{NaHCO}_{3}, 12 \mathrm{~h}$ at rt then $2 \mathrm{~h}$ at $80-85{ }^{\circ} \mathrm{C}, 95 \%$; d, $m$-CPBA, PTSA, $\mathrm{CH}_{2} \mathrm{Cl}_{2}$, rt, $12 \mathrm{~h}, 76 \%$; e, $\mathrm{LiAlH}_{4}, \mathrm{Et}_{2} \mathrm{O}, 0{ }^{\circ} \mathrm{C}$ at rt, $12 \mathrm{~h}, 78 \% ; f, \mathrm{ClCH}_{2} \mathrm{COCl}$, $\mathrm{CaH}_{2}, \mathrm{BnEt}_{3} \mathrm{~N}^{+} \mathrm{Cl}^{-}$, toluene, D, $3 \mathrm{~h}, 72 \% ; g$, $\mathrm{NaN}_{3}$, DMF, r.t., 12 h, $68 \% ; h, \mathrm{CuSO}_{4} \cdot 5 \mathrm{H}_{2} \mathrm{O}$, sodium ascorbate, $\mathrm{DMF} / \mathrm{H}_{2} \mathrm{O}, 60^{\circ} \mathrm{C}, 24 \mathrm{~h}, 62 \% ; i, \mathrm{NaBH}_{4}, \mathrm{THF}_{-}$diglyme, $\mathrm{BF}_{3} . \mathrm{Et}_{2} \mathrm{O}, 0{ }^{\circ} \mathrm{C}$ at $\mathrm{rt}, 12 \mathrm{~h}, 52 \%$

Scheme 28. Synthesis of ring-B-secosteroidal macrocycle $\mathbf{1 0 8}$ from cholic acid in a nine-step sequence. 
The same strategy based on an intramolecular 'click reaction' was used to prepare 7,8-secosteroidal macrocycles. As shown in Scheme 28, cholic acid was also the starting material, which was converted into propargyl cholate $\mathbf{9 0}$ in good yield. This latter was then reduced leading to the derivative 101 in satisfactory yield. The regioselective oxidation of the hydroxyl group at C-7 of 101 was performed with NBS. ${ }^{50}$ The resulting 7-keto derivative 102 was subjected to the Baeyer-Villiger oxidation. As expected, this reaction furnished exclusively regioisomer 103 , as a result of the favoured migration of the tertiary C-8 compared to the secondary $\mathrm{C}-6$. In the next step, the reductive opening of the lactone ring was done with lithium aluminium hydride and led to the secocholane 104 in a 72\% yield (over two steps). The chlorine in alkyne 104 was subsequently replaced by an azide group by treatment with sodium azide in DMF. Freshly obtained compound 105 was used as a substrate in the 'click reaction'.

It is worth pointing out similar results with the work described above for the synthesis of $12,13-$ secosteroidal macrocycles. Indeed, the use of $\mathrm{Cu}$ (I) precursor was not very efficient; on the other hand the system $\mathrm{CuSO}_{4}+\mathrm{Na}$ ascorbate used in $\mathrm{DMF} / \mathrm{H}_{2} \mathrm{O}$ as solvent at room temperature led to the cyclisation of 106 in a good yield. Here, too, the influence of the temperature on the reaction appeared to be much less important.

Finally, in order to obtain the ether-linked macrocycle 108, the ester function of 107 was then reduced and the ether derivative 108 was isolated in a satisfactory yield (48\%).

In 2014, Tiwari and co-workers ${ }^{51}$ have prepared a number of deoxy-azido sugars by nucleophilic substitution from O-ptoluenesulfonyl glycofurano/pyranoses using sodium azide in anhydrous DMF under inert condition. The deoxy-azido sugars were further subjected to CuAAC click reaction with ethisterone, a naturally occurring steroid alkyne to afford numerous ethisterone glycoconjugates in excellent yields. The reaction time has been significantly reduced (15 $\mathrm{min}$ ) under microwave heating. This methodology is efficient to synthesize novel steroidal triazolyl glycoconjugates with potential application in biological studies.

The synthetic strategy starts from cheap and readily available monosaccharides (D-glucose, D-galactose, D-ribose, D-xylose, and D-lactose), which, after processing in a number of high-yielding steps for protection and modification, afforded suitably protected sugars 109a-j. The compounds 109a-j were further converted into their respective tosyl/bromo-derivatives, which on reaction with sodium azide in dry DMF at $80^{\circ} \mathrm{C}$ under anhydrous conditions resulted in the formation of respective deoxy-azido sugars 110a-j in good yields. Thus, the treatment of 3-O-benzyl-1,2-O-isopropylidene- $\alpha$-D-xylofuranose 109a with $p$-toluenesulfonyl chloride in the presence of anhydrous pyridine at room temperature for $12 \mathrm{~h}$ afforded benzyl-1,2-O-isopropylidene-5- $\mathrm{O}$ tosyl- $\alpha$-D-xylofuranose, which on further treatment with sodium azide in anhydrous DMF at $80{ }^{\circ} \mathrm{C}$ led to the formation of 5-azido-3-O-benzyl-5-deoxy-1,2-O-isopropylidene- $\alpha$-D-xylofuranose 110a in 90\% yield.

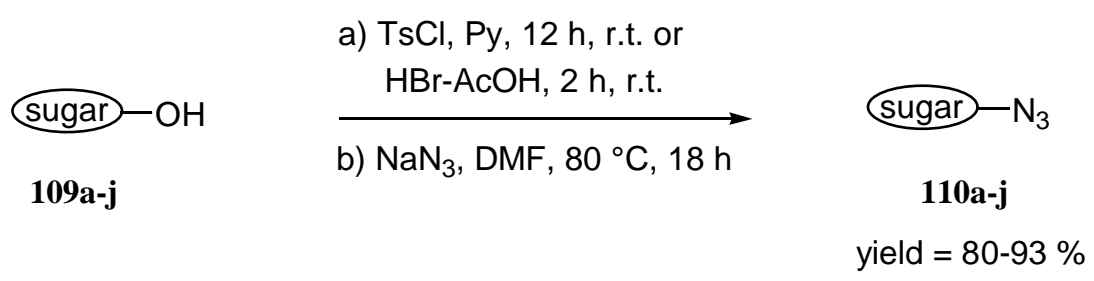

Scheme 29. Synthesis of deoxy-azido sugars 110a-j from protected sugars 109a-j.

Once the synthesis of azido-sugars 110a-j was achieved, they turned their attention towards the CuAAC click reaction of developed compounds 110a-j with ethisterone 111. Generally, such a reaction requires the generation of $\mathrm{Cu}(\mathrm{I})$ species in situ starting from $\mathrm{Cul}$ and DIPEA in dichloromethane or $\mathrm{CuSO}_{4} .5 \mathrm{H}_{2} \mathrm{O}$ and sodium ascorbate in aqueous medium or other copper catalyst. They primarily investigated the reactions using 
mixtures of $\mathrm{MeOH} / \mathrm{H}_{2} \mathrm{O}, t-\mathrm{BuOH} / \mathrm{H}_{2} \mathrm{O}, \mathrm{CH}_{2} \mathrm{Cl}_{2} / \mathrm{H}_{2} \mathrm{O}, \mathrm{Et} \mathrm{t}_{2} \mathrm{O} / \mathrm{H}_{2} \mathrm{O}$, acetone $/ \mathrm{H}_{2} \mathrm{O}$, and $\mathrm{THF} / \mathrm{H}_{2} \mathrm{O}$. Most of the reactions afforded corresponding ethisterone triazolyl glycoconjugate 112a using a variety of organic solvents in combination with $\mathrm{H}_{2} \mathrm{O}$. However, optimal yield of 112a was achieved using a mixture of $T H F / \mathrm{H}_{2} \mathrm{O}(1: 1)$ as a solvent. A remarkable feature of this reaction was the $\mathrm{H}_{2} \mathrm{O}$ dependence in the triazolyl glycoconjugate synthesis. Reactions using a mixture of $\mathrm{THF} / \mathrm{H}_{2} \mathrm{O}$ (1:0.5) or just THF resulted in poor yields of the desired product 112a. This may be due to the decreased solubility of sodium ascorbate and copper salt in this solvent. Earlier, several reports have established dichloromethane as a solvent of choice for CuAAC click transformations, hence the click reaction of deoxy-azido sugar 110a $(0.3 \mathrm{mmol})$ with $111(0.3 \mathrm{mmol})$ in presence of Cul (5 mol\%) and DIPEA (10 mol\%) is carried out in anhydrous DCM under argon atmosphere at rt. Reaction gave regioselectively the desired 1,4 triazole i.e. 1-(3-O-benzyl-5-deoxy-1,2-O-isopropylidene- $\alpha$-D-xylofuranos5 -yl)-4-ethisterone-1,2,3-triazole 112a in $90 \%$ yield. The regioisomeric nature of the compound 112a was established based on its spectroscopic data.
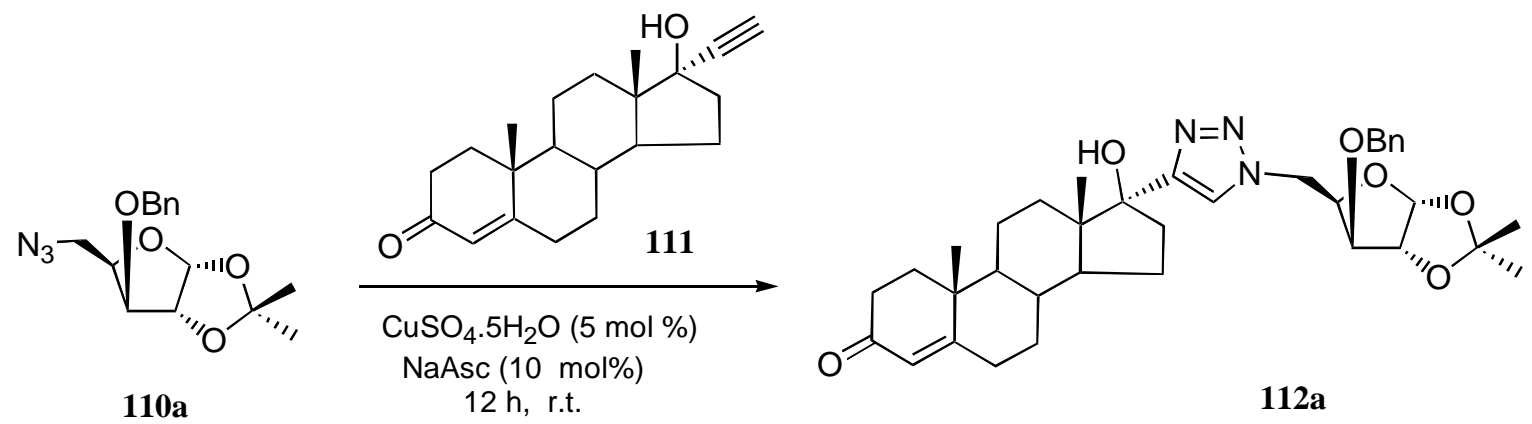

110a 12 h, r.t.

112a

Scheme 30. Synthesis of glycoconjugate 112a via Cu-catalyzed click chemistry.

Having established the reaction conditions for the regioselective cycloaddition of the terminal alkyne $\mathbf{1 1 1}$ and the xylofuranosyl azide 110a, they further explored the scope of other sugar azides in such cycloaddition and developed a library of ethisterone glycoconjugates like 112a in efficient yields. Furthermore, they investigated the reaction under microwave (MW) conditions, where significant reduction in reaction time (15 $\mathrm{min}$ ) was observed for comparative reaction yield at room temperature (10-12 h).

The same authors ${ }^{52}$ reported in 2014 the synthesis of a number of triazole containing glycosyl azidoalcohols by multicomponent click reaction of glycosyl alkynes with epichlorohydrin and $\mathrm{NaN}_{3}$ in the presence of $\mathrm{CuSO}_{4} .5 \mathrm{H}_{2} \mathrm{O} / \mathrm{NaAsc}$. These azido-alcohols were further subjected to Cu-catalyzed click reaction with ethisterone, a naturally occurring steroid alkyne to afford rare bis-triazolyl ethisterone glycoconjugates for potential application in androgen receptor (AR) pharmacology and chemical biology.

Their synthetic strategy began with cheap and readily available carbohydrates (D-glucose, D-galactose, Dmannose, D-ribose, and D-xylose), which after processing through a number of high-yielding protection, and modification steps afforded sugar based terminal alkynes $113 .^{52}$ They disclosed their results on the click reaction of $\mathbf{1 1 4}$ with the steroid alkyne ethisterone (ethynyltestosterone) $\mathbf{1 1 5}$ to afford bis-triazolyl ethisterone glycoconjugates $\mathbf{1 1 6}$ regioselectively in good yields (Scheme 31).

The targeted compounds $\mathbf{1 1 6 a}$ were also synthesized successfully by another pathway outlined in Scheme 34, where ethisterone linked triazolyl azido-alcohol 114j was synthesized from 115 under one-pot method using CuAAC reaction. However, the synthesis of precursor compound $\mathbf{1 1 4 j}$ via this route took longer reaction time (15 h) giving products in low yields after consuming excess of compound 115. A subsequent click reaction 
of $114 \mathbf{j}$ with compound $113 \mathrm{a}$ in the presence of Cul and DIPEA using DCM as a reaction medium furnished compound 116a in good yields.

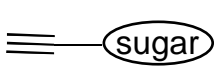

113

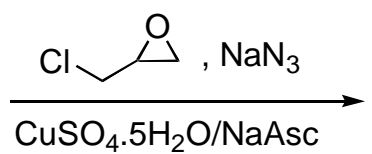

$\mathrm{H}_{2} \mathrm{O}, 12 \mathrm{~h}$

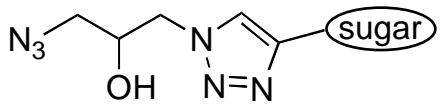

114

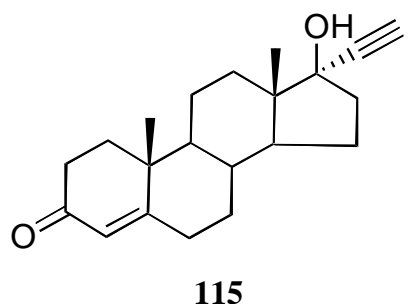

114

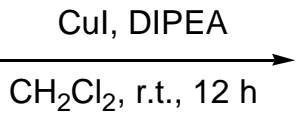<smiles>CCc1cn(CC(O)Cn2cc([C@]3(O)CCC4C5CCC6=CC(=O)CC[C@@]6(C)C5CC[C@@]43C)nn2)nn1</smiles>

116

Scheme 31. Synthesis of bis-triazolyl ethisterone glycoconjugates 116 from triazolyl azido-alcohols 114.<smiles>C#C[C@]1(O)CCC2C3CCC4=CC(=O)CC[C@]4(C)C3CC[C@]21C</smiles>

115

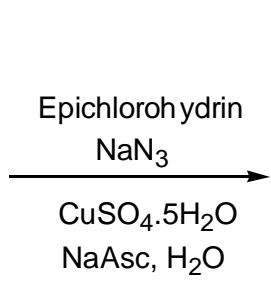<smiles>CC1CCC2OC(C)(C)OC12</smiles><smiles>C[C@H]1COC(C)(C)O1</smiles>

$116 a(82 \%)$<smiles>CCCCCOCC(C)CC(C)C</smiles>

Scheme 32. Synthesis of bis-triazolyl ethisterone glycoconjugates 116a via ethisterone azido-alcohol 114j.

In 2014, Maitra et al. ${ }^{53}$ reported the synthesis and aggregation behaviour of new water-soluble, bile acid derived tripodal architectures based on a core derived from triphenylphosphine oxide.

The synthesis of the target molecules 134-137 is outlined in Schemes 33 and 34. It starts from the methyl esters of deoxycholic and cholic acids, which in turn were obtained through acid-catalysed esterification of the

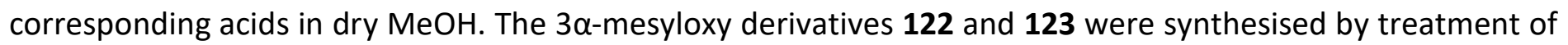
the methyl esters with mesyl chloride in the presence of triethylamine in dichloromethane. Nucleophilic substitution of compounds 122 and 123 with $\mathrm{NaN}_{3}$ in DMF then resulted in the $3 \beta$-azidoderivatives 124 and 125, respectively, in good yields. On the other hand, $3 \alpha$-azido derivatives 120 and 121 were obtained from the 
corresponding esters of cholic/deoxycholic acid by means of the Mitsunobu reaction, followed by substitution of the mesylates with $\mathrm{NaN}_{3}$ by a previously described procedure ${ }^{54}$ with some minor experimental changes as shown in Scheme 33. All the azido bile ester derivatives 120, 121, 124 and 125 were hydrolysed to the corresponding azido acid derivatives 126, 127, 128 and 129, respectively (Scheme 36) by heating in 5\% $\mathrm{KOH}$ (aq)/dioxane mixtures. These derivatives were coupled to the central phosphine oxide core under click conditions with $\mathrm{CuSO}_{4}$ and sodium ascorbate in $\mathrm{DMF}$ at $60{ }^{\circ} \mathrm{C}$ to afford the trimeric molecular architectures 130-133 in good yields. The sodium salts of the trimer-taurine conjugates 134-137 were synthesised from the corresponding acid derivatives by coupling with taurine in the presence of EEDQ ${ }^{55}$ ( $\mathrm{N}$-ethoxycarbonyl-2ethoxy-1,2-dihydroquinoline) in DMF at $90^{\circ} \mathrm{C}$, followed by treatment with Dowex- $\mathrm{Na}$ in methanol.
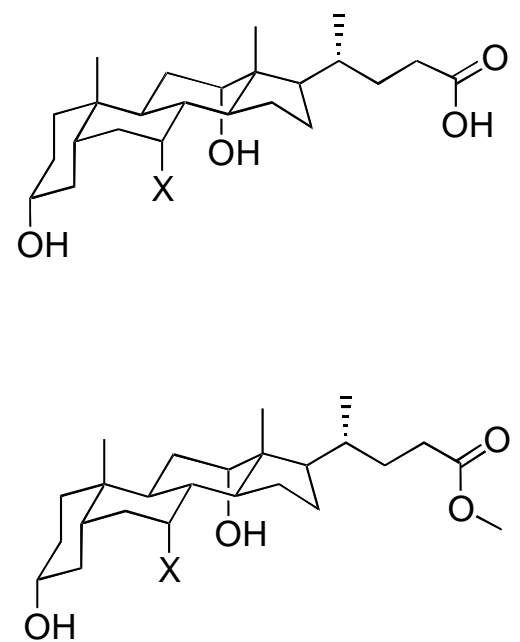

$\mathrm{MsCl}, \mathrm{NEt}_{3}$ DCM, $0{ }^{\circ} \mathrm{C}$

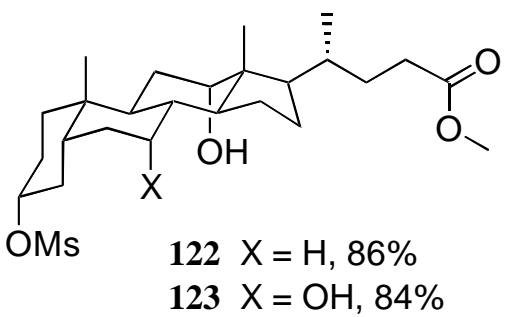
$123 \mathrm{X}=\mathrm{OH}, 84 \%$

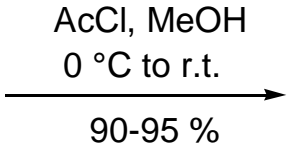

1. $\mathrm{DIAD}, \mathrm{MsOH}$, $\mathrm{PPh}_{3}, \mathrm{DMAP}$ THF, $40^{\circ} \mathrm{C}$

2. $\mathrm{NaN}_{3}$, DMF $80^{\circ} \mathrm{C}$

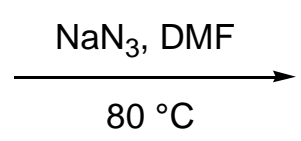
$80^{\circ} \mathrm{C}$
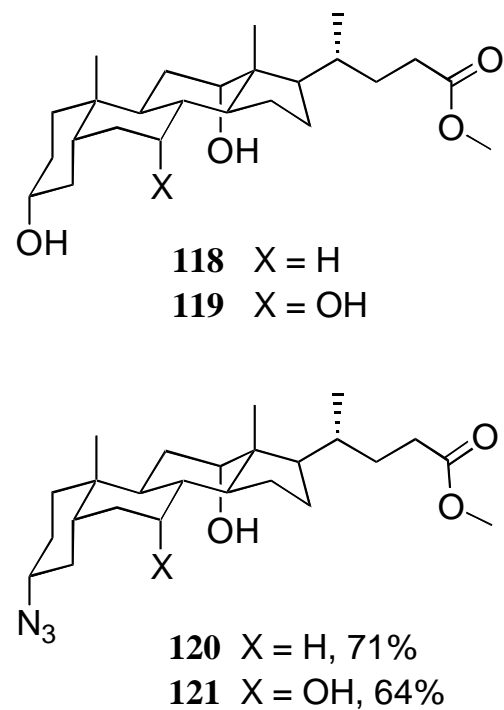

$121 X=O H, 64 \%$

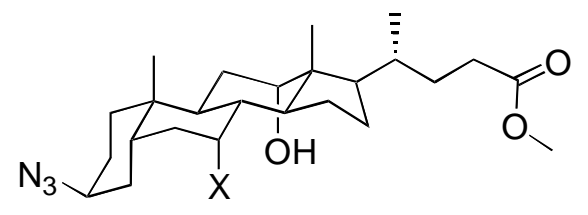

$124 \mathrm{X}=\mathrm{H}, 86 \%$ $125 \mathrm{X}=\mathrm{OH}, 79 \%$

Scheme 33. Synthesis of 3-azido derivatives of bile acid methyl esters.

The aggregation of these molecules was studied by dye-solubilisation experiments, and all the systems exhibited aggregation at micromolar concentrations. These results were further supported by NMR experiments, which showed aggregation at micromolar concentrations for these molecules at room temperature and improved resolution in the NMR spectra on heating. These aggregates were characterised by DLS and AFM methods. Only the $\alpha$ derivatives, both of deoxycholic and cholic acid derivatives, were found to be capable of gelation, which emphasises the importance of stereochemistry for defining the mode of aggregation. This is the first instance in which stereochemistry has been demonstrated to have an influence on bile acid derived supramolecular architectures. 

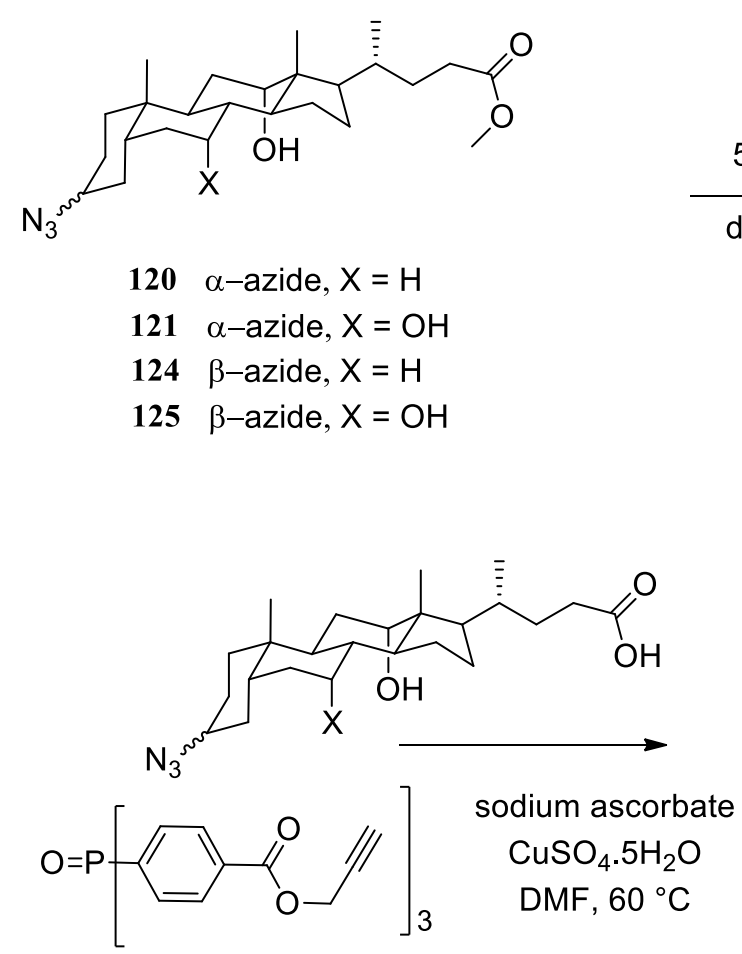

$5 \% \mathrm{KOH}(\mathrm{aq})$ dioxane, $80{ }^{\circ} \mathrm{C}$

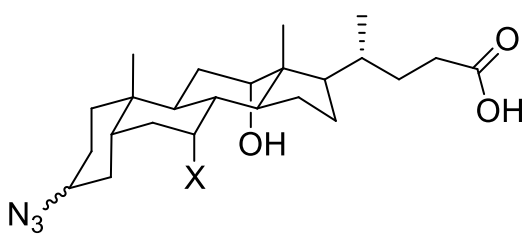

$126 \alpha, \mathrm{X}=\mathrm{H}(89 \%)$

$127 \alpha, \mathrm{X}=\mathrm{OH}(93 \%)$

$128 \beta, X=H(83 \%)$

$129 \beta, X=\mathrm{OH}(88 \%)$

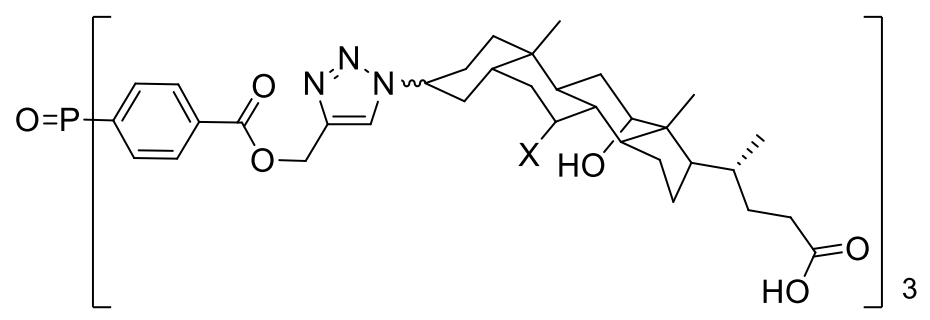

$$
\begin{aligned}
& 130 \alpha, \mathrm{X}=\mathrm{H}(82 \%) \quad 132 \quad \beta, \mathrm{X}=\mathrm{H}(84 \%) \\
& 131 \alpha, X=\mathrm{OH}(79 \%) \quad 133 \quad \beta, \mathrm{X}=\mathrm{OH}(82 \%)
\end{aligned}
$$

1. EEDQ, taurine, $\mathrm{NEt}_{3}$ DMF, $90{ }^{\circ} \mathrm{C}$

2. Dowex $-\mathrm{Na}^{+}, \mathrm{MeOH}$

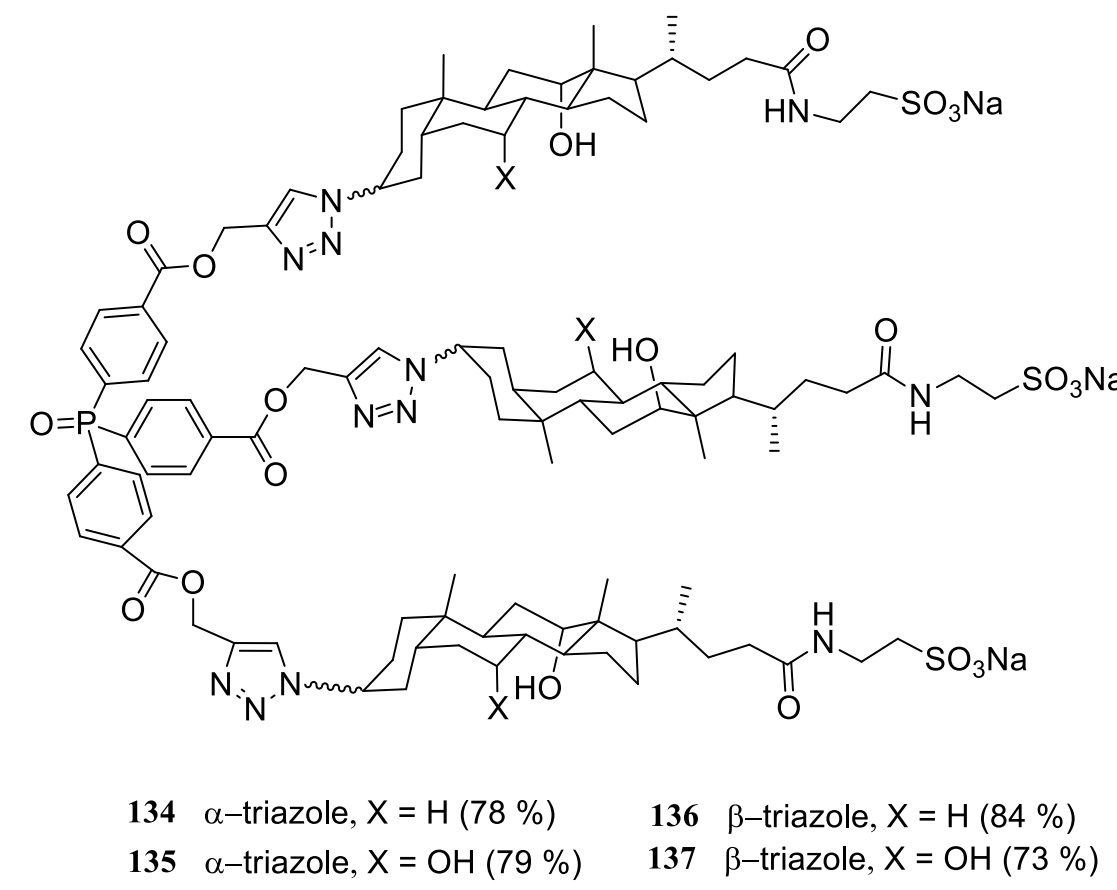

Scheme 34. Synthesis of trimer-taurine conjugates.

In 2014, Lukashev et al. ${ }^{56}$ prepared new types of 1,2,3-triazolyl steroids by the CuAAC reaction. A reaction of epoxide 138 with sodium azide in a $\mathrm{MeCN}-\mathrm{H}_{2} \mathrm{O}(1: 1)$ mixture for $16 \mathrm{~h}$ at $100{ }^{\circ} \mathrm{C}$ followed by hydrolysis of the enol ether group afforded azidosteroid 139 in high yield (Scheme 35). The reaction of azidosteroid 139 with a number of terminal alkynes was performed successfully using a standard catalytic system for CuAAC comprising copper(II) sulfate and sodium ascorbate (NaAsc) in a mixture of THF and water. All reactions of 
substrate 139 proceeded under mild conditions affording 1,4-substituted 1,2,3-triazoles 140 bearing both aliphatic and aromatic fragments in high yield. Hydroxy and amino groups were tolerated by the reaction conditions.

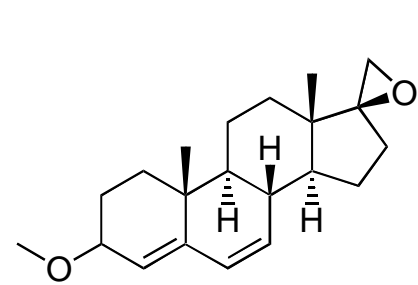

138

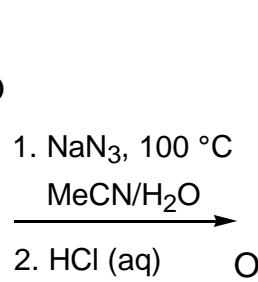

$\mathrm{EtOH}, \Delta$

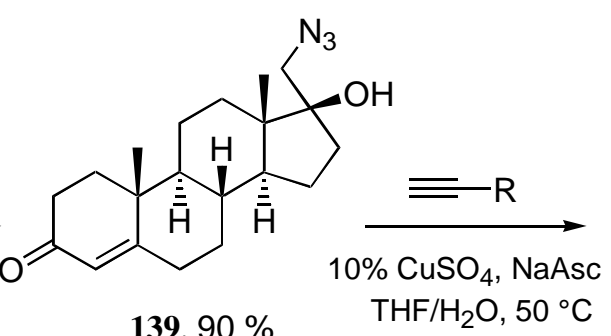

139, $90 \%$

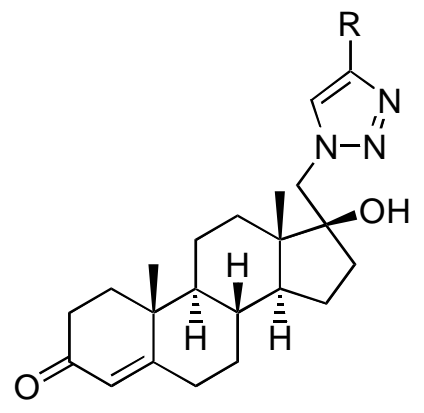

140, $70-96 \%$

Scheme 35. Synthesis of $17 \alpha$-(triazolylmethyl)steroids 140.

The standard catalytic system based on $\mathrm{CuSO}_{4} \cdot 5 \mathrm{H}_{2} \mathrm{O}$ and NaAsc also allowed synthesis of 1,2,3-triazoles attached to the $21-\mathrm{C}$ position of the steroidal backbone (Scheme 36). The corresponding 21-derivatives of $17 \alpha-$ hydroxyprogesterone 143 were isolated in excellent yields. Thus, both substrates 139 and 142 bearing the azide moiety in the side chain reacted with terminal alkynes rather easily, and the steroid fragment did not exert a noticeable steric effect on their reactivity.

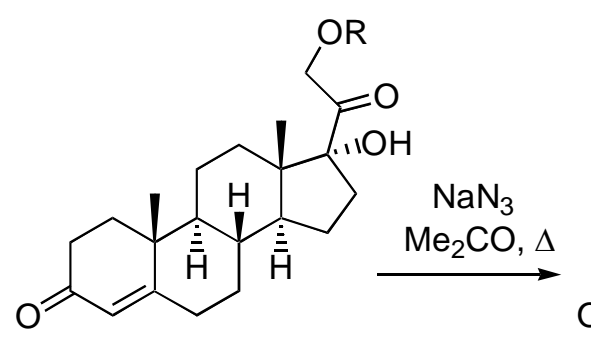

141, $R=H$
141a, $R=M s$

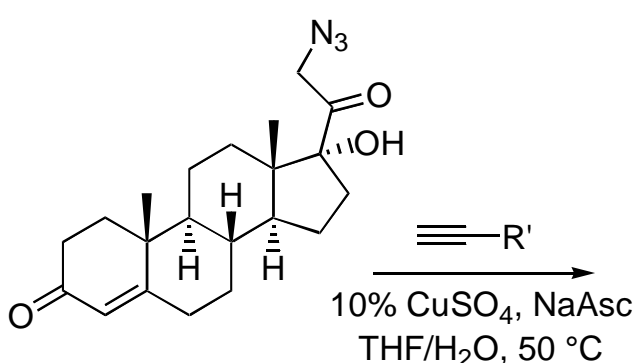

$142,72 \%$

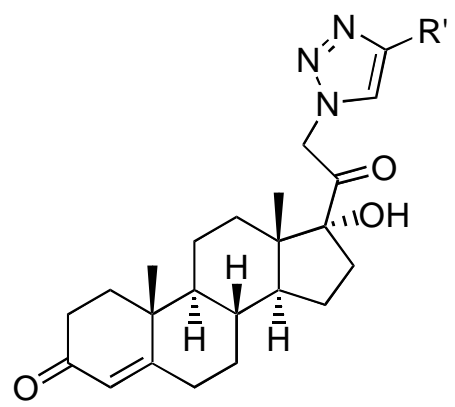

143a-g, $86-98 \%$

Scheme 36. Synthesis of 21-triazolylsteroids 143.

Since D-homo rearrangement is the expected metabolic degradation pathway of $17 \alpha$-hydroxy-20ketopregnanes 150 and D-homosteroids are known to exhibit valuable pharmacological properties ${ }^{57}$ both 146 and the corresponding D-homoandrostane 145 were studied in CuAAC. As was expected, the reaction of these more sterically hindered azidosteroids proceeded more slowly and proved sensitive to the composition of a catalytic system. The use of $\mathrm{CuSO}_{4} \cdot 5 \mathrm{H}_{2} \mathrm{O}$ and $\mathrm{NaAsc}$ in aqueous THF (method A) allowed them to obtain product 149c $(\mathrm{R}=\mathrm{Bu})$ via reaction of azidosteroid 145 with propargyl alcohol, but in the case of phenylacetylene conversion was only $48 \%$ after $14 \mathrm{~h}$. Since copper carboxylates are known to accelerate the CUAAC reaction, ${ }^{58}$ they applied presumably more active $\mathrm{Cu}(\mathrm{OAc})_{2} \cdot \mathrm{H}_{2} \mathrm{O}$ as a catalyst. Triethylamine was added to increase the solubility of the catalyst in $\mathrm{CH}_{2} \mathrm{Cl}_{2}$ and facilitate the formation of copper acetylide. This catalytic 
system (method B) appeared to be effective for both phenylacetylene and 1-hexyne. Reaction of azidosteroid 146 with phenylacetylene reached full conversion after $14 \mathrm{~h}$ when method $\mathrm{A}$ was used, while in the case of method $B$, the result was unexpected.

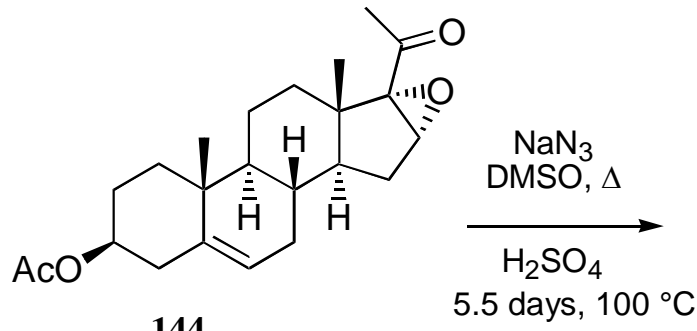

144

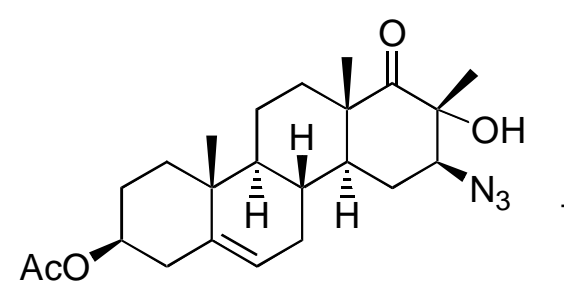

$145,46 \%$

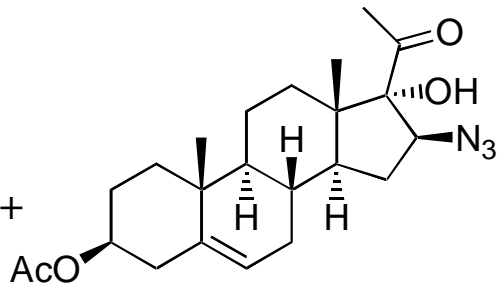

$146,25 \%$

Scheme 37. Synthesis of $16 \beta$-azidosteroids 145 and 146.<smiles>CC(=O)OC1CC[C@@]2(C)C(=CC[C@@H]3[C@H]4CC([N])[C@](C)(O)C(=O)[C@]4(C)CC[C@H]32)C1</smiles>

147

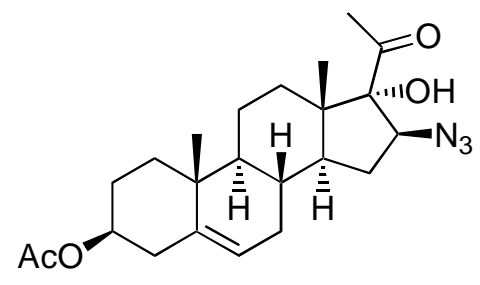

148
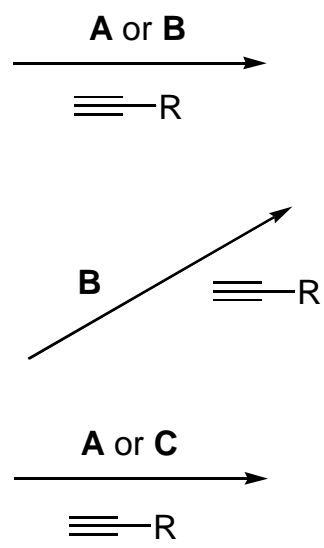

Method A: $\mathrm{CuSO}_{4} \cdot 5 \mathrm{H}_{2} \mathrm{O}(10 \%)$, NaAsc (40\%), $\mathrm{THF} / \mathrm{H}_{2} \mathrm{O}, 50{ }^{\circ} \mathrm{C}$.

Method B: $\mathrm{Cu}(\mathrm{OAc})_{2} \cdot 5 \mathrm{H}_{2} \mathrm{O}(5 \%), \mathrm{NaEt}_{3}(40 \%), \mathrm{CH}_{2} \mathrm{Cl}_{2}, 50{ }^{\circ} \mathrm{C}$.

Method C: $\mathrm{CuSO}_{4} .5 \mathrm{H}_{2} \mathrm{O}(10 \%)$, NaAsc (40\%), TBTA (10\%), THF/ $\mathrm{H}_{2} \mathrm{O}, 50{ }^{\circ} \mathrm{C}$.

Scheme 38. Synthesis of $16 \beta$-triazolylsteroids 149 and 150.

In 2014, Santillan and co-workers ${ }^{59}$ presented an efficient methodology to synthesized unimolecular micelles consisting of a hydrophobic interior (Fréchet type) functionalized with ethynylestradiol and hydrophilic exterior (PAMAM type). This type of dendrimers would make good candidates for carrying bioactive compounds in two scenarios: (i) encapsulation mediated by hydrophobic interactions, for example steroids ${ }^{60}$ and (ii) conjugation where drug molecules are covalently attached at the peripheral groups. ${ }^{61}$

Two steroidal cores were synthesized as hydrophobic part, taking in mind that with a larger core the encapsulating process will be more efficient. For the first core, 17 $\alpha$-ethynyl-estradiol 152 was directly coupled by ether linkage to 1,3,5-tri(bromomethyl)benzene 151 to give core 153 as a pale yellow solid in high yield (91\%). As the second core, a Fréchet type dendrimer was prepared by reaction of compound 151 with 
bis(hydroxymethyl)phenol 154 to give 1,3,5-tri-[3,5-bis(hydroxymethyl)phenoxy]benzene (dendrimer 155), followed by chlorination using thionyl chloride to achieve the coupling of $17 \alpha$-ethynylestradiol and obtain 157 as a pale yellow solid (Scheme 39). The cores 153 and 157 were completely insoluble in water, ethanol or methanol, but very soluble in chloroform or DMSO.
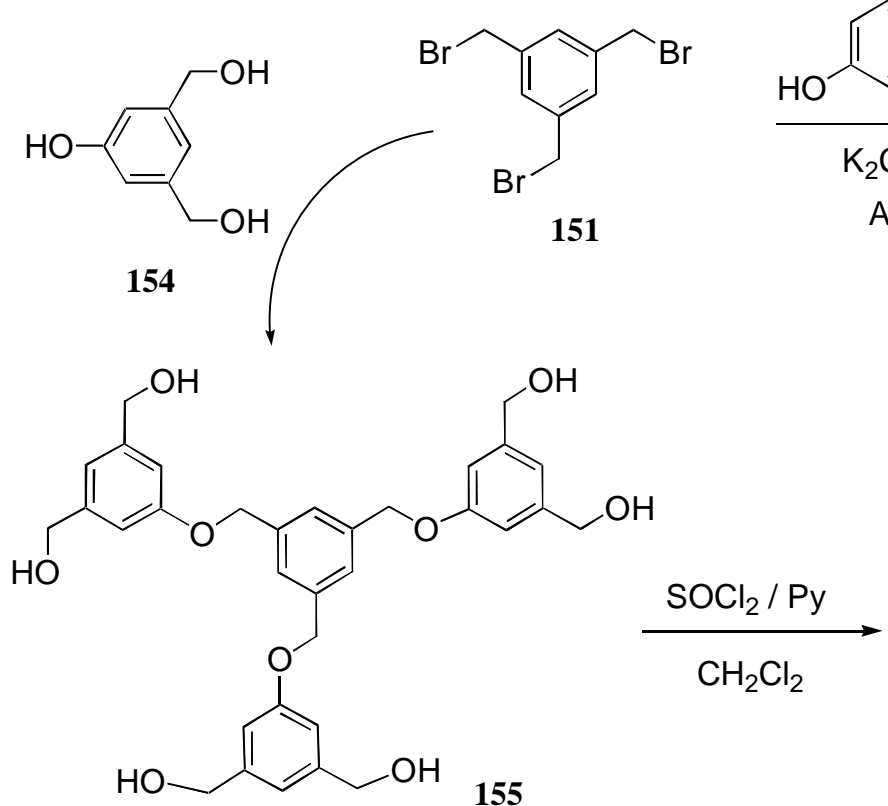

155

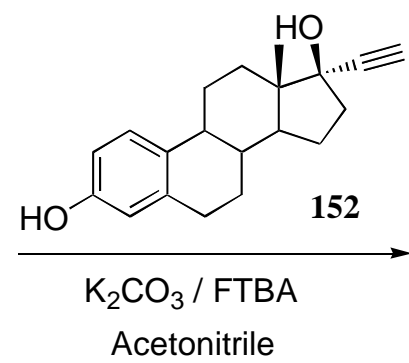

Acetonitrile<smiles>[R]Cc1cc(C[R])cc(C[R])c1</smiles>

153<smiles>ClCc1cc(CCl)cc(OCc2cc(COc3cc(CCl)cc(CCl)c3)cc(COc3cc(CCl)cc(CCl)c3)c2)c1</smiles>

156

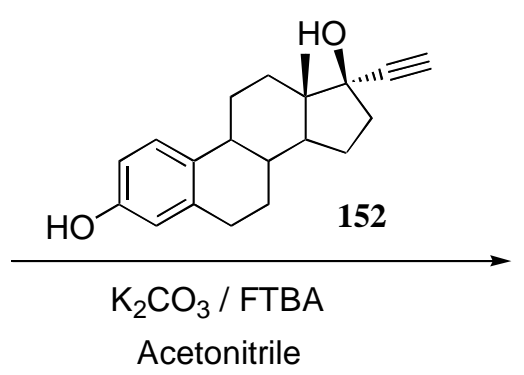<smiles>[R]Cc1cc(C[R])cc(OCc2cc(COc3cc(C[R])cc(C[R])c3)cc(COc3cc(C[R])cc(C[R])c3)c2)c1</smiles><smiles>[R]=C[C@]1(O)CC[C@H]2[C@@H]3CCc4cc(OC)ccc4[C@H]3CC[C@]21C#C</smiles>

Scheme 39. Synthesis of hydrophobic cores with $17 \alpha$-ethynylestradiol as end groups.

Along with the synthesis of the cores 153 and 157 and with the aim to synthesize the hydrophilic part, dendrons of half-generation were obtained by the Michael addition between 3-aminopropan-1-ol 158 and methyl acrylate 159, to give 161, as well as aminopropanol and tert-butyl acrylate 160 to obtain 162 under the conditions previously described. ${ }^{62}$ The reason to use these acrylates was firstly, to have the possibility to obtain higher generations by successive reactions with ethylenediamine and then with acrylate. Secondly, the tert-butyl ester terminal obtained opens the possibility to hydrolyze them and obtain carboxylic acids as noncytotoxic peripheral groups. ${ }^{63}$ Once dendrons 161 and 162 were synthesized, the focal point $-\mathrm{OH}$ was transformed into the iodide (compounds 164 and 165) with $I_{2}$ in the presence of imidazole and 
triphenylphosphine and subsequently into the corresponding azide derivatives $(166,167)$ with $\mathrm{NaN}_{3}$ in $\mathrm{DMF}$ at $70{ }^{\circ} \mathrm{C}$ (Scheme 40).

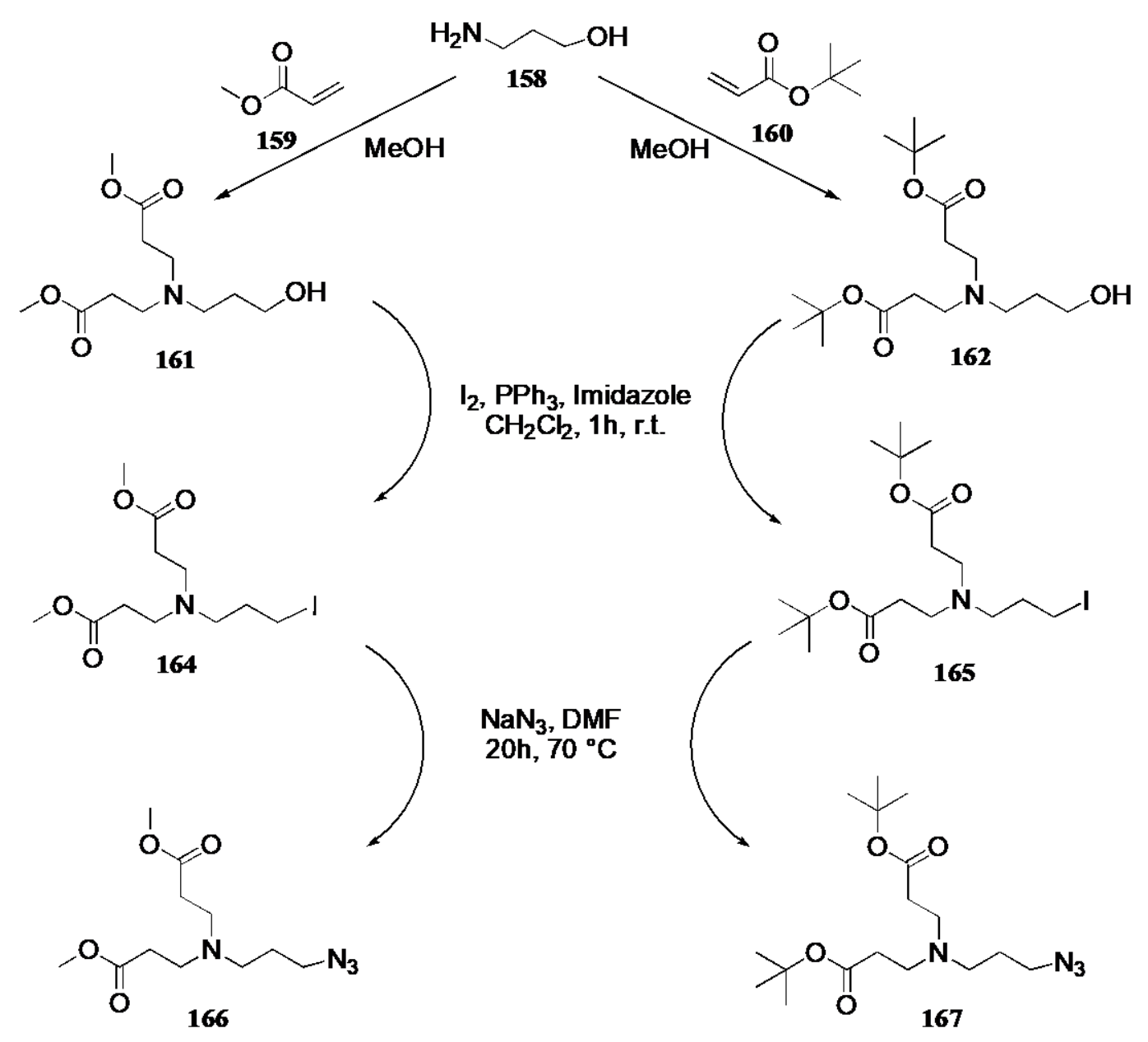

Scheme 40. Synthesis of dendrons with the azide group as focal point.

The subsequent cycloaddition reaction between the alkyne terminal on ethynylestradiol of hydrophobic cores 153 and 157 and the azide group of dendron 167 led to novel Fréchet-PAMAM dendrimers linked by steroids (Scheme 41). In order to obtain only a 1,4-disubstituted 1,2,3-triazole they used an adapted protocol established by Shao et al. ${ }^{64}$ where $\mathrm{CuSO}_{4} .5 \mathrm{H}_{2} \mathrm{O}$, sodium ascorbate, and $\mathrm{PhCO}_{2} \mathrm{H}$ were dissolved in a mixture of $\mathrm{t}-\mathrm{BuOH} / \mathrm{H}_{2} \mathrm{O}$, for core 153, and $\mathrm{EtOH} / \mathrm{H}_{2} \mathrm{O}$ for core 157, until the color associated with the copper reduction was observed. Then the alkyne (153 or 157) and the azide (167) derivatives were added and the reaction was allowed to proceed for 2 days to give the desired tri- and hexatriazoles in yields of $80 \%$ after a simple purification procedure which involves extraction with $\mathrm{CH}_{2} \mathrm{Cl}_{2} / \mathrm{NaHCO}_{3}$ solution, evaporation of the solvents under vacuum and washing with hexane to remove the unreacted azide. 

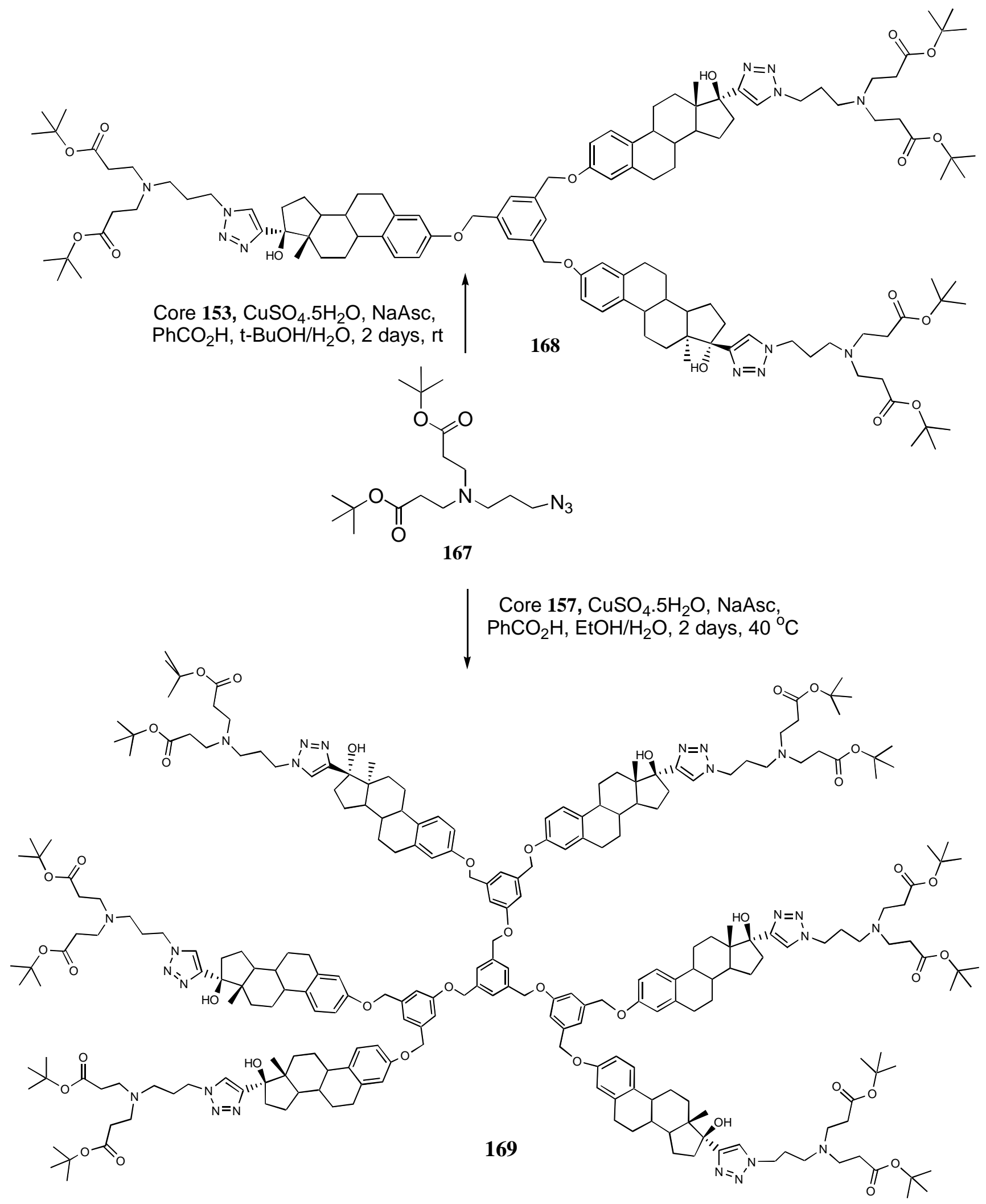

Scheme 41. Synthesis of hybrid Fréchet-PAMAM dendrimers linked via triazole units.

In order to show the possibility to grow the hydrophilic shell, a dendron of 1.5 generation was synthesized (Scheme 42). Thus compound $\mathbf{1 6 6}$ was reacted with ethylenediamine, thereafter with tert-butyl acrylate to 
give 170, as an amber oil. The cycloaddition between the core 153 and dendron 170 provided the corresponding tris-triazole 171 as a light green solid in $68 \%$ yield.

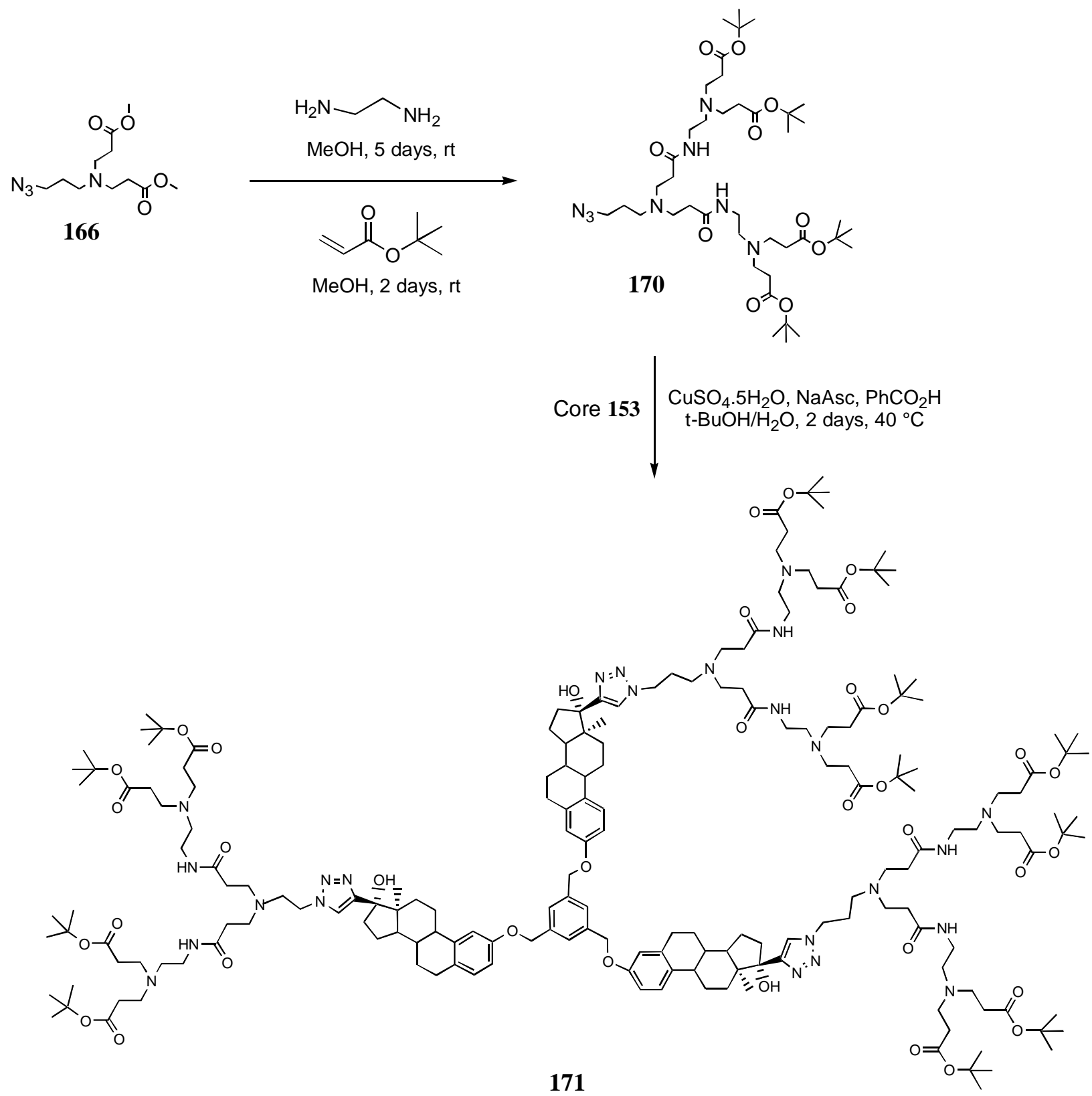

Scheme 42. Synthesis of hybrid dendrimer with Dendron of G15.

In 2015, Parizek et al. ${ }^{65}$ reported the synthesis of isomeric dimers of deoxycholic acid derivatives linked by 1,2,3-triazole. The azide 175 and alkynes 176 and 177 were required as substrates for the coupling reaction leading to the dimers. Thus, the alcohol 174 served as the substrate for the preparation of azide 175 and propiolic ester 177. In the first experiments, the direct reduction of ester $172^{6}$ with lithium aluminum hydride in tetrahydrofuran gave a mixture from which the desired alcohol 174 was obtained in only $43 \%$ yield. In an alternative approach to 24 -alcohol 174 , the $3 \alpha, 12 \alpha$-diacetoxy-5 $\beta$-cholan-24-oic acid $173^{67}$ upon treatment with chloroformate ethyl ester-triethylamine mixture was transformed to the mixed anhydride, which could be reduced with sodium borohydride to the alcohol 174 in $82 \%$ yield. The $3 \alpha, 12 \alpha$-diacetoxy-5 $\beta$-cholan- 24 -yl 
azide 175 was prepared from the 24-alcohol 174 in two steps (Scheme 45) according to literature procedure. ${ }^{68}$ The propargylic ester $\mathbf{1 7 6}$ was obtained by esterification of the acid $\mathbf{1 7 3}$ with propargyl alcohol in the presence of $\mathrm{N}, \mathrm{N}^{\prime}$-dicyclohexylcarbodiimide (DCC) as a condensing agent and 4-dimethylaminopyridine (DMAP) as the catalyst (Scheme 43). The yield of the pure ester 176 usually exceeded $80 \%$.

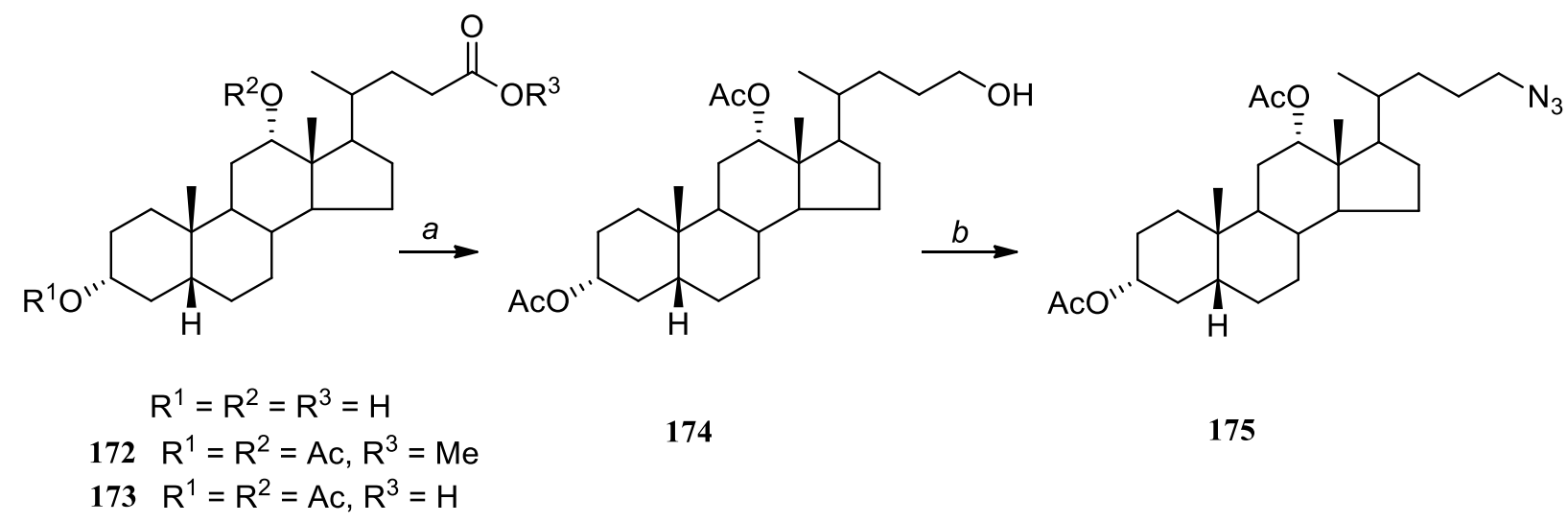

Reaction conditions : a, 1. $\mathrm{ClCO}_{2} \mathrm{Et}, \mathrm{NEt}_{3} / \mathrm{THF}$, r.t, 2. $\mathrm{NaBH}_{4}, \mathrm{H}_{2} \mathrm{O}$, r.t.

b, 1. $p-\mathrm{TsCl}, \mathrm{Py} / \mathrm{CH}_{2} \mathrm{Cl}_{2}$, r.t., 2. $\mathrm{NaN}_{3} / \mathrm{DMF}, 65^{\circ} \mathrm{C}$

Scheme 43. Synthesis of $3 \alpha, 12 \alpha$-diacetoxy-5 $\beta$-cholan-24-yl azide 175.

The $3 \alpha, 12 \alpha$-diacetoxy-5 $\beta$-cholan-24-yl propiolate 177 was obtained under similar esterification conditions from the alcohol 174 and the propiolic acid (Scheme 44).

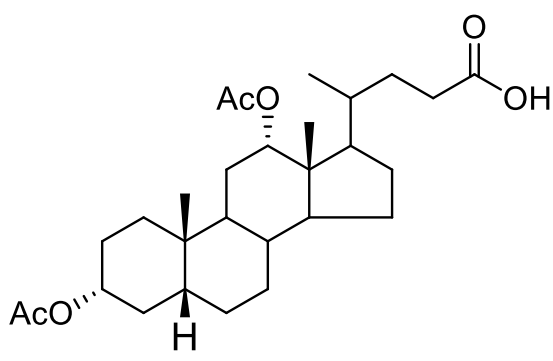

173<smiles>CC(=O)O[C@H]1CC2C(CC[C@H]3C[C@H](OC4CC4)CC[C@]23C)C2CCC(C(C)C)[C@@]21C</smiles>

174<smiles>C#CCOC(=O)CCC(C)C1CCC2C3CC[C@H]4C[C@@H](OC(C)=O)CC[C@]4(C)C3C[C@H](OC(C)=O)[C@@]12C</smiles>

176

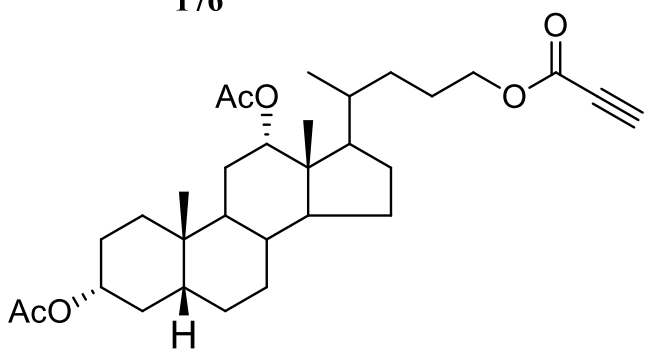

177

Reaction conditions : (a) propargyl alcohol, DMAP, DCC/CH${ }_{2} \mathrm{Cl}_{2}$, r.t.,

(b) propiolic acid, DMAP, DCC/ $\mathrm{CH}_{2} \mathrm{Cl}_{2}$, r.t..

Scheme 44. Synthesis of yne esters 176 and 177. 
1,3-Dipolar cycloaddition of terminal alkynes 176 and 177 with 24-azido-5 $\beta$-cholane derivative 175 was carried out in $t$-butanol-methanol-water in a presence of copper sulfate hydrate and sodium ascorbate under gentle reflux $\left(60-65^{\circ} \mathrm{C}\right.$ ) for 2.5 and $2 \mathrm{~h}$, respectively (Scheme 45). The dimeric compounds 178 and 179 were obtained in excellent yields of 94 and $84 \%$ respectively.

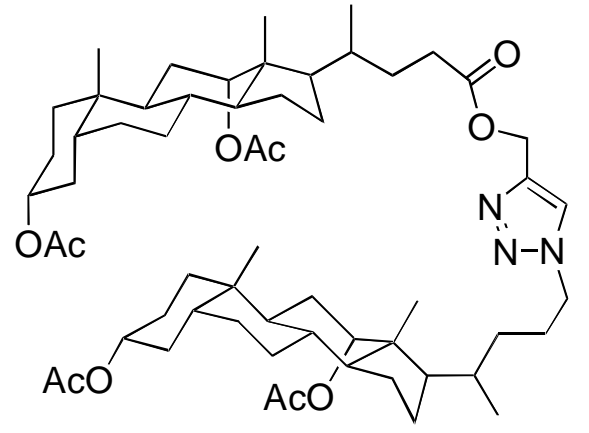

178

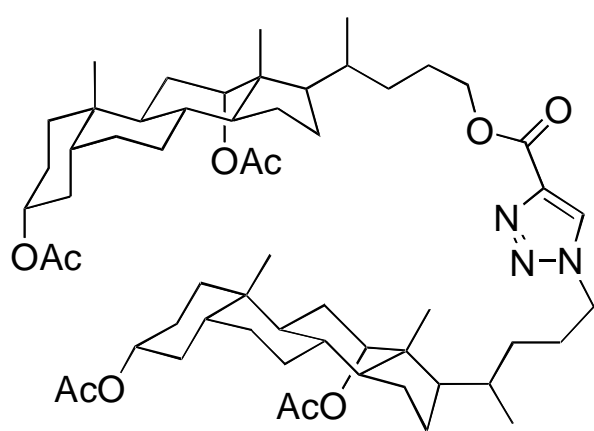

179

Reaction conditions : a, $\mathrm{CuSO}_{4} \cdot 5 \mathrm{H}_{2} \mathrm{O}$, sodium ascorbate $/ \mathrm{tBuOH} / \mathrm{MeOH} / \mathrm{H}_{2} \mathrm{O}, 65^{\circ} \mathrm{C}$

Scheme 45. 1,3-Dipolar cycloaddition of terminal alkynes 176 and 177 with 24-azido-5 $\beta$-cholane derivative 175 to produce triazole 178 and 179 respectively.

The copper-catalyzed azide-alkyne cycloaddition reaction was used in 2015 by Lukashev and co-workers ${ }^{69}$ for the preparation of a series of bis- and tris-3-and 24-5 $\beta$-cholanetriazolyl derivatives of phosphorus acids, which contained anion-binding triazolium sites and hydrophobic cholane residues.

Bile azides 181a-c and 182 were synthesized by using a standard route by nucleophilic substitution of the corresponding $\alpha$ - and $\beta$-mesylates with sodium azide in dimethyl sulfoxide (DMSO; Scheme 46 ). ${ }^{70}$ A previously reported synthesis of 24-azidocholane derivatives relied upon the rather unselective mesylation of 3,24cholanediols (75:25 ratio for mono/dimesylate). ${ }^{71}$ To avoid a tedious separation of mono- and dimesylates the 3-OH was protected with a trityl group. Subsequent reduction with $\mathrm{LiAlH}_{4}$, mesylation, nucleophilic substitution with $\mathrm{NaN}_{3}$, and removal of the protective group afforded azides 183a and 183b (Scheme 47).

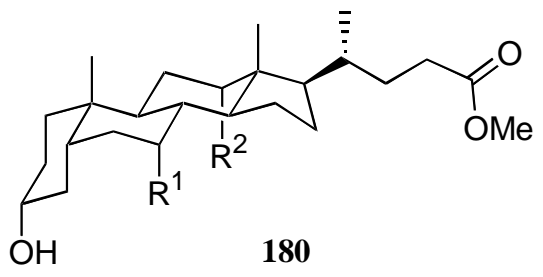

180
1. $\mathrm{MsCl}, \mathrm{NEt}_{3}$

$\mathrm{CH}_{2} \mathrm{Cl}_{2}, 0^{\circ} \mathrm{C}$

2. $\mathrm{NaN}_{3}, \mathrm{DMSO}$

$60^{\circ} \mathrm{C}, 48 \mathrm{~h}$

1. $\mathrm{MsOH}, \mathrm{PPh}_{3}$ DEAD, THF, $45^{\circ} \mathrm{C}$

2. $\mathrm{NaN}_{3}, \mathrm{DMSO}$ $60^{\circ} \mathrm{C}, 48 \mathrm{~h}$

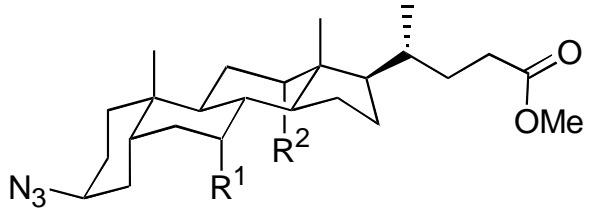

$181 \mathrm{a} \mathrm{R}^{1}=\mathrm{R}^{2}=\mathrm{H}$

181b $R^{1}=H, R^{2}=O H$

181c $R^{1}=R^{2}=O H$

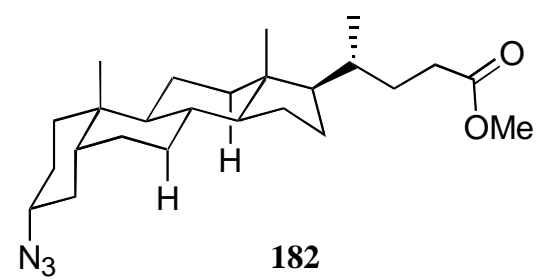

Scheme 46. Synthesis of $3 \alpha$ - and $3 \beta$-azidocholane derivatives. 


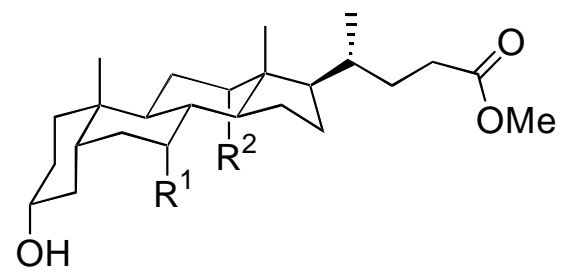

1. $\mathrm{TrCl}, \mathrm{NEt}_{3}, \mathrm{DCE}, \Delta, 24 \mathrm{~h}$

2. $\mathrm{LiAlH}_{4}, \mathrm{THF}, \Delta$

3. $\mathrm{MsCl}, \mathrm{NEt}_{3}, \mathrm{CH}_{2} \mathrm{Cl}_{2}, 0^{\circ} \mathrm{C}$

4. $\mathrm{NaN}_{3}, \mathrm{DMSO}, 60^{\circ} \mathrm{C}, 48 \mathrm{~h}$

5. $\mathrm{HCl} / \mathrm{EtOH} / \mathrm{H}_{2} \mathrm{O}, \Delta$

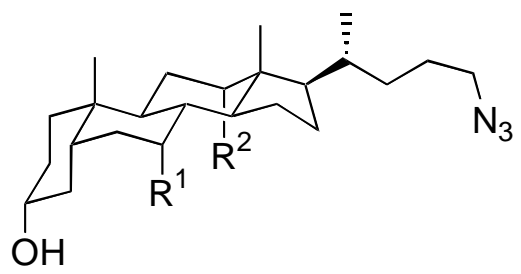

$$
\begin{array}{ll}
\text { 183a } & R^{1}=R^{2}=H \\
\text { 183c } & R^{1}=R^{2}=O H
\end{array}
$$

Scheme 47. Synthesis of 24-azidocholane derivatives 183.

"Extended 3 $\alpha$-" bile azide $\mathbf{1 8 4}$ that contains an azido group separated by a flexible acetate linker from the steroid core was prepared by a simple two-step procedure from methyl lithocholate ${ }^{72}$ (Scheme 48 ).
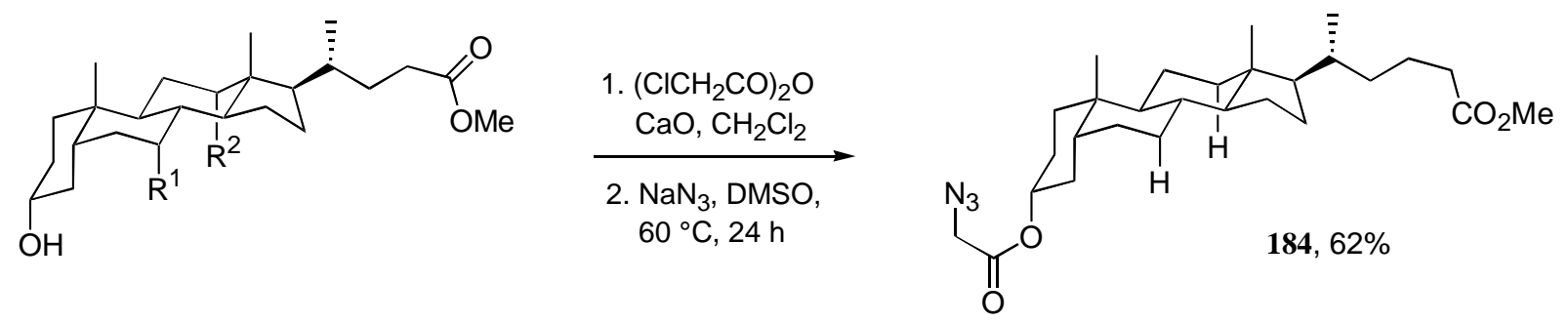

Scheme 48. Preparation of $3 \alpha$-azidoacetoxy derivative 184.

Propargyl esters 185a-c and propargyl amides 186a-c of various hydrophilicity were chosen as precursors for the core of their tripodal ligands. Preparation of esters $185 a-c$ was described previously in the literature. ${ }^{73}$ Amides 186a-c were obtained from the corresponding phosphoryl chlorides and propargylamine in the presence of triethylamine in $58-73 \%$ yields (Scheme 49 ).
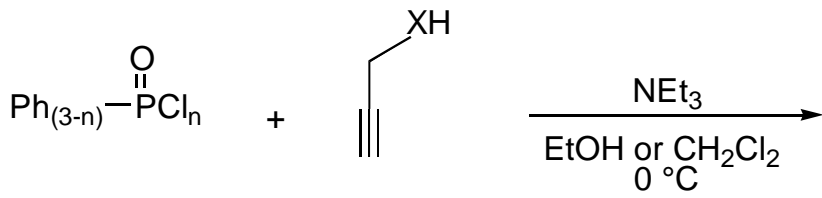

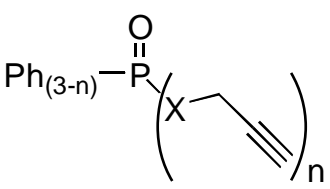

$185,186 a-c$

185a-c: $(X=0) ; a, n=1,68 \% ; \mathbf{b}, n=2,90 \% ; \mathbf{c}, n=3,34 \%$

186a-c: $(X=N H) ; \mathbf{a}, n=1,64 \% ; \mathbf{b}, n=2,73 \% ; \mathbf{c}, n=3,58 \%$

Scheme 49. Synthesis of phosphorus-containing propargyl derivatives.

CUAAC reaction of $183 a$ with hydrophobic amide 186 a in the presence of $\mathrm{CuSO}_{4}$ and sodium ascorbate in a tetrahydrofuran (THF)/ $\mathrm{H}_{2} \mathrm{O}$ system (conditions A) afforded 187 in $80 \%$ yield within 15 min (Scheme 50). The reaction proved to be insensitive to the nature of the copper(I) precursor. Similar yields and reaction times were observed for other copper catalysts such as $\mathrm{Cul}$ or $\mathrm{Cu}(\mathrm{phen})\left(\mathrm{PPh}_{3}\right) \mathrm{Br}$. Therefore, they use the most popular $\mathrm{CuSO}_{4}$-ascorbate system as the most convenient one. Similarly, 3-and 24-azidocholane derivatives 
181c and $183 a$ readily react with propargyl ester 185 a at room temperature to afford cycloadducts 188 and 189 in $15 \mathrm{~min}$ in $75-77 \%$ yield.

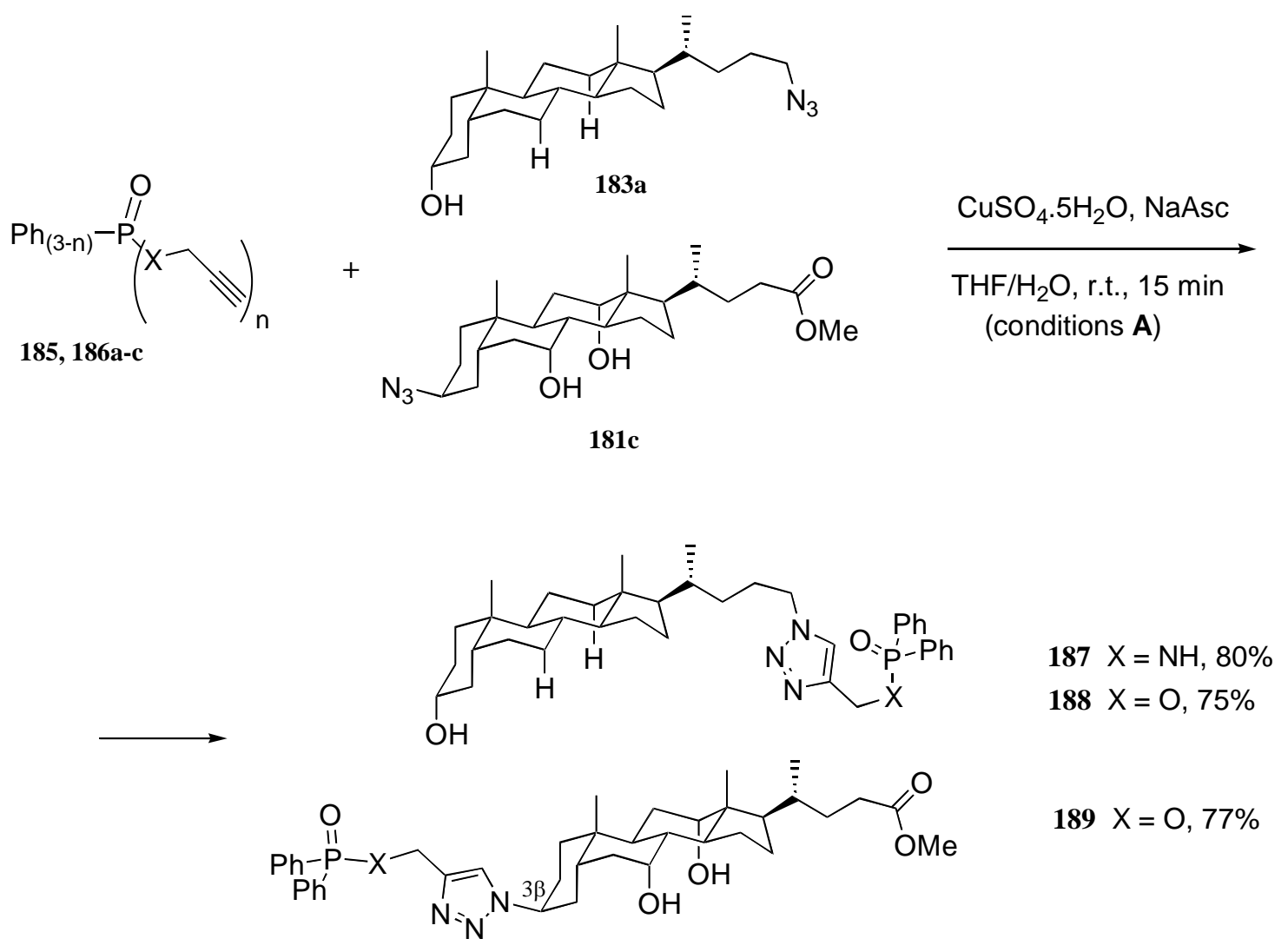

Scheme 50. Synthesis of mono bile-acid phosphorus(V) conjugates.

In contrast, dipropargyl derivative 186b appeared to be significantly less reactive, and only traces of products 190 and 191 were observed after stirring at room temperature for prolonged times under conditions A. However, excellent yields (80-88\%) were obtained when the temperature was raised to $60{ }^{\circ} \mathrm{C}$ (conditions $\mathbf{B}$; Scheme 51).

It is well known that polytriazolyl ligands accelerate CuAAC reactions, this effect probably related to stabilization of the Cul oxidation state and the decomposition of polynuclear copper acetylide clusters. ${ }^{74}$ For pincer-like compounds $\mathbf{2 1 0}$ and $\mathbf{2 1 1}$ the use of tris(benzyltriazolylmethyl) amine (TBTA) allowed the CuAAC reaction to be conducted at room temperature in $2 \mathrm{~h}$ and significantly increases the yield of 191. Unfortunately, phosphonate-based pincer 192a was labile even under such mild conditions and the obtained product was contaminated by $\approx 10 \%$ of 24 -(4-hydroxymethyltriazolyl)-5- $\beta$-cholan-3-ol (192b), which could not be separated from the major product (Scheme 51 ). 
<smiles>C#CCNP(=O)(NCC#C)c1ccccc1</smiles>

$186 b$

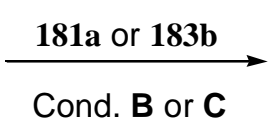

Cond. B or C

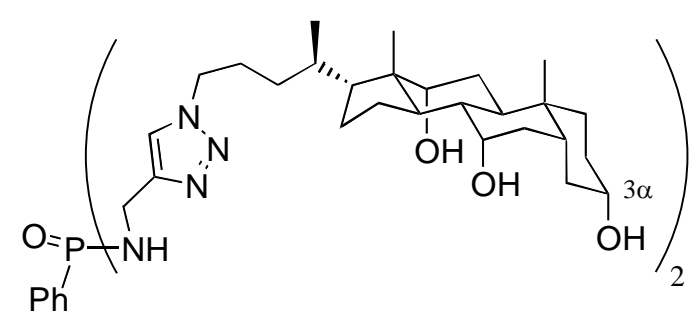

$190,80 \%(B)$

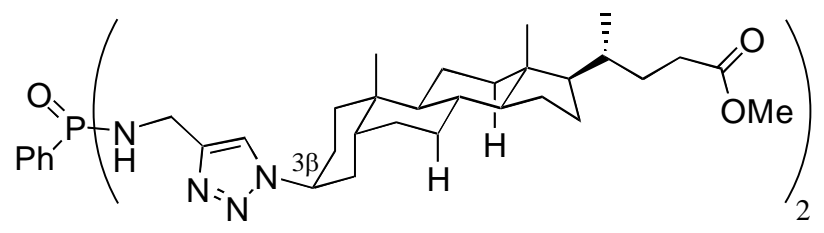

$191,88 \%(B), 99 \%(C)$

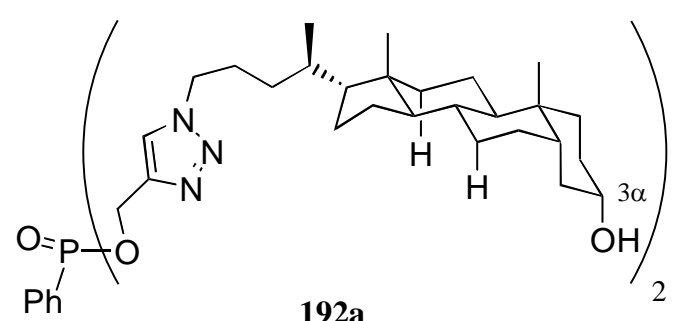

192a

Cond. B

$185 b$

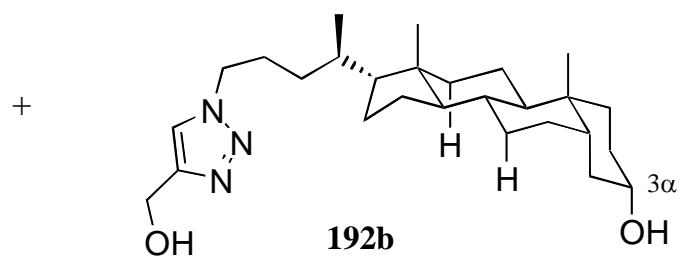

Conditions: B: Cu SO $4.5 \mathrm{H}_{2} \mathrm{O}$ (5 mol\%), NaAsc (40 mol\%), $\mathrm{THF} / \mathrm{H}_{2} \mathrm{O}(4 / 1), 60^{\circ} \mathrm{C}, 24 \mathrm{~h}$; C: $\mathrm{Cu} \mathrm{SO} 4 \cdot 5 \mathrm{H}_{2} \mathrm{O}(5 \mathrm{~mol} \%)$, NaAsc $(40 \mathrm{~mol} \%)$, TBTA (5 mol\%), r.t., 2 h.

Scheme 51. Synthesis of pincer-like bile acid conjugates.

Both conditions B and C were successfully applied to the preparation of the bile acid based tripods 193198 (Scheme 52). However, up to $24 \mathrm{~h}$ were required for complete disappearance of the copper acetylides in

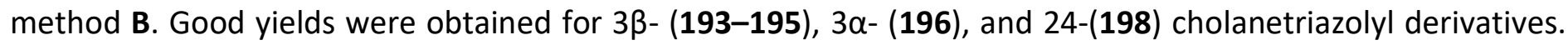
Slightly higher yields were observed for lithocholic acid based tripods relative todeoxycholic and cholic acid based products. Also, they obtained click adduct 197 with 3-azidoacetoxycholane derivative 196, because derivatives that contain a longer triazolylacetoxy linker may have a bigger cavity and be capable of effective complexation with anions. ${ }^{75}$ Surprisingly, CuAAC reaction of tripropargyl phosphate $185 \mathrm{c}$ with steroidal azides gave a complex mixture of products, which were insoluble in most organic solvents including DMSO. 

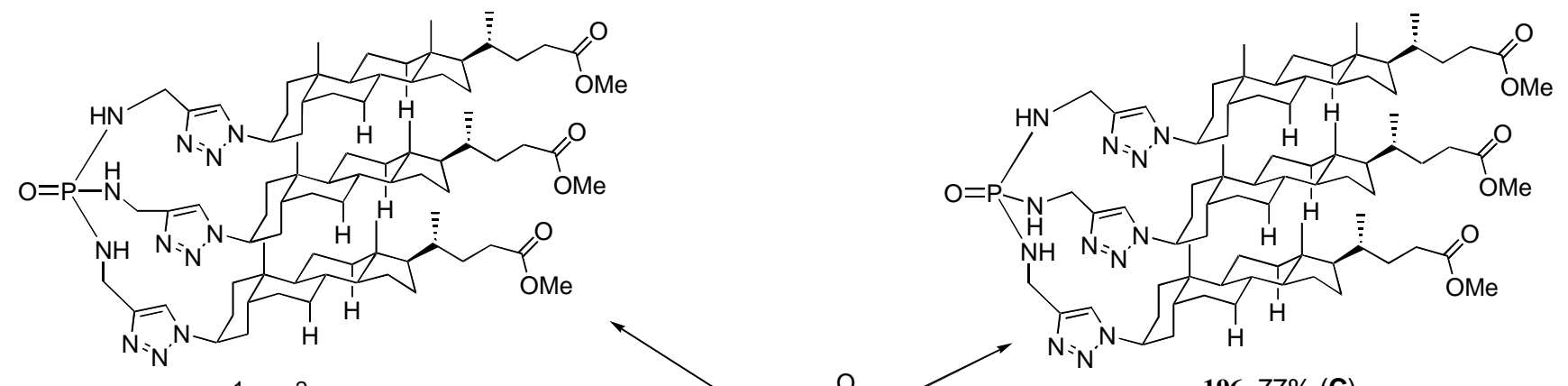

$193, R^{1}=R^{2}=H, 72 \%(B)$

194, $\mathrm{R}^{1}=\mathrm{H}, \mathrm{R}^{2}=\mathrm{OH}, 61 \%(\mathbf{C})$

$195, R^{1}=R^{2}=O H, 52 \%(B), 65 \%(C)$

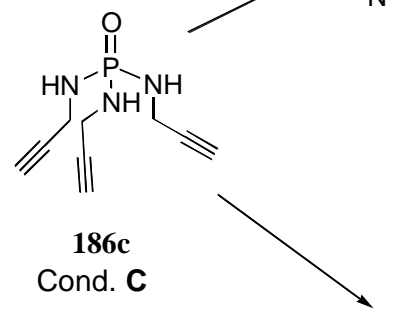

$196,77 \%(\mathbf{C})$

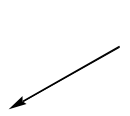

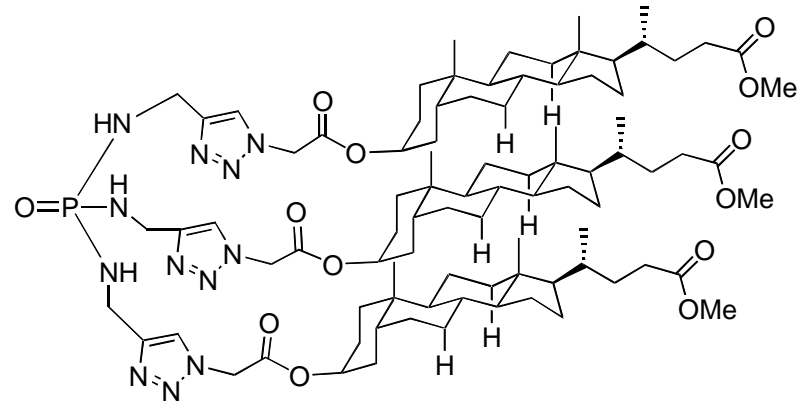

$197,66 \%(C)$

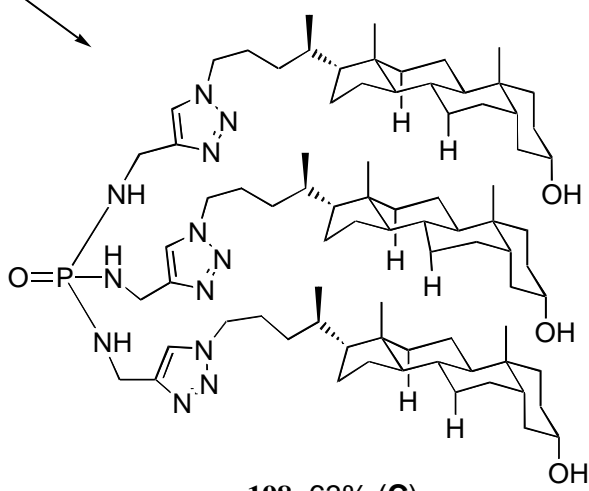

$198,63 \%(C)$

Conditions: B: $\mathrm{CuSO}_{4} \cdot 5 \mathrm{H}_{2} \mathrm{O}(5 \mathrm{~mol} \%)$, NaAsc $(40 \mathrm{~mol} \%), \mathrm{THF} / \mathrm{H}_{2} \mathrm{O}(4 / 1), 60^{\circ} \mathrm{C}, 24 \mathrm{~h}$;

C: $\mathrm{CuSO}_{4} \cdot 5 \mathrm{H}_{2} \mathrm{O}(5 \mathrm{~mol} \%), \mathrm{NaAsc}(40 \mathrm{~mol} \%)$, TBTA (5 mol\%), r.t., $24 \mathrm{~h}$.

Scheme 52. Synthesis of tripodal derivatives.

In 2015, a series 203a-c and 204a-c of novel 17 $\alpha$-[1-(substituted phenyl)-1,2,3-triazol-4-yl]-19-nortestosteron-17 $\beta$-yl acetates were designed and synthesized by Mohamed et al. ${ }^{76}$ using click chemistry approach searching progestogenic derivatives with potential anticancer activity.

Compounds 203a-c and 204a-c were synthesized by conventional methods outlined in Scheme 53. Different methods were reported for the synthesis of organic azides. ${ }^{77}$ In their work 2-,3-, and 4-azidobenzoic acids 200a-c were prepared by diazotization of the available 2-, 3-, and 4-aminobenzoic acids 199a-c, followed by azidation of the resulting diazonium salts with sodium azide. ${ }^{78}$ Methyl azidobenzoates 201a-c were obtained via esterification of the corresponding azidobenzoic acids 200a-c with methanol under reflux in presence of sulfuric acid as catalyst. The o-azidobenzoic acid, 200a and its methyl ester, 201a showed the lowest yield ( 83 and $63 \%$ respectively) relative to the other two isomers that may be attributed to the steric hindrance of the vicinal moieties on the reacting substrates. The targeted derivatives of NEA, 203a-c and 204ac, were prepared under click reaction conditions through 1,3-cycloaddition of the terminal ethynyl group of NEA, 202 and the respective azides, 200a-c and 201a-c catalyzed by $\mathrm{Cu}(\mathrm{I})$. The reactions were performed at room temperature under nitrogen and in presence of ten equivalents of sodium ascorbate in (1:1) aqueous $t$-BuOH milieu. Trial to accelerate the synthesis of compound $203 \mathrm{c}$ by heating the reaction mixture up to $60{ }^{\circ} \mathrm{C}$ was unsuccessful where unidentified products were obtained. Sensitivity of CuAAC reaction to steric 
hindrance was observed through the decreased yields (45\% and 50\%) of the triazoles 203a and 204a derived from 0 -azidobenzoic acid, 200a and its methyl ester, 201a relative to the other ligands prepared from the $m$ and $p$-isomers (55-75\%).

The newly synthesized $17 \alpha$-(1-substituted-1,2,3-triazol-4-yl)-19-nortestosterone acetates, 203a-c and 204-c (Conc. $10^{-5} \mathrm{M}$ ) were screened for their anticancer activity according to $\mathrm{NCl}$ in vitro protocols against a panel consisting of 60 human tumor cell lines. Anchored polar carboxyl moiety to NEA via 1,2,3-triazole ring provided the acid isomers 203a,b and the esters 204a,c with potent progestational activity at nM levels without exerting any toxicity up to $40 \mathrm{mg} / \mathrm{kg}$ dose. Molecular docking analysis of the bound conformers to PR revealed that the added moieties to the steroid nucleus strongly affected the binding modes which can be correlated with the biological activity. A number of the prepared compounds disclosed varied activities against certain cell lines of prostate, renal and CNS cancers. Compound 204b exerted the most prominent cytotoxic activity which was mediated by cell cycle arrest. Their results strongly suggest that their agents may provide a promising new avenue for the development of progestogens with anticancer activity.

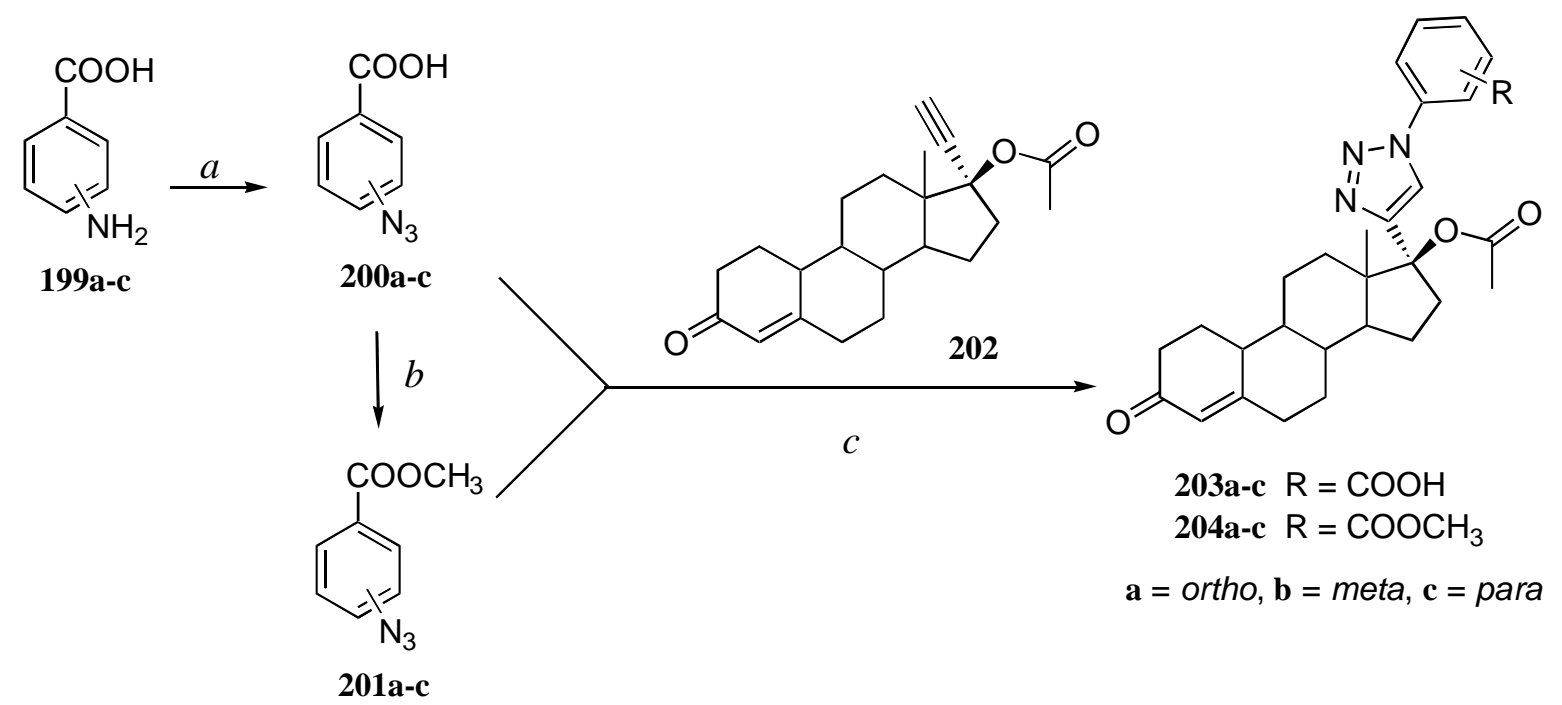

Reaction conditions : $a, \mathrm{H}_{2} \mathrm{SO}_{4}, \mathrm{NaNO}_{2}$ then $\mathrm{NaN}_{3}, b, \mathrm{CH}_{3} \mathrm{OH}, \mathrm{H}_{2} \mathrm{SO}_{4}$, reflux, $4 \mathrm{~h}$, c, $\mathrm{CuSO}_{4} .5 \mathrm{H}_{2} \mathrm{O}$, sodium ascorbate $\mathrm{H}_{2} \mathrm{O} / \mathrm{tBuOH}(1: 1)$, r.t., $\mathrm{N}_{2}, 8$ h.

Scheme 53. Synthesis of the target compounds 203a-c and 204a-c.

Lützen and co-workers ${ }^{79}$ have described the synthesis of rotaxane $\mathbf{2 2 2} \cdot \mathrm{HBF}_{4}$ that contained a crown ether threaded onto a non-symmetrical axis with a tetraphenylmethane and a cholesterol stopper unit in a CuAAC reaction of an azide and an alkyne terminated half axis through an ammonium-ion template effect. Schemes 56 and 57 show the syntheses of half-axes 214 and 219. Alkyne half-axis 214 was prepared in ten steps by starting from 4-bromobenzoic acid 215 (Scheme 54). By following literature procedures, 215 was first transformed into corresponding methyl ester $\mathbf{2 1 6}$ before it was subjected to a twofold Grignard addition reaction to give tertiary alcohol 217. Compound $\mathbf{2 1 7}$ was then condensed with phenol under acidic conditions to give tetraphenylmethane derivative 208, which was subsequently methylated to give tris(4-methoxyphenyl)(4-bromophenyl)methane 209. 
<smiles>O=C(O)c1ccc(Br)cc1</smiles>

205<smiles>CC(=O)c1ccc(Br)cc1</smiles><smiles>COc1ccc(C(O)(c2ccccc2)c2ccc(Br)cc2)cc1OC</smiles>

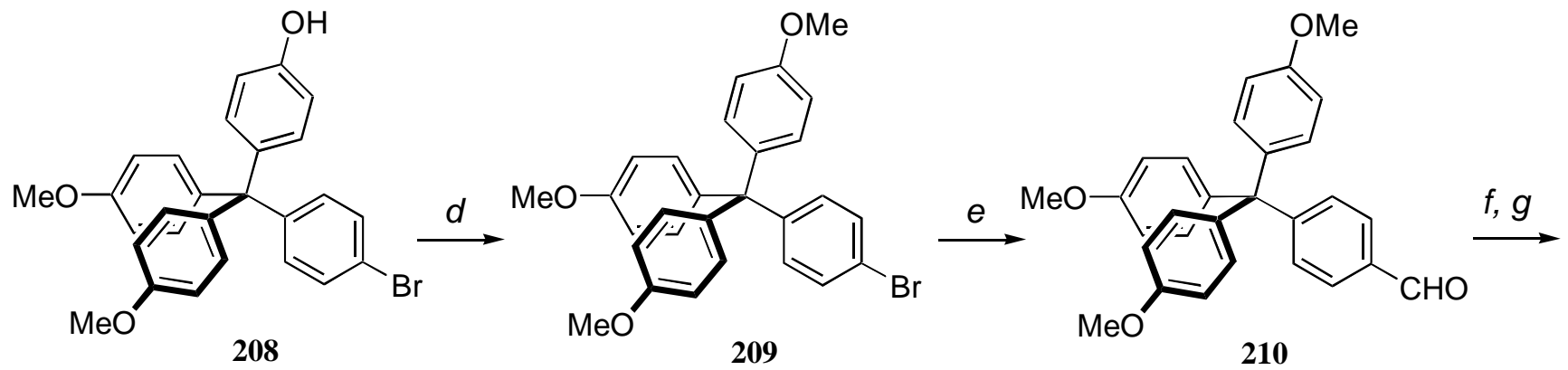<smiles>C#CCCCCOc1ccc(CN(Cc2ccc(C(c3ccc(OC)cc3)(c3ccc(OC)cc3)c3ccc(OC)c(OC)c3)cc2)c2ccc(OC)c(OC)c2)cc1</smiles><smiles>C#CCCCCOc1ccc(C[NH2+]Cc2ccc(C(c3ccc(Br)cc3)(c3ccc(OC)cc3)c3ccc(OC)cc3)cc2)cc1</smiles>

Reaction conditions : $a, \mathrm{MeOH}, \mathrm{H}_{2} \mathrm{SO}_{4}, \Delta, 24 \mathrm{~h}, 64 \% ; b, 4-\mathrm{MeOPhMgBr}, \mathrm{THF}, \mathrm{r}$. t., $18 \mathrm{~h}, 62 \%$; c, $\mathrm{PhOH}, \mathrm{HBr}, \Delta, 18 \mathrm{~h}, 48 \%$; $d$, NaH, Mel, r. t., 78\%; e, tBuLi, THF, $1 \mathrm{~h},-78{ }^{\circ} \mathrm{C}$, then DMF, $\mathrm{HCl}$, 1.5 h, r.t., quant.; $f$, 4-(aminomethyl)phenol, EtOH, 24 h, $\Delta$, quant.; $g, \mathrm{NaBH}_{4}, \mathrm{MeOH} / \mathrm{THF}, 18 \mathrm{~h}$, r.t., $83 \% ; h$, $t$-BuOCO${ }_{2} \mathrm{CO}_{2} t-\mathrm{Bu} ; i$, 6-chloro-1-hexyne, $\mathrm{Cs}_{2} \mathrm{CO}_{3}, \mathrm{KI}, \mathrm{DMF}, 18 \mathrm{~h}, 70{ }^{\circ} \mathrm{C}, 77 \% ; j, \mathrm{HCl}$, $\mathrm{CH}_{2} \mathrm{Cl}_{2}, 18$ h, r.t., then aq. $\mathrm{NH}_{4} \mathrm{BF}_{4}, 18$ h, r. t., $74 \%$.

Scheme 54. Synthesis of alkyne half-axes 214.

To achieve formylation of $\mathbf{2 0 9}$ a bromine lithium exchange was first performed with tert-butyllithium; neither $n$ - nor sec-butyllithium was successful in this reaction. Addition of $N, N$-dimethylformamide to the 
lithium organyl followed by quenching with aqueous $\mathrm{HCl}$ then gave rise to desired aldehyde $\mathbf{2 1 0}$ in quantitative yield. Reductive amination upon reaction of $\mathbf{2 1 0}$ with 4-(aminomethyl)phenol in anhydrous ethanol, but without the typical use of anhydrous magnesium sulfate, and subsequent reduction of the intermediate imine by $\mathrm{NaBH}_{4}$ in tetrahydrofuran (THF)/MeOH gave amine 211 in $64 \%$ yield over both steps. Base stable tert-butyloxycarbonyl (Boc) protecting group was introduced by reacting 211 with di-tert-butyl dicarbonate to give $\mathbf{2 1 2}$ in 83\% yield. Boc protected phenol $\mathbf{2 1 2}$ was then deprotonated with caesium carbonate and the reaction with the chloroalkyne in the presence of catalytic amounts of potassium iodide gave desired alkynylated ether $\mathbf{2 1 3}$ in 77\% yield. Next, the Boc protecting group was removed by treatment with $\mathrm{HCl}(2 \mathrm{~N})$ in diethyl ether to form the ammonium ion. To make this an even better template for the formation of the pseudo-rotaxane with dibenzo-24-crown-8, the counterion was finally exchanged against the much weaker coordinating tetrafluoroborate by using a saturated aqueous solution of ammonium tetrafluoroborate to give protonated alkyne-terminated half-axis $\mathbf{2 1 4} \cdot \mathrm{HBF}_{4}$ in $\mathbf{7 4 \%}$ yield. Azide half-axis $\mathbf{2 1 9}$ was prepared in four steps starting from commercially available cholesterol (215; Scheme 55). By following literature protocols, ${ }^{80} \mathbf{2 1 5}$ was first tosylated to give sulfonate $\mathbf{2 1 6}$ in $\mathbf{7 8 \%}$ yield. Nucleophilic substitution with ethylene glycol then afforded chain-elongated alcohol $\mathbf{2 1 7}$ with retention of stereochemistry in $86 \%$ yield. Another tosylation gave $\mathbf{2 1 8}$ in 76\% yield, which was finally transformed into desired azide $\mathbf{2 1 9}$ upon treatment with sodium azide in 1,3-dimethyl-3,4,5,6-tetrahydro-2(1H)-pyrimidinone (DMPU). In this way cholesterol derivative $\mathbf{2 1 9}$ could be isolated in 90\% yield after recrystallization from ethanol.
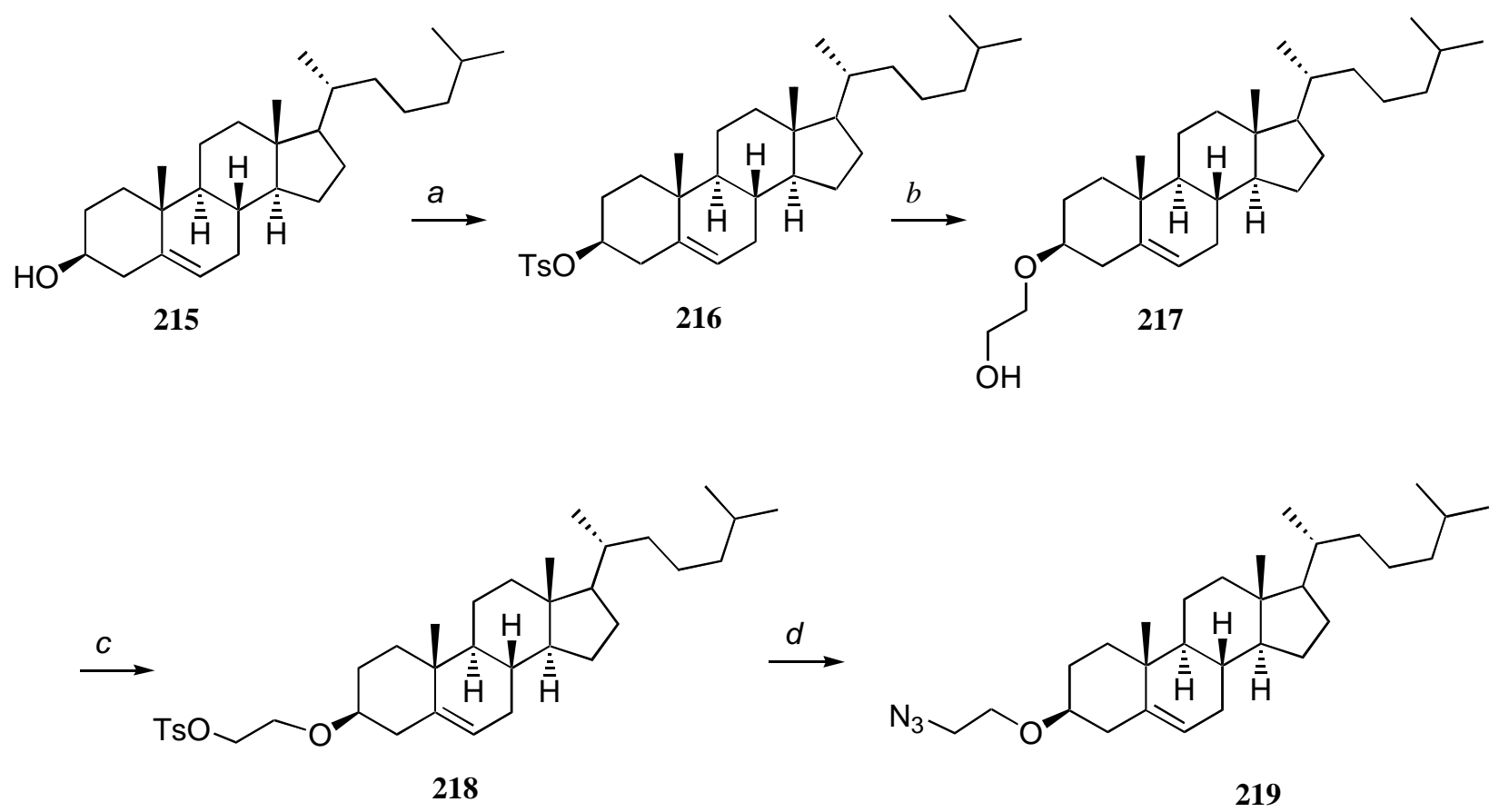

Reaction conditions : a, $p$-TsCl, pyridine r.t., $1 \mathrm{~h}, 78 \%$; $b, \mathrm{HOCH}_{2}-\mathrm{CH}_{2} \mathrm{OH}, 1,4$-dioxane, $\Delta, 18 \mathrm{~h}, 86 \%$; c, $p$-TsCl, pyridine, $0^{\circ} \mathrm{C}, 18 \mathrm{~h}, 76 \% ; d, \mathrm{NaN}_{3}$, DMPU, $18 \mathrm{~h}, 50^{\circ} \mathrm{C}, 90 \%$.

Scheme 55. Synthesis of azide half-axis 219. 


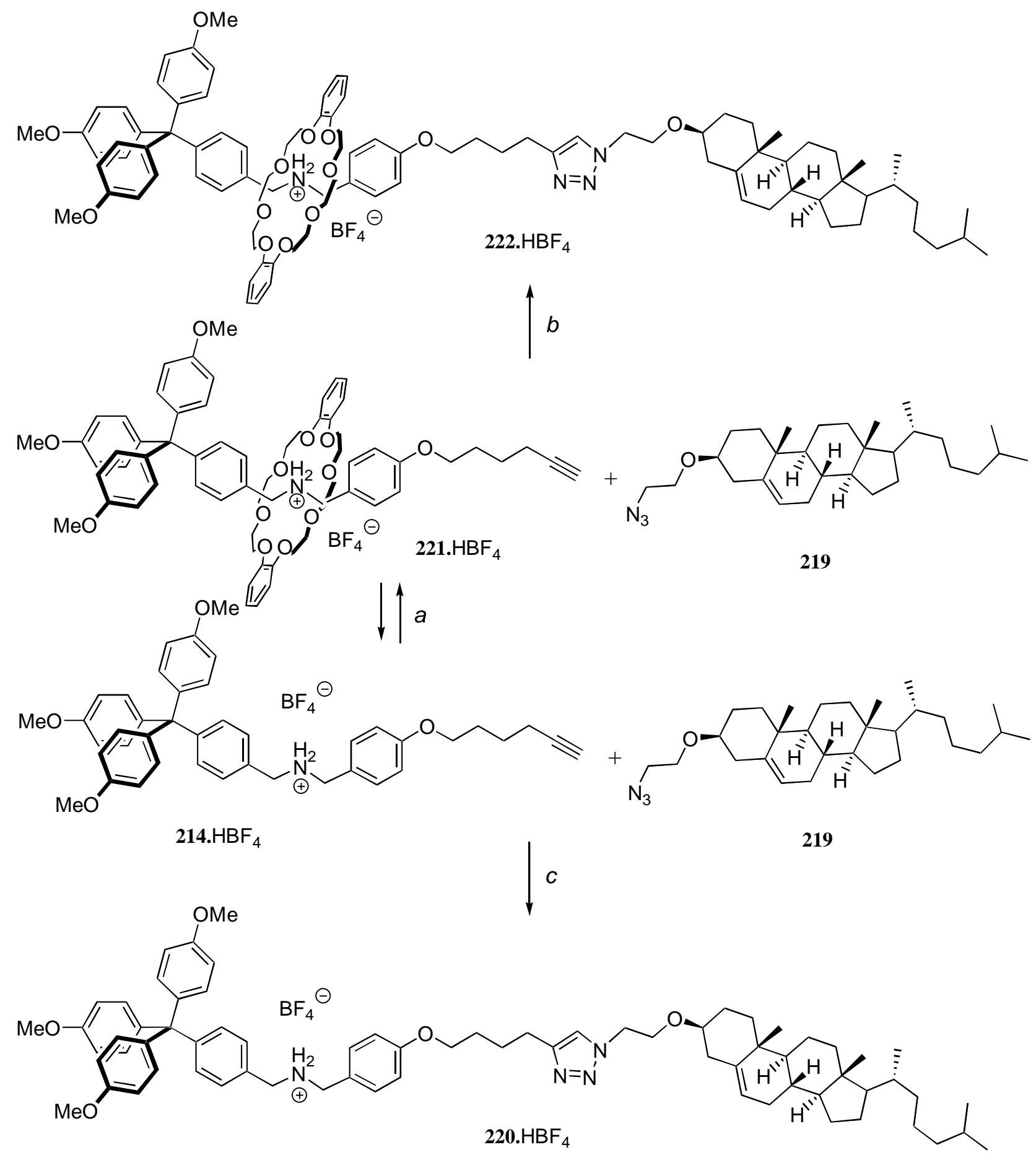

Reaction conditions : a, dibenzo-24-crown-8, $\mathrm{CH}_{2} \mathrm{Cl}_{2}, 2$ h, r.t.; $b, \mathrm{Cu}\left(\mathrm{CH}_{3} \mathrm{CN}\right)_{4} \mathrm{BF}_{4}$, tri[(1-benzyl-1H1,2,3-triazol-4-yl)methyl]amine (TBTA), $\mathrm{CH}_{2} \mathrm{Cl}_{2}, 2 \mathrm{~d}, 5 \%$; $, \mathrm{Cu}\left(\mathrm{CH}_{3} \mathrm{CN}\right)_{4} \mathrm{BF}_{4}, \mathrm{CH}_{2} \mathrm{Cl}_{2}, 2 \mathrm{~d}, 55 \%$

Scheme 56. Synthesis of rotaxane $222 . \mathrm{HBF}_{4}$ and isolated axis $220 . \mathrm{HBF}_{4}$.

With both building blocks in hands the next task was to prepare isolated axis $\mathbf{2 2 0}$ and the formation of rotaxane $\mathbf{2 2 2} \cdot \mathrm{HBF}_{4}$ through CuAAC (Scheme 56 ). Therefore, alkyne-terminated half-axis $\mathbf{2 3 4} \cdot \mathrm{HBF}_{4}$ was mixed with dibenzo-24-crown-8 and stirred for two hours in degassed dichloromethane to achieve formation of pseudo-rotaxane $\mathbf{2 2 1} \cdot \mathrm{HBF}_{4}$. This was treated with 219 for two days in dichloromethane with $\mathrm{Cu}\left(\mathrm{CH}_{3} \mathrm{CN}\right)_{4} \mathrm{BF}_{4}$ as 
catalyst and tris[(1-benzyl-1H-1,2,3-triazol-4-yl)methyl]amine (TBTA) as a copper(I) stabilizing ligand ${ }^{81}$ to afford desired rotaxane $\mathbf{2 1 2} \cdot \mathrm{HBF}_{4}$ in a yield of $4 \%$ after recrystallization from ethanol and additional column chromatography. Interestingly, the same conditions were not successful to prepare the isolated axis from $\mathbf{2 1 4} \cdot \mathrm{HBF}_{4}$ and 219 because they were unable to remove TBTA from the desired product. Only when they repeated the synthesis without the stabilizing ligand they were able to isolate axis $\mathbf{2 2 0} \cdot \mathrm{HBF}_{4}$ in a reasonable yield of $55 \%$ after column chromatography.

In 2015, Pandey et al. ${ }^{82}$ reported the synthesis of novel bile acid-based anion-receptors using $\mathrm{Cu}(\mathrm{I})$ catalyzed click reaction of steroidal azide and various terminal alkynes and a study of their anion sensing properties using UV-visible titration.

The bile acid-based triazole and triazolium receptors have been synthesized as shown in Schemes 57 and 58. The 1,3-dipolar cycloaddition reactions of methyl $3 \alpha, 12 \alpha$-bis-(azidoacetyl)deoxycholate with alkyne derivatives in the presence of $\mathrm{CuSO}_{4}(10 \mathrm{~mol} \%)$ and sodium ascorbate $(20 \mathrm{~mol} \%)$ in t-BuOH$/ \mathrm{H}_{2} \mathrm{O}$ at $60{ }^{\circ} \mathrm{C}$ led to the formation of compounds 223a, 223b, and 223c, respectively. The alkynes used in the synthesis of 223a223c were prepared by the known literature procedures. ${ }^{83}$ The methylation of 1,2,3-triazole rings in $\mathbf{2 4 3 b}$ and 223c with methyl iodide gave compounds $\mathbf{2 2 3 d}$ and $223 e$, respectively. The $223 d .\left(P F_{6}\right)_{2}$ and $223 e .\left(P F_{6}\right)_{2}$ salts were synthesized by the anion-exchange of $\mathbf{2 2 3 d}$ and $223 e$ with $\mathrm{NH}_{4} \mathrm{PF}_{6}$.
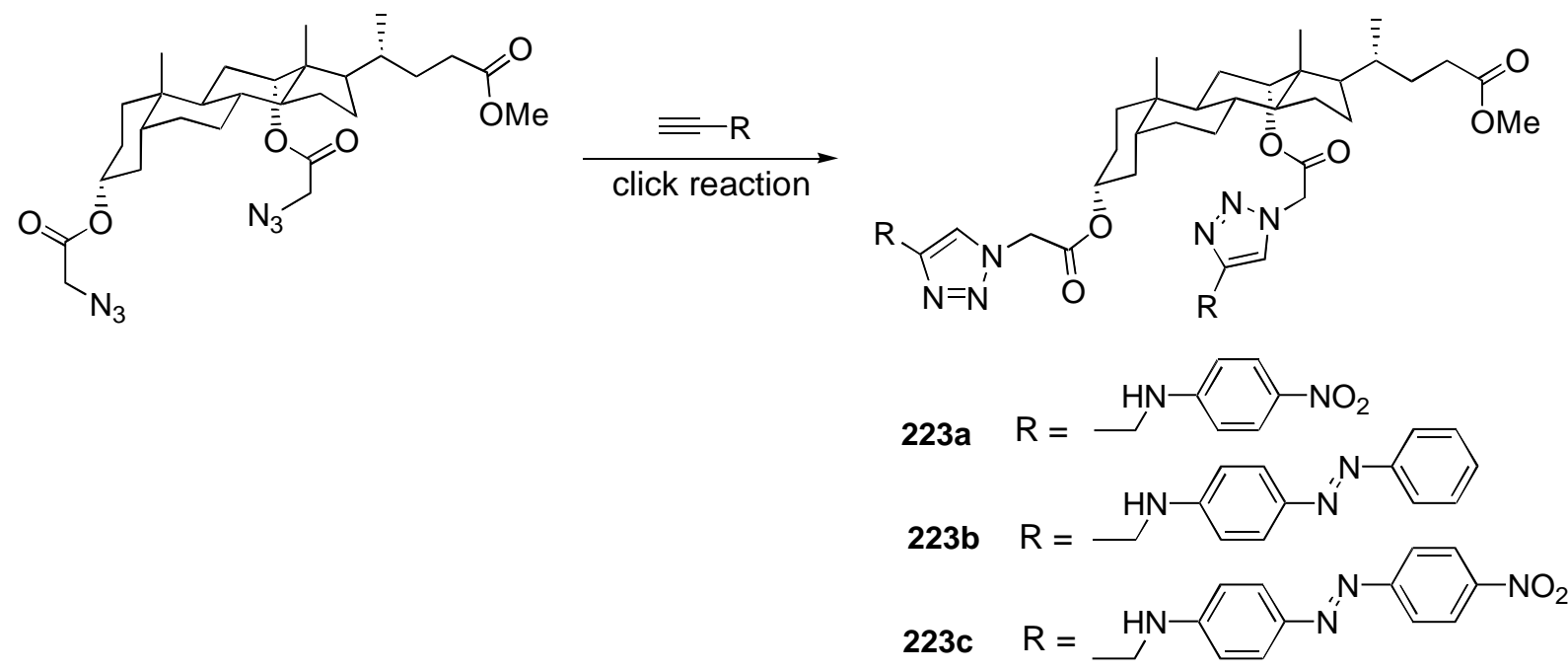

Scheme 57. Synthesis of triazole receptors.

The receptor 223a with p-nitroaniline group shows colorimetric recognition of $\mathrm{H}_{2} \mathrm{PO}_{4}$ and highest binding affinity for $\mathrm{F}^{-}$ion. The triazole receptor $223 \mathrm{c}$ with $\mathrm{p}$-nitroazobenzene group shows high selectivity and considerable binding affinity for $\mathrm{CH}_{3} \mathrm{CO}_{2}^{-}$ion. The azobenzenecontaining triazolium receptors $223 \mathrm{~d}$. $\left(\mathrm{PF}_{6}\right)_{2}$ and 223e. $\left(\mathrm{PF}_{6}\right)_{2}$ also show the highest affinity for $\mathrm{CH}_{3} \mathrm{CO}_{2}^{-}$ion. The receptor 223e. $\left(\mathrm{PF}_{6}\right)_{2}$ with pnitroazobenzene group shows the colorimetric sensing for $\mathrm{F}^{-}, \mathrm{CH}_{3} \mathrm{CO}_{2}$ and $\mathrm{H}_{2} \mathrm{PO}_{4}^{-}$ions. Hence, some of these receptors can be employed for colorimetric anion-sensing.

Fouquet and co-workers ${ }^{84}$ have described the synthesis of new tags for a mild carbonylation reaction, and the linking to biomolecules by click chemistry.

The synthetic building-block $\mathbf{2 2 5}$ was easily obtained from commercial compound $\mathbf{2 2 4}$ in a three-step procedure in an $84 \%$ overall yield (Scheme 59). This phenol 225 was then functionalized by 3-azidopropyl group to lead to the synthetic tag $\mathbf{2 2 6}$ with a yield of $68 \%$. 


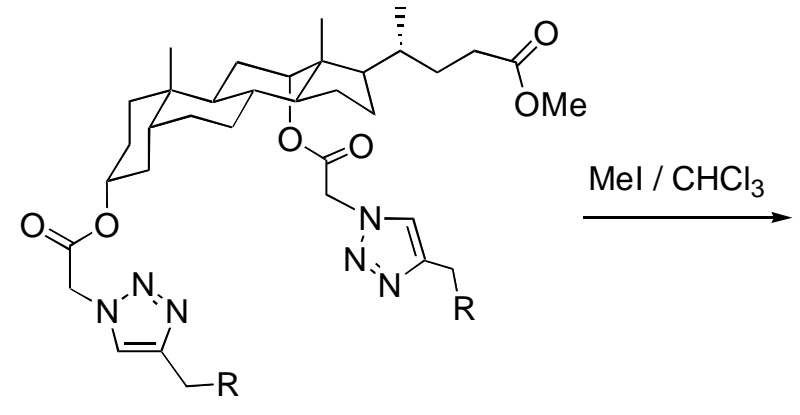

223b, 223c

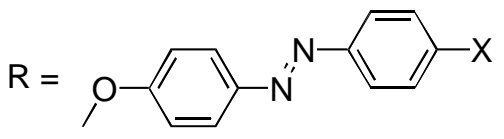

223d; $\mathrm{X}=\mathrm{H}$

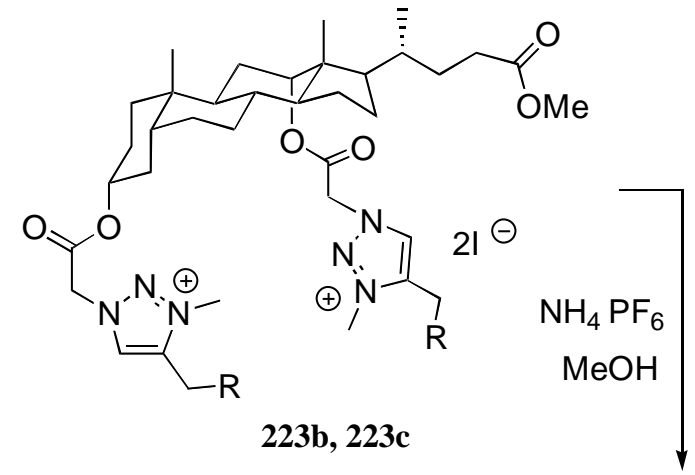

223c; $X=\mathrm{NO}_{2}$

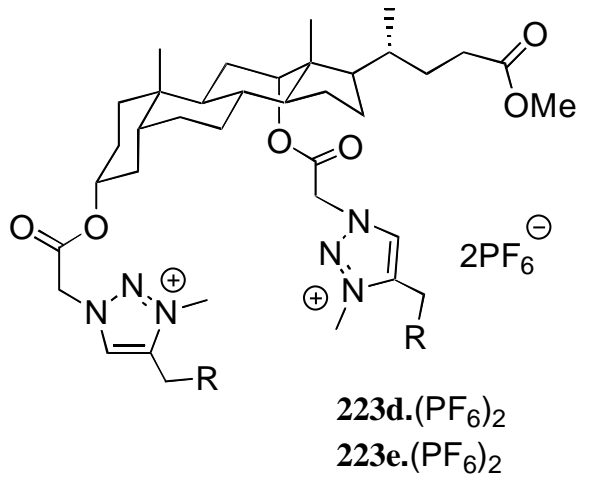

Scheme 58. Synthesis of triazolium receptors.<smiles>COC(=O)c1ccc(C)c(O)c1</smiles>

224
1. NIS, TFA, $\mathrm{CH}_{3} \mathrm{CN}$

2. $\mathrm{BBr}_{3}, \mathrm{CH}_{2} \mathrm{Cl}_{2}, \mathrm{rt}, 16 \mathrm{~h}$

3. $\mathrm{BH}_{3}, \mathrm{THF}, \mathrm{rt}, 16 \mathrm{~h}$ $82 \%$<smiles>Cc1cc(I)c(CO)cc1O</smiles>

225<smiles>Cc1cc(I)c(CO)cc1OCCCN</smiles>

226

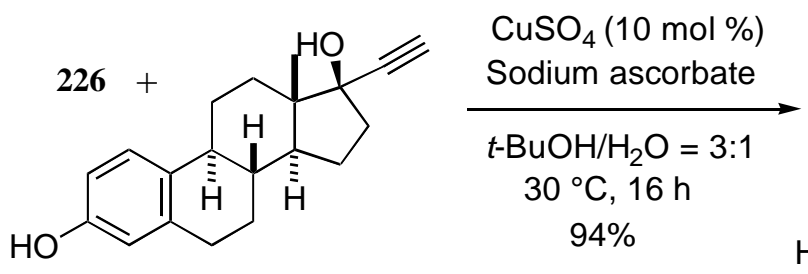<smiles>COCCCn1cc([C@]2(O)CC[C@H]3[C@H]4CCc5cc(O)ccc5[C@H]4CC[C@@]32C)nn1</smiles>

227<smiles>Cc1cc(I)c(CO)cc1C</smiles>

Scheme 59. Preparation of substrate $\mathbf{2 2 7}$ by copper-catalyzed Huisgen cycloaddition with 226. 


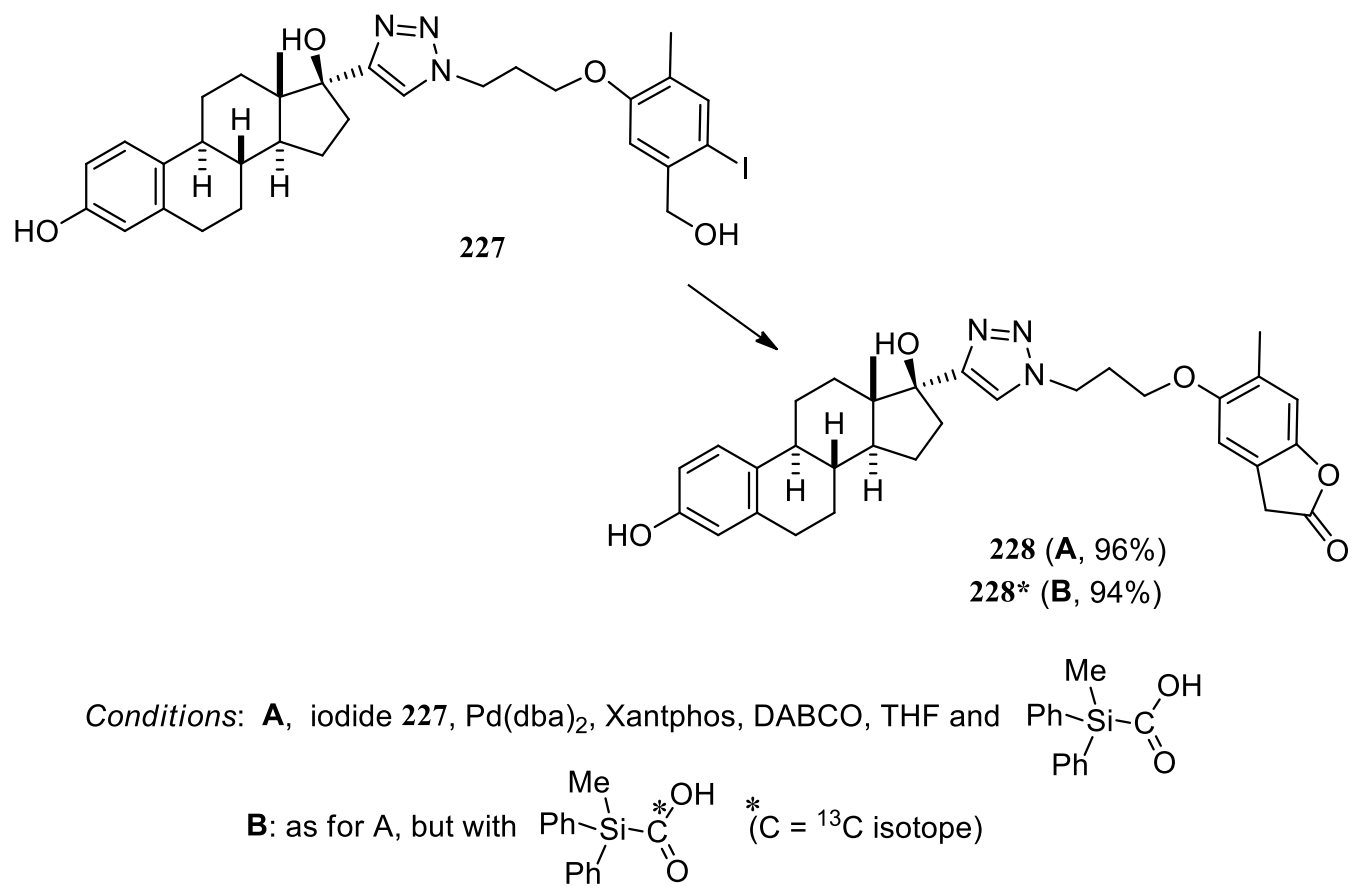

Scheme 60. Carbonylation of substrate 228.

Then, more biologically relevant molecules were examined. The bioconjugate $\mathbf{2 2 7}$ derived from moxestrol (a specific ligand to estrogen receptor) was submitted to conditions A and B to give products 228 and $228 *$ (product with carbon isotope $\left[{ }^{13} \mathrm{C}\right]$ ) with very good yields of $96 \%$ and $94 \%$. As a potential estrogen receptor tracer, the 228* could be useful for instance to detect hormone responsive cancers. ${ }^{85}$

Up to 2015, no work has been published on the synthesis or the physicochemical properties of bile acidsterol conjugates linked by a 1,2,3-triazole ring. Pospieszny ${ }^{86}$ reported in literature in 2015 the first report on the mixed steroid conjugates linked via a 1,2,3-triazole ring. This work reports the synthesis and physicochemical properties of new bile acid-sterol conjugates linked with a 1,2,3-triazole ring of propargyl esters of bile acid and ster-3 $\beta$-yl 2-azido-acetates.

The ergoster-3 $\beta$-yl 2-bromoacetate 231 and cholester-3 $\beta$-yl 2-bromoacetate 232, as well as propargyl esters of bile acids 238-240, were prepared according to the literature procedures. ${ }^{87}$ The ster-3 3 -yl 2bromoacetates, as well as bile acid esters, were obtained with high yields (85-94\%). The ergoster-3 $\beta$-yl 2azidoacetate $\mathbf{2 3 3}$ and cholester-3 $\beta$-yl 2-azidoacetate $\mathbf{2 3 4}$ were synthesized in the reaction of corresponding ster-3 $\beta$-yl 2-bromoacetate with $\mathrm{NaN}_{3}$ in $\mathrm{DMF}$ at $50^{\circ} \mathrm{C}$. This one-pot reaction leads to azide derivatives in 95 and 93\% yield, respectively. The azides $\mathbf{2 3 3}$ or $\mathbf{2 3 4}$ and propargyl esters of bile acids 238-240 were used as a substrate in the "click" reaction in the presence of $\mathrm{CuSO}_{4} \cdot 5 \mathrm{H}_{2} \mathrm{O}$ and sodium ascorbate. Application of two different mixtures of solvents $t-\mathrm{BuOH} / \mathrm{H}_{2} \mathrm{O}(5: 1)$ and $\mathrm{DMF} / \mathrm{H}_{2} \mathrm{O}(4: 1)$ gave the same results. A mixture of products 241-246 were obtained and separated by column chromatography. 


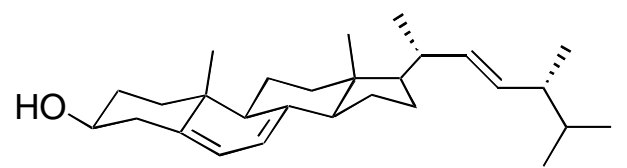

229

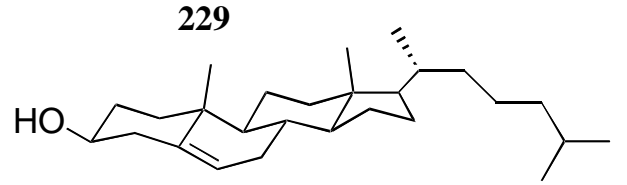

230
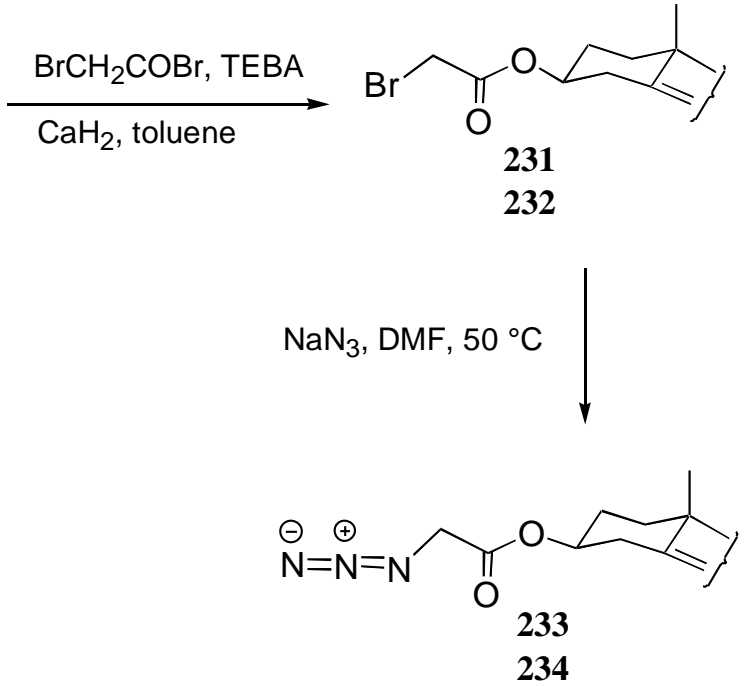

Scheme 61. Preparation of the azides 233 and 234.
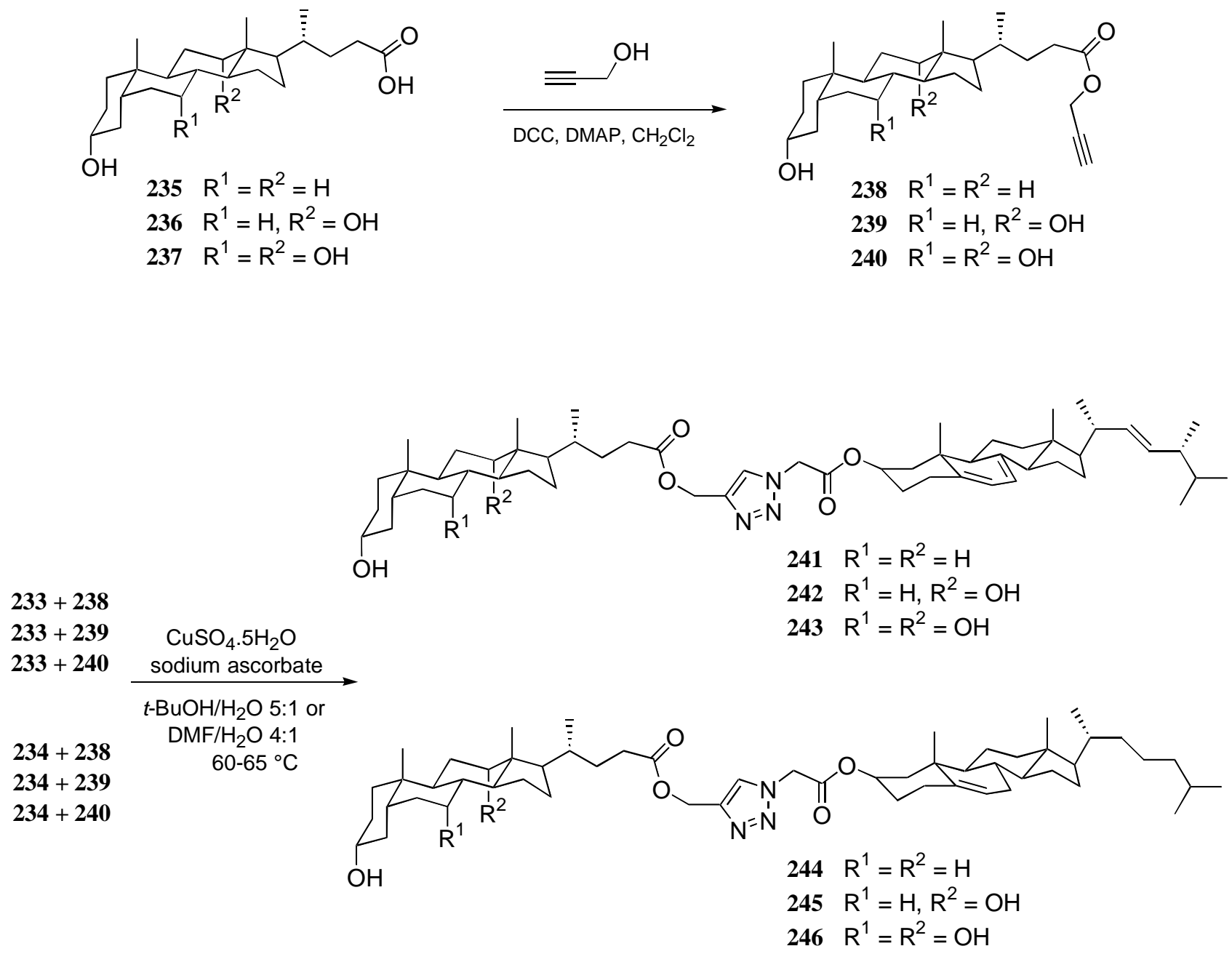

Scheme 62. Click coupling of azides $\mathbf{2 3 3}$ and $\mathbf{2 3 4}$ with propargyl esters of bile acids. 


\section{Conclusions}

The syntheses of steroids reported in literature, from 2011 up to now, using copper as catalyst, have been reviewed. The growing number of Cu-catalyzed steroid transformations has allowed chemists to carry out straightforward syntheses of complex steroid molecules and other natural products. Several of these syntheses constitute the first ones in this domain. This route is particularly attractive for the preparation of steroids and allow us to develop more novel molecules with characteristic functions.

\section{4- Acknowledgements}

This work has been financially supported by the CNRS and the Ministère de l'Enseignement Supérieur et de la Recherche.

\section{References}

1. Biellmann, J.-F. Chem. Rev. 2003, 103, 2019.

https://doi.org/10.1021/cr020071b

2. Hu, J.; Lu, J.-R.; Ju, Y. Chem. Asian J. 2011, 6, 2636.

https://doi.org/10.1002/asia.201100378

3. Kádár, Z.; Kovács, D.; Frank, É.; Schneider, G.; Huber, J.; Zupkó, I.; Bartók, T.; Wölfling, J. Molecules 2011, 16, 4786.

https://doi.org/10.3390/molecules16064786

4. Ruzička, L.; Prelog, V.; Battegay, J. Helv. Chim. Acta 1948, 31, 1296.

5. Schneider, G; Vincze, I; Vass, A. Acta Chim. Acad. Sci. Hung. 1979, 99, 51.

6. Meldal, M; Tornøe, C. W. Chem. Rev. 2008, 108, 2952.

https://doi.org/10.1021/cr0783479

7. Pospieszny, T; Małecka, I; Paryzek, Z. Tetrahedron Lett. 2012, 53, 301.

https://doi.org/10.1016/j.tetlet.2011.11.027

8. Tserng, K. Y., Klein, P. D. Steroids 1977, 29, 635.

https://doi.org/10.1016/0039-128X(77)90015-0

9. Aher, N.G.; Pore, V. S.; Patil, S. P. Tetrahedron 2007, 63, 12927.

https://doi.org/10.1016/j.tet.2007.10.042

10. Fehér, K.; Balogh, J.; Csók, Z.; Kégl, T.; Kollár, L.; Skoda-Földes, R. Steroids 2012, 77, 738.

https://doi.org/10.1016/j.steroids.2012.04.005

11. Balogh, J.; Kégl, T.; Párkányi, L.; Kollár, L.; Ungváry, F.; Skoda-Földes, R. J. Organomet. Chem. 2011, 696, 1394.

https://doi.org/10.1016/j.jorganchem.2011.01.008

12. van Staveren, D. R.; Metzler-Nolte, N. Chem. Rev. 2004, 104, 5931.

https://doi.org/10.1021/cr0101510

13. Mamidyala, S. K.; Finn, M. G. Chem. Soc. Rev. 2010, 39, 1252.

https://doi.org/10.1039/b901969n 
14. Gogoi, J.; Bezbaruah, P.; Saikia, P.; Goswami, J.; Gogoi, P.; Boruah, R. C. Tetrahedron Lett. 2012, 53, 1497. https://doi.org/10.1016/j.tetlet.2012.01.050

15. Bori, I. D.; Hung, H.-Y.; Qian, K.; Chen, C.-H.; Morris-Natschke, S. L.; Lee, K.-H. Tetrahedron Lett. 2012, 53, 1987.

https://doi.org/10.1016/j.tetlet.2012.02.022

16. Kádár, Z.; Frank, E.; Schneider, G.; Molnár, J.; Zupkó, I.; Kóti, J.; Schönecker, B.; Wölfling, J. Arkivoc 2012, (iii), 279.

http://dx.doi.org/10.3998/ark.5550190.0008.517

17. Fieser, L. F.; Dominguez, X. A. J. Am. Chem. Soc. 1953, 75, 1704.

https://doi.org/10.1021/ja01103a055

18. Gonschior, M.; Kötteritzsch, M.; Rost, M.; Schönecker, B.; Wunderwald, M. Tetrahedron Asymmetry 2000, 11, 2159.

https://doi.org/10.1016/S0957-4166(00)00168-3

19. Szánti-Pintér, E.; Csók, Z.; Kollár, L.; Vékey, K.; Skoda-Földes, R. J. Organomet. Chem. 2012, 718, 105. https://doi.org/10.1016/j.jorganchem.2012.08.013

20. Masi, S.; Top, S.; Boubekeur, L.; Jaouen, G.; Mundwiler, S.; Spingler, B.; Alberto, R. Eur. J. Inorg. Chem. 2004, 2013.

21. Deobald, A. M.; Camargo, L. R. S.; Alves, D.; Zukerman-Schpector, J.; Corrêa, A. G.; Paixão, M. W. Synthesis 2011, 24, 4003.

22. Sun, Q.; Cai, S.; Peterson, R. B. Org. Lett. 2009, 11, 567.

https://doi.org/10.1021/ol802343z

23. Severin, R; Reimer, J; Doye, S. J. Org. Chem. 2010, 75, 3518.

https://doi.org/10.1021/jo100460v

24. Han, M.; Hou, J. G.; Dong, C. M.; Li, W.; Yu, H. L.; Zheng, Y. N.; Chen, L. Molecules 2010, 15, 399; https://doi.org/10.3390/molecules15010399

25. Hanson, R. N.; Hua, E.; Labaree, D.; Hochberg, R. B.; Proffitt, K.; Essigmann, J. M.; Croy, R. G. Org. Biomol. Chem. 2012, 10, 8501.

https://doi.org/10.1039/c2ob25902h

26. Hanson, R. N.; Napolitano, E.; Fiaschi, R. Steroids 1998, 63, 479.

https://doi.org/10.1016/S0039-128X(98)00052-X

27. Prat, D.; Benedetti, F.; Bouda, L. N.; Girard, G. F. Tetrahedron Lett. 2004, 45, 765.

https://doi.org/10.1016/j.tetlet.2003.11.028

28. Mohler, D. L.; Shen, G. Org. Biomol. Chem. 2006, 4, 2082.

https://doi.org/10.1039/B600848H

29. Lundt, I.; Steiner, A. J.; Stuetz, A. E.; Tarling, C. A.; Ully, S.; Withers, S. G.; Wrodnigg, T. M. Bioorg. Med. Chem. 2006, 14, 1737.

https://doi.org/10.1016/i.bmc.2005.10.021

30. Sami, S. M.; Iyengar, B. S.; Tarnow, S. E.; Remers, W. A.; Bradner, W. T.; Schurig, J. E. J. Med. Chem. 1984, $27,701$.

https://doi.org/10.1021/jm00371a026

31. Rostovtsev, V. V.; Green, L. G.; Fokin, V. V.; Sharpless, K. B. Angew. Chem. Int. Ed. 2002, 41, 2596.

https://doi.org/10.1002/1521-3773(20020715)41:14<2596::AID-ANIE2596>3.0.CO;2-4

32. Kotovshchikov, Y. N.; Latyshev, G. V.; Lukashev, Beletskaya I. P. Eur. J. Org. Chem. 2013, 7823. 
https://doi.org/10.1002/ejoc.201300719

33. Latyshev, G. V.; Lukashev, N. V.; Beletskaya, I. P. Russ. J. Org. Chem. 2008, 44, 785.

https://doi.org/10.1134/S107042800806002X

34. Barton, D. H. R.; Bashiardes, G.; Fourrey, J. Tetrahedron 1988, 44, 147.

https://doi.org/10.1016/S0040-4020(01)85102-4

35. Yang, Q.; Wang, Y., Lin, D.; Zhang, M. Tetrahedron Lett. 2013, 54, 1994.

https://doi.org/10.1016/j.tetlet.2013.02.004

36. Wang, H.; Li, Y.; Jiang, L.; Zhang, R.; Jin, K.; Zhao, D.; Duan, C. Org. Biomol. Chem. 2011, 9, 4983.

https://doi.org/10.1039/c1ob05549f

37. Maksymowicz, R. M.; Roth, P. M. C.; Thompsony, A. L.; Fletcher, S. P. Chem. Commun. 2013, 49, 4211. https://doi.org/10.1039/C2CC37155C

38. Brazier, E. J.; Hogan, P. J.; Leung, C. W.; O’Kearney-McMullan, A.; Norton, A. K.; Powell, L.; Robinson, G. E.; Williams, E. G. Org. Process Res. Dev. 2010, 14, 544.

https://doi.org/10.1021/op900315j

39. Tachibana, K.; Imaoka, I.; Yoshino, H.; Emura, T.; Kodama, H.; Furuta, Y.; Kato, N.; Nakamura, M.; Ohta, M.; Taniguchi, K.; Ishikura, N.; Nagamuta, M.; Onuma, E.; Sato, H. Bioorg. Med. Chem. 2007, 5, 174.

https://doi.org/10.1016/j.bmc.2006.09.072

40. Jurášek, M.; Dzubák, P.; Sedlák, D.; Dvoráková, H.; Hajdúch, M.; Bartunek, P.; Drašar, P. Steroids 2013, 78, 356.

https://doi.org/10.1016/i.steroids.2012.11.016

41. Vatmurge, N. S.; Hazra, B. G.; Pore, V. S.; Shirazi, F.; Deshpande, M. V.; Kadreppa, S.; Chattopadhyay, S.; Gonnade, R. G. Org. Biomol. Chem. 2008, 6, 3823.

https://doi.org/10.1039/b809221d

42. Skorobogatyi, M. V.; Pchelintseva, A. A.; Petrunina, L. A.; Stepanova, A. I.; Andronova, L. V.; Galegov, G. A.; Malakhov, A. D.; Korshun, V. A. Tetrahedron 2006, 62, 1279.

https://doi.org/10.1016/j.tet.2005.10.057

43. Thomas, J. R.; Liu, X.; Hergenrother, P. J. Am. Chem. Soc. 2005, 127, 12434.

https://doi.org/10.1021/ja051685b

44. Baron, A.; Bleriot, Y.; Sollogoub, M.; Vauzeilles, B. Org. Biomol. Chem. 2008, 6, 1898.

https://doi.org/10.1039/b805528a

45. Ibrahim-Ouali.; M.; Hamze, K. Steroids 2014, 80, 102.

46. Pettit, G. R.; Piatak, D. M. J. Org. Chem. 1962, 27, 2127.

https://doi.org/10.1021/jo01053a054

47. Lidstrom, P.; Tierney, J.; Wathey, B.; Westman, J. Tetrahedron 2001, 57, 225.

48. Jung, M. F.; Lyster M. A. J. Am. Chem. Soc. 1977, 99, 968.

https://doi.org/10.1021/ja00445a062

49. Olah, G. A.; Narang, S. C.; Gupta, B. G. B.; Malhotra, R. J. Org. Chem. 1979, 44, 1247.

https://doi.org/10.1021/jo01322a012

50. Fieser, T. L.; Rajagopalan, S. J. Am. Chem. Soc. 1949, 71, 3935.

https://doi.org/10.1021/ja01180a015

51. Kumar, D.; Mishra, K. B.; Mishra, B. B.; Mondal, S.; Tiwari, V. K. Steroids 2014, 80, 71. https://doi.org/10.1016/j.steroids.2013.11.022

52. Kunj, B.; Mishra B. B.; Mishra, K.B.; Tiwari, V. K. Carbohydrate Res. 2014, 399, 2. 
https://doi.org/10.1016/j.carres.2014.09.001

53. Thota, B. N. S.; Savyasachi, A. J.; Lukashev, N.; Beletskaya, I. P.; Maitra, U. Eur. J. Org. Chem. 2014, 1406. https://doi.org/10.1002/ejoc.201301443

54. Davis, A. P.; Dresen, S.; Lawless, L. Tetrahedron Lett. 1997, 38, 4305.

https://doi.org/10.1016/S0040-4039(97)00886-1

55. Lack, L.; Dorrity, F. O.; Walker, T.; Singletary, G. D. J. Lipid Res. 1973, 14, 367.

56. Kotovshchikov, Y. N.; Latyshev, G. V.; Lukashev, N. V.; Beletskaya, I. P. Org. Biomol. Chem. 2014, $12,3707$. https://doi.org/10.1039/C4OB00404C

57. Wölfling, J. Arkivoc 2007, 210.

http://dx.doi.org/10.3998/ark.5550190.0008.517

58. Shao, C.; Wang, X.; Zhang, Q.; Luo, S.; Zhao, J.; Hu, Y. J. Org. Chem. 2011, 76, 6832.

https://doi.org/10.1021/jo200869a

59. Soto-Castro, D.; Magaña-Vergara, N. E.; Farfán, N.; Santillan, R. Tetrahedron Lett. 2014, 55, 1014-1019.

https://doi.org/10.1016/j.tetlet.2013.12.066

60. Wallimann, P.; Seiler, P.; Diederich, F. Helv. Chim. Acta 1996, 79, 779.

https://doi.org/10.1002/hlca.19960790320

61. Zhang, Y.; Thomas, T. P.; Lee, K.; Li, M.; Zong, H.; Desai, A. M.; Kotlyar, A.; Huang, B.; Holl, M. M. B.; Baker, J. R. Bioorg. Med. Chem. 2011, 19, 2557.

https://doi.org/10.1016/j.bmc.2011.03.019

62. Soto-Castro, D.; Cruz-Morales, J. A.; Ramírez, M. T.; Guadarrama, P. Molecules 2010, 15, 8082.

https://doi.org/10.3390/molecules15118082

63. Fuchs, S.; Kapp, T.; Otto, H.; Schoneberg, T.; Franke, P.; Gust, R.; Schluter, A. D. Chem. Eur. J. 2004, 10, 1167.

https://doi.org/10.1002/chem.200305386

64. Shao, C.; Wang, X.; Xu, J.; Zhao, J.; Zhang, Q.; Hu, Y. J. Org. Chem. 2010, 75, 7002.

https://doi.org/10.1021/jo101495k

65. Mądrzak-Litwa, I.; Wojciechowska, A.; Paryzek, Z. Synth. Commun. 2015, 45, 1222.

https://doi.org/10.1080/00397911.2015.1014116

66. Gao, H.; Dias, J. R. Synth. Commun. 1997, 27, 757.

https://doi.org/10.1080/00397919708004196

67. Balasubramanian, R.; Maitra, U. J. Org. Chem. 2001, 66, 3035.

https://doi.org/10.1021/jo0013305

68. Maulucci, N.; De Riccardis, F.; Botta, C. B.; Casapullo, A.; Cressina, E.; Fregnose, M.; Tecilla, P.; Izzo, I. Chem. Commun. 2005, 1354.

https://doi.org/10.1039/b415908j

69. Erzunov, D. A.; Latyshev, G. V.; Beletskaya, I. P.; Lukashev, N. V. Eur. J. Org. Chem. 2015, 6289.

https://doi.org/10.1002/ejoc.201500835

70. Aher, N. G.; Pore, V. S. Synlett 2005, 2155.

71. Aher, N. G.; Pore, V. S.; Kumar, M.; Shukla, P. K. Tetrahedron 2006, 62, 11178.

https://doi.org/10.1016/j.tet.2006.09.021

72. Ghosh, S.; Maitra, U.; Choudhury, U.; Guru, R. Org. Lett. 2005, 7, 1441.

https://doi.org/10.1021/ol047462s

73. Cherbuliez, E.; Gowhari, M.; Rabinowitz, J. Helv. Chim. Acta 1964, 47, 2098. 


\section{https://doi.org/10.1002/hlca.19640470753}

74. Chan, T. R.; Hilgraf, R.; Sharpless, K. B.; Fokin, V. V. Org. Lett. 2004, 6, 2853.

https://doi.org/10.1021/ol0493094

75. Kumar, A.; Pandey, P. S. Org. Lett. 2008, 10, 165.

https://doi.org/10.1021/ol702457w

76. Mohamed, Z. H; El-Koussi, N. A; Mahfouz, N. M; Youssef, A. F.; Abdel Jaleel, G. A.; Shouman, S. A. Eur. J. Med. Chem. 2015, 97, 75.

https://doi.org/10.1016/i.ejmech.2015.04.045

77. Brase, S.; Gil, C.; Kneppe, K.; Zimmermann, V. Angew. Chem. Int. Ed. 2005, 5188.

https://doi.org/10.1002/anie.200400657

78. Xiong, Y.; Bernardi, D.; Bratton, S.; Ward, M. D.; Battaglia, E.; Finel, M.; Drake, R. R.; Radominska-Pandya, A. Biochemistry 2006, 2322. https://doi.org/10.1021/bi0519001

79. Berg, M.; Nozinovic, S.; Engeser, M.; Lützen, A. Eur. J. Org. Chem. 2015, 5966.

https://doi.org/10.1002/ejoc.201500657

80. Bhattacharya, S.; Krishnan-Ghosh, Y. Langmuir 2001, 17, 2067.

https://doi.org/10.1021/la000498i

81. Chan, T. R.; Hilgraf, R.; Sharpless, B. K.; Fokin, V. V. Org. Lett. 2004, 17, 2853.

https://doi.org/10.1021/ol0493094

82. Nayal, A.; Pandey, P. S. Tetrahedron 2015, 71, 6991.

https://doi.org/10.1016/j.tet.2015.07.006

83. Liu, Y.; Yang, Z. X.; Chen, Y. J. Org. Chem. 2008, 73, 5298.

https://doi.org/10.1021/jo800488f

84. Cornilleau, T.; Audrain, H.; Guillemet, A.; Hermange, P.; Fouquet, E. Org. Lett. 2015, 17, 354. https://doi.org/10.1021/ol503471e

85. Zielinski, J.E.; Larner, J. M.; Hoffer, P. B.; Hochberg, R. B. J. Nucl. Med. 1989, 30, 209.

86. Pospieszny, T. Helv. Chim. Acta 2015, 98, 1337.

https://doi.org/10.1002/hlca.201500118

87. Laha, J. K.; Cuny, G. D. Synthesis 2008, 4002. 


\section{Authors' Biographies}

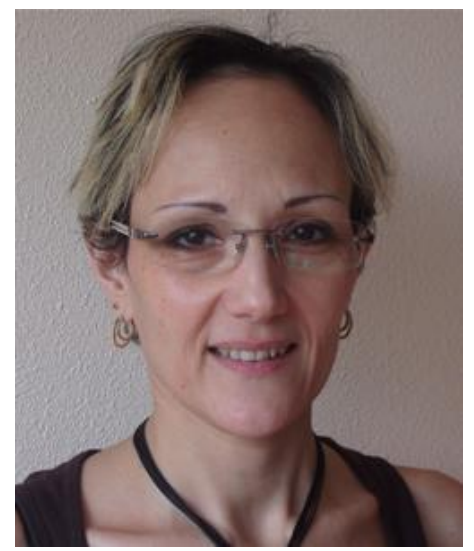

Malika Ibrahim-Ouali carried out her PhD under the supervision of Professor Gramain in Clermont-Ferrand (France) in 1996. The work was focused on the synthesis of alkaloids. She was a postdoctoral fellow with Prof. Knochel in 1996 where she got her first training in organometallic chemistry. In 1997, she joined Professor H. P Husson's group at the ICSN (Paris) as a postdoctoral researcher. Since 1998, she is currently an assistant professor at Aix-Marseille University and her field of interest remains the total synthesis of natural compounds.

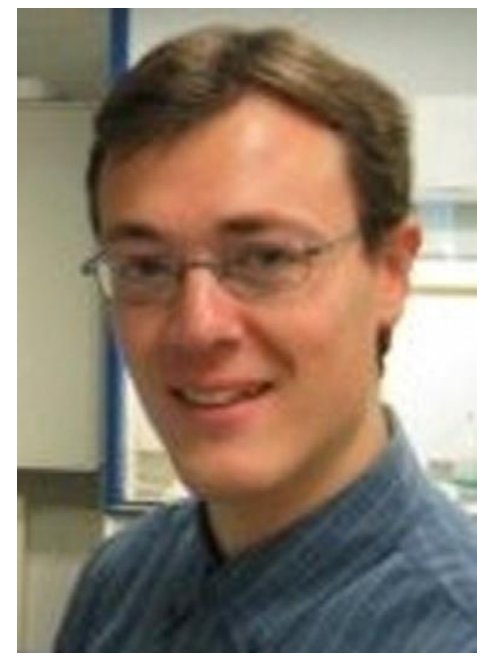

Frédéric Dumur received his PhD in chemistry in 2002 from the University of Angers (France) under the supervision of Professor Pietrick Hudhomme. After Post-Doctoral studies at the University of Groningen (The Netherlands), Reims Champagne-Ardennes (France) and Versailles Saint-Quentin-en-Yvelines (France), he joined the Faculty of Sciences at Aix-Marseille University in 2008, where he is currently working as an Associate Professor. His research interests include the synthesis of phosphorescent dopants for OLEDs and photoinitiators of polymerization. He co-authored about 160 publications and 5 book chapters. 